\title{
MODELO AGROMETEOROLÓGICO PARA ESTIMATIVA DOS EFEITOS DE DEFICIÊNCIA HÍDRICA NA PRODUTIVIDADE AGRO-INDUSTRIAL DA CANA-DE-AÇÚCAR
}

\author{
JUAN SINFORIANO DELGADO ROJAS \\ Engenheiro Agrônomo
}

Orientador: Prof. Dr. VALTER BARBIERI

Dissertação apresentada à Escola Superior de Agricultura "Luiz de Queiroz", Universidade de São Paulo, para obtenção do título de mestre em Agronomia, Área de Concentração: Agrometeorologia.

P I R A C I C A B A

Estado de São Paulo - Brasil

Agosto - 1998 


\section{Dados Internacionais de Catalogação na Publicação (CIP) DIVISĀo DE BIBLIOTECA E DOCUMENTAÇĀO - Campus "Luiz de Queiroz"/USP}

Delgado Rojas, Juan Sinforiano

Modelo agrometeorológico para estimativa dos efeitos de deficiência hídrica na produtividade agro-industrial da cana-de-açúcar / Juan Sinforiano Delgado Rojas. - Piracicaba, 1998.

74 p. : il.

Dissertação (mestrado) - - Escola Superior de Agricultura Luiz de Queiroz, 1998. Bibliografia.

1. Balanço hídrico 2. Cana-de-açúcar 3. Climatologia agricola 4. Deficiência hidrica 5. Indústria agricola 6. Produtividade agricola I. Titulo 


\section{MODELO AGROMETEOROLÓGICO PARA ESTINiATIVA DOS EFEITOS DE DEFICIÊNCIA HÍDRICA NA PRODUTIVIDADE AGRO-INDUSTRIAL DA CANA-DE-AÇÚCAR}

JUAN SINFORIANO DELGADO ROJAS

Aprovada em: 17.09.1998

Comissão julgadora:

Prof. Dr. Valter Barbieri

ESALQ/USP

Prof. Dr. Antonio Roberto Pereira ESALQ/USP

Prof. Dra. Dalva Martinelli Cury FCA/UNESP

Prof. Dr. VALTER BARBIERI

Orientador 
"La Humanidad posee la capacidad de conseguir que el desarrollo sea sostenible, esto es, de garantizar que el desarrollo satisfaga las necesidades del presente sin comprometer la capacidad de las generaciones futuras de atender a sus propias necesidades"

OMM 
Aos meus queridos pais, Don Sinforiano e Dona Francisca que me ensinaram através da suas vivências, os melhores exemplos para vencer as incertezas da vida $\mathrm{e}$ confiar no futuro.

Dedico

As minhas novas amizades ganhas durante o tempo de estudo em Piracicaba, pela convivência e estímulo para chegar à meta que me propus. 


\section{AGRADECIMENTOS}

À Deus, por ter-me dado boa saúde e liberdade para cumprir com minhas obrigações.

Ao Professor Valter Barbieri, pelos ensinamentos e constante orientação durante meu trabalho.

Ao Professor Paulo Sentelhas, pelo apoio e colaboração durante meu trabalho.

Aos demais Professores do Departamento de Física e Meteorologia, pelos ensinamentos e amizade.

À meus caros colegas de estudo, Rosa, Zilda, Lucy, Angélica, Adriana, Ricardo e Gabriel, pela amizade.

Sou especialmente grato a Valeria Modolo por ter-me oferecido todo o seu tempo e apoiado durante a realização do meu trabalho.

Aos funcionários do Departamento, Robinson, Ana, Edivaldo, Vanderlino, Francisco e Fernando, por todo o apoio brindado durante a realização do meu trabalho.

Ao Departamento de Física e Meteorologia por aceitar-me como aluno de pósgraduação.

Ao Instituto Agronômico Nacional, por ter-me concedido afastamento durante todo este tempo.

Ao $\mathrm{CNPq}$, por ter-me concedido bolsa de estudo para a realização do meu estudo. 


\section{SUMÁRIO}

Página

LISTA DE FIGURAS.............................................................................. vii

LISTA DE TABELAS............................................................................ viii

LISTA DE TABELAS DE ANEXOS............................................................ $\quad$ x

RESUMO............................................................................................

SUMMARY .......................................................................................... xiv

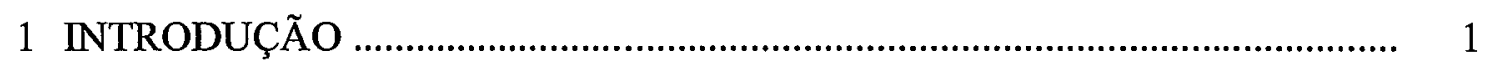

2 REVISÃO DE LITERATURA................................................................. 3

2.1 Generalidades sobre as características agroclimáticás da cana-de-açúcar....... 3

2.2 Conceitos gerais sobre produtividade da cana-de-açúcar............................. 5

2.3 Modelos de estimativas de produtividade das culturas................................. 6

2.4 Efeitos da deficiência hídrica sobre a produtividade da cana-de-açúcar......... 8

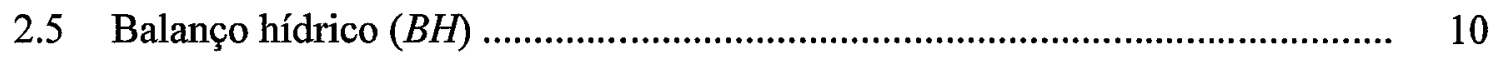

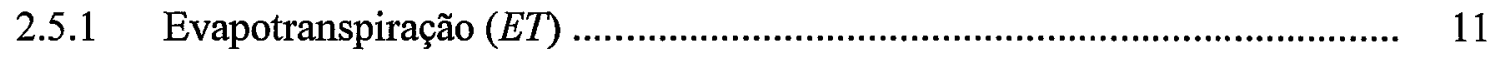

2.5.2 Coeficiente de cultura $(k c)$............................................................ 13

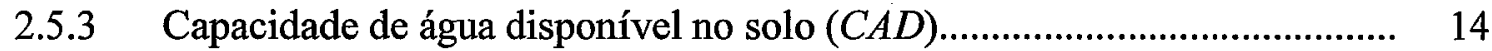

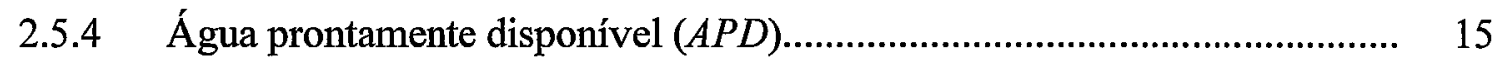

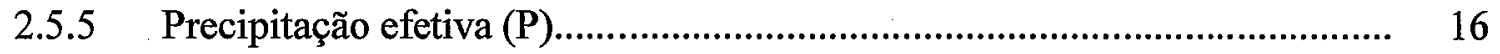

2.6 Conceitos gerais sobre o cálculo do balanço hídrico pelo método de

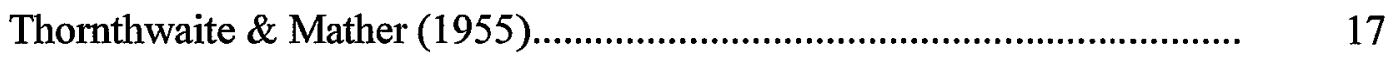

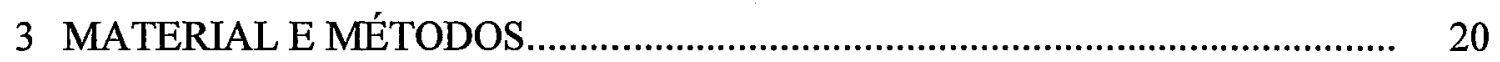

3.1 Obtenção dos dados............................................................................. 20

3.2 Generalidades sobre o modelo de Jensen (1968)........................................ 22

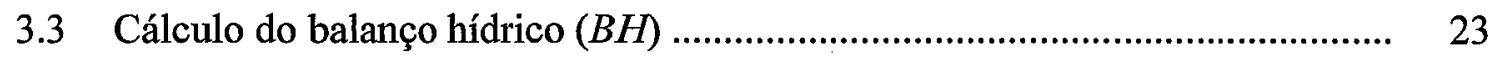

3.4 Ajuste do modelo......................................................................... 26

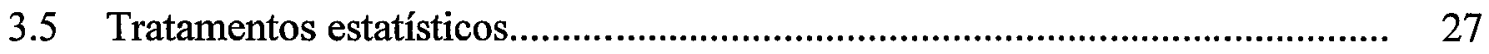

4 RESULTADOS E DISCUSSÃO........................................................... 31 
4.1 - Resultados Preliminares............................................................................. 31

4.2 Aperfeiçoamento do modelo....................................................................... 36

4.3 Simplificação do modelo............................................................................ 38

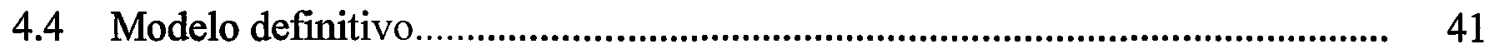

4.5 Principais utilidades do modelo................................................................... 44

4.6 Alguns exemplos de aplicação do modelo....................................................... 45

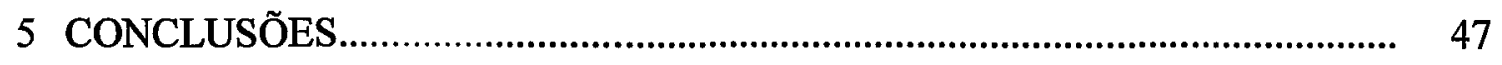

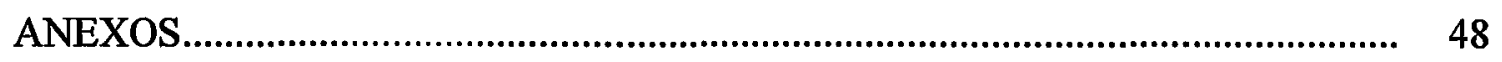

REFERÊNCIAS BIBLIOGRÁFICAS............................................................... 70 


\section{LISTA DE FIGURAS}

Página

1 Períodos de desenvolvimento da cana-de-açúcar............................................... 4

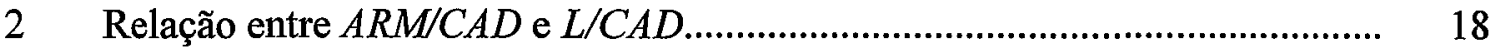

3 Localização geográfica dos locais onde foram realizados os experimentos envolvidos no presente trabalho.

4 Análise de regressão entre produtividade observada e produtividade estimada pelo método proposto para colmo eq. (20)

5 Análise de regressão entre produtividade observada e produtividade estimada pelo método proposto para açúcar eq. (21)

6 Análise de regressão entre produtividade observada e produtividade estimada pelo método proposto para colmo (eq. 24).

7 Análise de regressão entre produtividade observada e produtividade estimada pelo método proposto para açúcar (eq. 25).

8 Análise de regressão entre produtividade observada e produtividade estimada pelo método proposto para colmo (eq. 28)

9 Análise de regressão entre produtividade observada e produtividade estimada pelo método proposto para açúcar (eq. 29)

10 Análise de regressão entre produtividade observada e produtividade estimada pelo método proposto para colmo (eq. 32).

11 Análise de regressão entre produtividade observada e produtividade estimada pelo método proposto para açúcar (eq. 33) 


\section{LISTA DE TABELAS}

Página

1 Produtividade de colmo e de açúcar de cinco variedades de canas irrigadas $(Y m)$ e não irrigadas $(Y a)$, em t/ha, cultivadas em Araras, SP, no período de 1974 a 1985

2 Valores de $Y a / Y m$ e $E T r / E T m$ médios, por fase da cultura, observados na localidade de Araras.

3 Produtividade de colmo e de açúcar de cinco variedades de canas, irrigadas $(\mathrm{Ym})$ e não irrigadas $(\mathrm{Ya})$, em t/ha, cultivadas em Araras e Pradópolis, SP, no período de 1975 a 1986.

4 Valores de produtividade agro-industrial da cana e evapotranspiração relativa $(E T r / E T m)$ média, de três fases da cultura, observados nas localidades de Araras e Pradópolis.

5 Valores logarítmicos de $Y a / Y m$ e $E T r / E T m$ médios, por fase da cultura, na localidade de Araras.

6 Valores comparativos entre produtividade agro-industrial estimados pelos modelos proposto (eq. 20 e 21 ) e os observados nas localidadades de Araras e Pradópolis, em tha de colmo e de açúcar.

7 Valores dos índices estatísticos utilizados na avaliação dos modelos de estimativa de produtividade de colmo e de açúcar (eq. 20 e 21).

8 Valores comparativos entre produtividade agro-industrial estimados pelos modelos propostos (eq. 24 e 25) e os observados nas localidades de Araras e Pradópolis, em $\mathrm{t} / \mathrm{ha}$ de colmo e de açúcar.

9 Valores dos índices estatísticos utilizados na avaliação dos modelos de estimativa de produtividade de colmo e de açúcar, através das equações 24 e 25. 
10 Valores comparativos entre produtividade agro-industrial estimados pelos modelos proposto (eq.28 e 29) e os observados nas localidades de Araras e

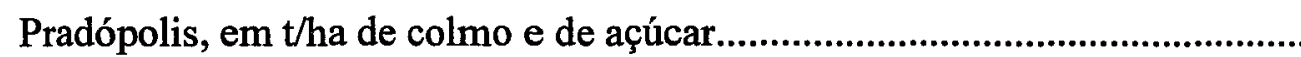

11 Valores dos índices estatísticos utilizados na avaliação dos modelos de estimativa de produtividade de colmo e de açúcar (eq.28 e 29)........................

12 Valores comparativos entre produtividade agro-industrial estimados pelos modelos proposto (eq. 32 e 33) e os observados nas localidades de Araras e Pradópolis, em t/ha de colmo e de açúcar.........................................................

13 Valores dos índices estatísticos utilizados na avaliação dos modelos de estimativa de produtividade de colmo e de açúcar (eq. 32 e 33)....................... 


\section{LISTA DE TABELAS DE ANEXOS}

Pagina

1 Dados de temperatura e precipitação utilizados para calcular o balanço hídrico.

2 Ciclo das variedades de cana-de-açúcar cultivadas em Araras, cujos valores de produtividade, apresentados na pagina 21 , foram utilizados para correlacionar com os valores do balanço hídrico.

3 Ciclo das variedades de cana-de-açúcar, cujos valores de produtividade, apresentados na pagina 28 , foram utilizados para o teste estatístico do modelo proposto.

4 Balanço hídrico sequencial, método de Thornthwaite-Mather (1955), para cana de açúcar no período de setembro/1977 a julio/1978 na localidade de Araras.

5 a Dados de ETr e ETm durante o ciclo da cana planta, variedade CB 41-76, período 1974 - 1975, em Araras.

5 b Dados de $E T r$ e ETm durante o ciclo da cana soca, variedade CB 41-76, período 1974 - 1975, em Araras.

5 c Dados de $E T r$ e $E T m$ durante o ciclo da cana soca, variedade CB 41-76, período 1976 - 1977, em Araras.

5 d Dados de ETr e ETm durante o ciclo da cana soca, variedade CB 41-76, período 1977 - 1978, em Araras.

5 e Dados de ETr e ETm durante o ciclo da cana planta, variedades NA 5679; CB47-355 e CB41-76, período 1977 - 1978, em Araras.

$5 \mathrm{f} \quad$ Dados de $E T r$ e $E T m$ durante o ciclo da cana soca, variedades NA 56-79; CB47-355 e CB41-76, período 1978 - 1979, em Araras 
$5 \mathrm{~g} \quad$ Dados de ETr e ETm durante o ciclo a cana soca, variedades NA 56-79; CB47-355 e CB41-76, período 1979 - 1980, em Araras................................ 59

$5 \mathrm{~h}$ Dados de $E T r$ e $E T m$ durante o ciclo da cana planta, variedades CP51-22, período 1979 - 1980, em Araras.

5 i Dados de ETr e ETm durante o ciclo a cana soca, variedades CB41-76; NA 56-79; CB47-355 e CP51-22, período 1980 - 1981, em Araras..

$5 \mathrm{j} \quad$ Dados de ETr e ETm durante o ciclo da cana soca, variedades CB41-76; NA 56-79; CB47-355 e CP51-22, período 1981 - 1982, em Araras.

$5 \mathrm{k} \quad$ Dados de ETr e ETm durante o ciclo da cana soca, variedades CB41-76; NA 56-79; CB47-355 e CP51-22, período 1982 - 1983, em Araras.

51 Dados de ETr e ETm durante o ciclo da cana soca, variedades CB41-76; NA 56-79; CB47-355 e CP51-22, período 1983 - 1984, em Araras.

$5 \mathrm{~g}$ Dados de ETr e ETm durante o ciclo da cana soca, variedade CB41-76, período 1984 - 1985, em Araras.

6 a Dados de ETr e ETm durante o ciclo da cana planta, variedade IAC 51/205, período 1975-1976, em Araras.

6 b Dados de ETr e ETm durante o ciclo da cana soca, variedade IAC 51/205, período 1976 - 1977, em Araras.

6 c Dados de ETr e ETm durante o ciclo da cana soca, variedade IAC 51/205, período 1977 - 1978, em Araras.

6 d Dados de ETr e ETm durante o ciclo da cana planta, variedade CB41-76, período 1978 - 1979, em Araras.

6 e Dados de ETr e ETm durante o ciclo da cana soca, variedade NA56-79, período 1985-1986.

$6 \mathrm{f}$ Dados de ETr e ETm durante o ciclo da cana soca, variedade CB41-76, período 1985-1986. 
$6 \mathrm{~g}$ Dados de ETr e ETm durante o ciclo da cana soca, variedade CB41-76, período 1985-1986, em Araras....................................................................... 66

$6 \mathrm{~h}$ Dados de ETr e ETm durante o ciclo da cana planta, variedade CB41-76, período 1978 - 1979, em Pradópolis................................................................ $\quad 66$

6 i Dados de ETr e ETm durante o ciclo da cana soca, variedade CB41-76, período 1979-1980, em Pradópolis................................................................... 67

$6 \mathrm{j}$ Dados de ETr e ETm durante o ciclo da cana planta, variedade CO775,

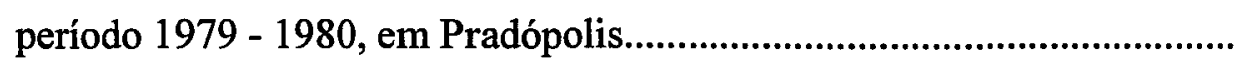

$6 \mathrm{k}$ Dados de ETr e ETm durante o ciclo da cana planta, variedade CO775, período 1979-1980, em Pradópolis............................................................... 68

61 Dados de ETr e ETm durante o ciclo da cana soca, variedade RE-725828, período 1985-1986, em Pradópolis. 


\section{MODELO AGROMETEOROLÓGICO PARA ESTIMATIVA DOS EFEITOS DE DEFICIÊNCIA HÍDRICA NA PRODUTIVIDADE AGRO-INDUSTRIAL DA CANA-DE-AÇÚCAR}

Autor: JUAN SINFORIANO DELGADO ROJAS Orientador: Prof. Dr. VALTER BARBIERI

\section{RESUMO}

$\mathrm{Na}$ elaboração do modelo de estimativa da produtividade agro-industrial da cana-de-açúcar foram analisados resultados de ensaios experimentais de variedades de cana irrigadas e não irrigadas, realizados entre os anos de 1974 e 1984, no Instituto do Açúcar e Álcool (Município de Araras/SP). O trabalho foi baseado no modelo de penalização proposto por Jensen (1968), o qual considera que a produtividade pode ser relacionada às condições hídricas nos períodos fenológicos críticos por modelo multiplicativo. Conforme essa metodologia, a relação entre os valores da Produtividade Real $(Y a)$, cana não irrigada, e da Produtividade Máxima ( $Y m)$, cana irrigada, tanto do colmo como do açúcar, foram correlacionados com a Evapotranspiração Relativa (ETr/ETm) determinadas durante três fases do ciclo da cultura. Conclui-se que as condições hídricas do solo durante a terceira fase da cultura têm pouco peso na produtividade final, e, portanto o modelo pode ser simplificado. Segundo um teste de validação que foi realizado com doze ciclos independentes da cultura, o modelo teve bons ajustes entre os valores estimados e observados. Através destas equações pode-se estimar satisfatoriamente a produtividade agro-industrial da cana-de-açúcar, tanto em condições irrigadas como de não irrigadas em função das condições hídricas do solo; podendo ser utilizada dados reais ou médias climáticas, com possibilidade de se estimar a produtividade, quatro meses antes das colheitas. 


\section{AGROMETEOROLOGICAL MODEL FOR ESTIMATING WATER \\ DEFICIT EFECTS ON THE AGROINDUSTRIAL YIELD OF \\ SUGAR-CANE}

Author: JUAN SINFORIANO DELGADO ROJAS

Adviser: Prof. Dr. VALTER BARBIERI

\section{SUMMARY}

Results from irrigated and non irrigated sugar cane experiments carried out at the Instituto do Açúcar e Álcool, Araras county, São Paulo state, Brazil, between 1974 and 1984 were analyzed in order to model the sugar cane agro-industrial productivity. Research was based on the penalization model proposed by Jensen (1968). He suggests that productivity may be related to hydric conditions, during critical phenological periods, by a multiplicative model. Following Jensen's model, the ratio actual/maximum productivity $(\mathrm{Ya} / \mathrm{Ym})$ of stalks and sugar was correlated with Relative Evapotranspiration (ETa/ETm), being $a$ and $m$ related to the non irrigated and irrigated conditions, respectively, determined during three phenological periods. It was observed that the soil water availability during the third phase of the crop had little effect on the final productivity, so, the model could be simplified. A validation test was accomplished with twelve independent cycles of the crop, showing that the model allows good fittings between the estimated and observed values. The model permitted good estimate of agroindustrial yield of sugar cane from soil water balance, in irrigated or not irrigated conditions, by the use of actual or mean climatical data, with the possibility to estimate the productivity four months before the harvest. 


\section{INTRODUÇÃO}

Os elementos meteorológicos influem diretamente sobre a produtividade da cultura, especialmente aqueles relacionados ao aspecto hídrico, que caso não seja adequado à cultura, poderá afetar seu rendimento. A quantificação das interações entre os elementos meteorológicos e a produtividade é bastante complexa. No entanto, pode ser feita através de modelos agrometeorológicos, desenvolvidos a partir do estudo do efeito desses elementos sobre a produtividade da cultura, a medida que ocorrem nas diferentes fases do seu ciclo.

Conhecendo o grau de resposta da produtividade da cana-de-açúcar com relação às variáveis meteorológicas, é possível desenvolver modelos agrometeorológicos que sirvam para medir os efeitos dessas variações sobre a produção vegetal.

Sendo o fator hídrico um dos que mais influencia a produtividade das culturas, em especial da cana-de-açúcar, modelos matemáticos que expliquem a interrelação clima-produtividade podem ser elaborados, permitindo boa determinação do grau de importância desse fator, associados aos elementos chuva e evapotranspiração sobre a produtividade, para as fases fenológicas da cultura.

Este tipo de modelo pode ajudar na definição da época na qual a água é mais importante para a cultura, também pode ser utilizado para determinar a queda de produtividade, bem como estimar a produtividade potencial conhecendo-se a produtividade real. Através destas determinações, pode-se visualizar os parâmetros que servem como índice para estudar a viabilidade de aplicação de irrigação numa cultura. Isto é importante, pois tanto a aplicação excessiva ou insuficiente de água, além de afetar diretamente a produtividade, pode acarretar perdas econômicas. Portanto, para que a 
irrigação apresente desempenho adequado, ela deve ser aplicada obedecendo a critérios econômicos e técnicos para garantir uma boa produção, respeitando ainda a sustentabilidade dos recursos naturais.

Entre os diferentes modelos agrometeorológicos, aquele proposto por Jensen (1968) é o que vem sendo mais empregado, tanto pelos bons resultados como pela sua racionalidade. Este modelo permite relacionar a produtividade em condições naturais de chuva com as condições hídricas do solo, que ocorrem nas diferentes fases do ciclo da cultura.

Considerando as observações expostas, este trabalho pretende oferecer uma ferramenta que ajude o produtor ligado ao setor canavieiro, na planificação de suas atividades rurais, bem como para qualquer decisão inerente à produção, como transporte e comercialização da cana-de-açúcar. Para tanto, pretende-se atingir os seguintes objetivos:

1) Ajustar e testar o modelo de Jensen (1968), para a estimativa da produtividade agro-industrial da cana-de-açúcar.

2) Caracterizar os efeitos da deficiência hídrica sobre o rendimento do colmo e do açúcar, nas principais fases da cultura. 


\section{REVISÃO DE LITERATURA}

\subsection{Generalidades sobre as características agroclimáticas da cana-de-açúcar}

A cana-de-açúcar (Saccharum officinarum L.) tem como origem a Ásia, provavelmente a Nova Guiné. A maior parte da cana-de-açúcar comercial é produzida entre as latitudes de $35^{\circ}$ ao Norte e $35^{\circ}$ ao Sul. A temperatura ótima para o brotamento das estacas do talo é de $32^{\circ}$ a $38^{\circ} \mathrm{C}$. O crescimento ótimo é obtido com médias diurnas de temperaturas entre $22^{\circ}$ e $30^{\circ} \mathrm{C}$. A temperatura mínima para um crescimento vigoroso é de aproximadámente $20^{\circ} \mathrm{C}$; no entanto, para a maturação são convenientes temperaturas relativamente baixas, de $20^{\circ}$ a $10^{\circ} \mathrm{C}$, já que isto tem uma influência notória na redução do processo de crescimento vegetativo e no enriquecimento da sacarose da cana (Doorenbos \& Kassam, 1979).

Segundo Irvine (1980), a cana-de-açúcar é uma gramínea tropical do tipo $\mathrm{C} 4$, que se caracteriza por apresentar elevada taxa fotossintética e alta produtividade biológica, sendo uma das mais eficientes e produtivas dentre todas as outras.

Para obter rendimento elevado é fundamental uma estação vegetativa alongada. A duração normal do período vegetativo total varia de 9 meses, com a colheita antes das geadas invernais, até 24 meses no Hawai. No entanto, geralmente é de 15 a 16 meses no Brasil, Cuba, África do Sul e Austrália, quando trata-se de cana planta. A cultura procedente da cana planta, normalmente vem seguida de 2 a 4 culturas de rebrota (cana soca), e em certos casos chegam até no máximo de 8 ciclos. A princípio, o crescimento do colmo é lento, aumentando gradualmente até alcançar o ritmo máximo, depois do qual diminui à medida que a cana começa a amadurecer devido a idade, frio e/ou seca (Doorenbos \& Kassam, 1979). O acúmulo de matéria seca apresenta a forma 
sigmóide, podendo ser dividido em três fases: 1) fase inicial, na qual o crescimento é lento; 2) fase de crescimento rápido, onde 70 a $80 \%$ de toda massa seca é acumulada, e 3) fase final, em que o crescimento é novamente lento, acumulando cerca de $10 \%$ de matéria seca (Machado, 1987). Segundo Kuyper (1952), citado por Doorenbos \& Kassam (1979), para cana-de-açúcar, podem ser distinguidas 4 grandes fases de crescimento, conforme pode ser apreciado na figura 1.

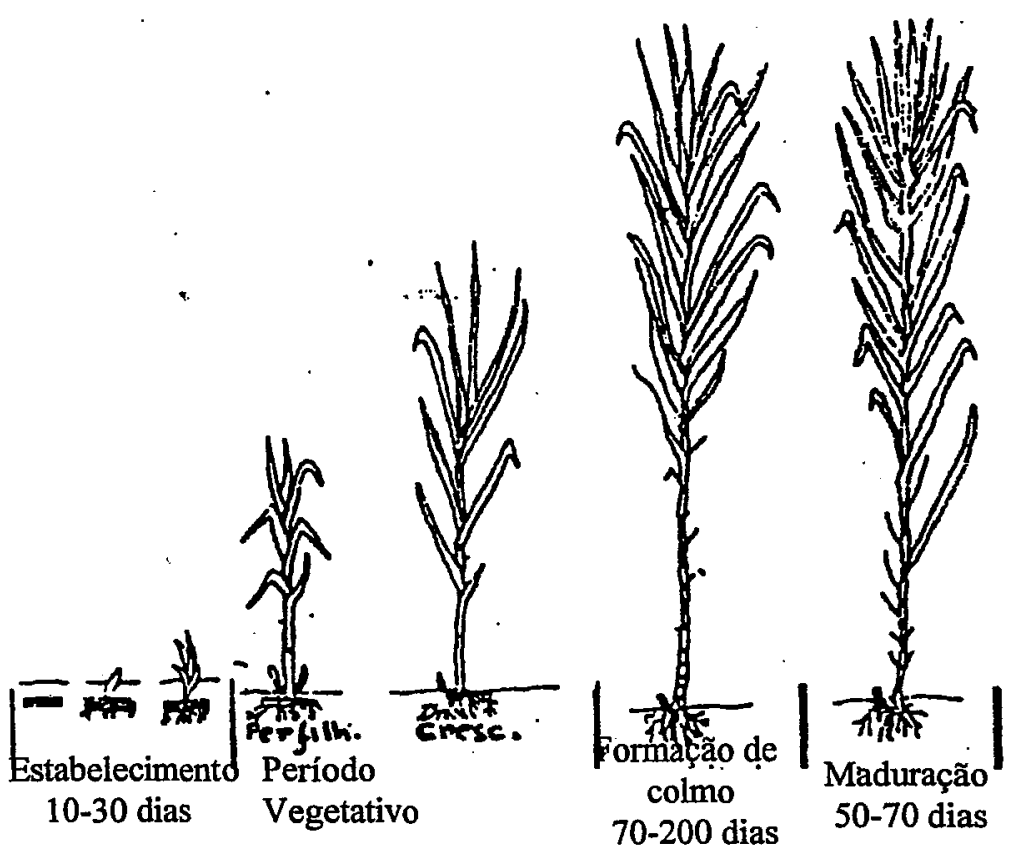

Figura 1 - Períodos de desenvolvimento da cana-de-açúcar. Fonte: Doorenbos \& Kassam (1979).

No entanto, para fins práticos tem se adotado apenas 3 grandes fases: (i) período vegetativo total, (ii) formação da colheita e (iii) maturação.

Outras observações que podem ser ressaltadas referem-se ao sistema radicular, cuja característica é a seguinte: depois de completar seu ciclo produtivo com a colheita, as raízes começam a nascer a partir da base do talo principal, morrendo as raízes que tinham servido de sustento às plantas do ciclo anterior. Esta característica faz com que a cana seja tratada como uma cultura anual, quanto à disponibilidade de água no solo, em razão de que as raízes nascem e crescem gradualmente acompanhando o desenvolvimento da parte aérea da cultura. Outra característica que deve ser ressaltada é 
o fato de que o sistema radicular das socas é mais superficial que o da cana planta. Isto está associado ao fato de que nas brotas da soca, as raízes nascem no solo a um nível mais alto daquelas que são originadas a partir das brotas da gema do colmo (Camargo, 1976).

Quanto à umidade do solo, pode-se dizer que um suprimento adequado de água é essencial para o crescimento da cultura. Segundo Doorenbos \& Kassam (1979), dependendo do clima, as necessidades hídricas da cana-de-açúcar são de 1500 a 2500 $\mathrm{mm}$, distribuídos de maneira uniforme durante a temporada de desenvolvimento; enquanto que Blackburn (1984), citado por Teruel (1996) observou que é necessário ao redor de $1200 \mathrm{~mm} / \mathrm{ano}$ para a cultura durante todo o seu ciclo. No entanto, Barbieri (1981), trabalhando com evapotranspirógrafo de nível freático constante, na localidade de Araras, Estado de São Paulo, constatou que um consumo de $1300 \mathrm{~mm}$ de água durante todo seu ciclo (cana planta, 14,5 meses) é o requerimento mínimo para a cultura atingir seu máximo potencial.

\subsection{Conceitos gerais sobre produtividade da cana-de-açúcar}

Sabe-se que o efeito da deficiência hídrica sobre a produtividade da canade-açúcar depende da fase na qual a planta sofreu essa deficiência.

Em condições de ótima disponibilidade de água no solo, a planta evapotranspira na máxima taxa que permite a fase do seu desenvolvimento. Este conceito é conhecido como evapotranspiração máxima ( $E T m$ ) (Ometto, 1988). Na prática, a determinação da $E T m$ é por via indireta, utilizando a evapotranspiração de referência (ETo) ajustada a um coeficiente de cultura $(k c)$ variável de acordo com a fase fenológica.

Se prevalecer disponibilidade ótima de água no solo durante todo o ciclo da cultura, uma produtividade máxima $(\mathrm{Ym})$ será obtida, considerando-se os demais fatores em condições ótimas (boa fertilidade do solo, ausência de pragas e doenças).

A partir do instante no qual a água é retida com maior força pelo solo, a planta sofrerá restrições à retirada e isso refletirá em seu crescimento, desenvolvimento e 
finalmente na sua produtividade. Em condições naturais as plantas experimentam durante o ciclo vegetativo, tanto momentos de boa disponibilidade hídrica (depois de uma chuva), como de déficit hídrico. Neste último caso elas suportam uma evapotranspiração real em condições não irrigadas $(E T r)$, chegando finalmente a atingir uma produtividade em condições naturais $(Y a)$.

\subsection{Modelos de estimativas de produtividade das culturas}

Uma prática comum na ciência é tentar explicar fenômenos naturais mediante modelos. Por exemplo, dizemos que a terra é redonda e gira sobre um eixo Norte - Sul. Isto nos permite explicar de um ponto de vista rudimentar, observações tais como o desaparecimento de um barco no horizonte, dia e noite, etc. Modelos mais aperfeiçoados dependem de equações matemáticas e nos permitem explicar, não somente fatos observáveis, mas também possíveis sucessos não observados. $O$ aspecto mais importante de um modelo matemático é que possui as características intrínsecas do problema real da natureza estudada (Steel \& Torrie, 1985).

Costa (1997), referindo-se à literatura cientifica mundial, que se ocupa desta ciência, alega que levando-se em consideração principalmente a arquitetura e a filosofia dos modelos, eles se classificam em dois tipos: empíricos e mecanísticos; sendo que para modelar, por exemplo a produtividade de culturas, se utiliza preferencialmente $o$ primeiro.

Inúmeros estudos têm sido realizados com o objetivo de quantificar os efeitos do ambiente sobre o crescimento, desenvolvimento e rendimento de culturas. Entre os principais elementos do ambiente que têm maior efeito sobre a produtividade das plantas, pode-se destacar a radiação solar, umidade do solo e a temperatura do ar (Coelho \& Dale, 1980).

Os modelos matemáticos empíricos, que estimam a produtividade de culturas específicas, são cada vez mais utilizados. Alguns deles utilizam só um elemento como fator independente para modelar a produtividade de uma cultura, como o exemplo 
apresentado por Tubelis (1988), que utiliza somente dados de precipitações pluviométricas para modelos de produção de citros no Estado de São Paulo. Modelos estatísticos de regressão múltipla, tal como o de Thompson (1969), utiliza apenas duas variáveis (médias mensais de temperatura e precipitação acumulada) para estimar o rendimento de numerosas plantas cultivadas. Outros autores como De Wit (1965), descritos por Barbieri \& Tuon (1992), utilizam três parâmetros de acordo com a sensibilidade da planta em resposta a esses elementos meteorológicos. Os mencionados autores utilizam radiação solar, temperatura e eficiência fotossintética para modelar a produtividade da cana-de-açúcar. Na maioria das vezes, os modelos que utilizam numerosas variáveis são tão complexos e pouco práticos que apenas são utilizados na experimentação científica.

Doorenbos \& Kassam (1979), quantificaram empiricamente o efeito da água sobre a produção de diversas culturas encontrando um fator de correlação entre a produtividade relativa $(\mathrm{Ya} / \mathrm{Ym})$, e a evapotranspiração relativa $(E T r / E T m)$, o qual chamaram de fator de efeito sobre o rendimento $(k y)$.

$\mathrm{O}$ valor de $k y$ para distintas culturas está baseado na avaliação de numerosos resultados de investigações, dados pela bibliografia, que abrangem uma ampla variedade de condições vegetativas e climáticas.

Os mencionados autores propõem um modelo aditivo para estimar a produtividade da cana-de-açúcar utilizando os seguintes valores de $k y: 0,75 ; 0,5$ e 0,1 , para a primeira (brotação e estabelecimento), segunda (crescimento vegetativo) e terceira fase (maturação) da cultura, respectivamente. Percebe-se que na primeira fase, o valor de ky é superior quando comparada a última, indicando de que nessa primeira fase, a planta é muito mais sensível à deficiência hídrica que na última.

Soares (1996), utilizou igualmente este modelo para determinar o efeito do déficit e excesso hídrico sobre o rendimento da cultura do milho na localidade de Urussanga em Santa Catarina. Alfonsi (1996), determinou a época de semeadura para a cultura do milho no Estado de São Paulo, relacionando os fatores de efeitos da cultura 
(ky) sob as condições hídricas do solo nas fases críticas de desenvolvimento e os dados de precipitação pluvial, com o auxilio do mencionado modelo.

Jensen (1968) propôs um modelo multiplicativo que relaciona a evapotranspiração relativa $(E T r / E T m)$ para estimar o rendimento relativo $(\mathrm{Ya} / \mathrm{Ym})$ de uma cultura. Este modelo permite estabelecer pesos diferentes para os diversos estádios de desenvolvimento dessa cultura.

Camargo (1992), estudando o efeito da água aplicada em diferentes fases fenológicas da cultura do sorgo no Estado de Nebraska, EUA, observou o melhor ajuste do modelo proposto por Jensen (1968) comparado ao modelo proposto por Doorenbos \& Kassam (1979).

Barni et al. (1995) também utilizaram este modelo, correlacionando o rendimento relativo $(\mathrm{Ya} / \mathrm{Ym})$ do girassol e os índices hídricos (ETr/ETm), correspondentes a quatro períodos de desenvolvimento. Eles determinaram os índices de sensibilidade da cultura aos efeitos do déficit hídrico para distintas variedades de girassol, no Estado de Rio Grande do Sul. Matzenauer et al. (1995), utilizando o mesmo modelo, relacionaram o rendimento de grãos de milho com o consumo relativo de água, em diferentes períodos do ciclo da cultura, para determinar o índice de sensibilidade da cultura.

Camargo et al. (1995), testando 6 modelos agrometeorológicos de estimativa da produtividade de laranjas tardias, médias e precoces; observaram que o modelo de Jensen (1968) apresentou melhores resultados. Igualmente, Ortolani et al. (1996), utilizaram estes dois modelos para estimar a produção de látex em seringueira, observando bons ajustes em ambos os casos.

\subsection{Efeitos da deficiência hídrica sobre a produtividade da cana-de-açúcar}

Como visto anteriormente, o coeficiente de sensibilidade $(k y)$, proposto por Doorenbos \& Kassam (1979) para cana-de-açúcar, correspondente à terceira fase, tem baixa influência sobre a produtividade; entretanto, a maior influência ocorre na primeira 
fase. Nesse sentido, Doorenbos \& Pruitt (1997), recomendaram, referente à cultura da cana soca com duração do período vegetativo de 12 meses, a suspensão da irrigação durante 4 a 6 semanas antes da colheita.

Rosenfeld \& Leme (1984), estudando épocas de irrigação em cana-deaçúcar no Estado de São Paulo, concluíram que as maiores reduções da produtividade ocorreram com déficits hídricos nos primeiros oito meses do ciclo da cana planta.

Rosenfeld (1989), num experimento realizado em Araras, Estado de São Paulo, observou que a maior redução de produção, tanto de colmo quanto de açúcar, ocorreu com o período de seca compreendido entre 133 aos 246 dias de idade da cultura.

Scardua (1985) fazendo uma análise de correlação entre a queda de produtividade da cana-de-açúcar e as deficiências hídricas em três fases da cultura, revelou que na primeira fase, o coeficiente angular da regressão teve maior peso que na segunda; e que, na terceira fase, o efeito do déficit poderia ser considerado insignificante. O autor explica que, talvez, isso seja devido ao fato do estabelecimento da cultura (enraizamento e perfilhamento) ocorrer durante o $1^{\circ}$ estádio de desenvolvimento, constituindo-se na fase mais sensível aos déficits hídricos, podendo acarretar, caso sofra deficiência hídrica, um mau desenvolvimento das raízes e baixo perfilhamento, e por consequência um baixo aproveitamento da água e nutrientes disponíveis nas fases posteriores.

Vazquez (1970), citado por Rosenfeld (1989), estudando épocas de irrigação de cana-de-açúcar em Porto Rico, já tinha observado a mesma tendência e recomendou que para diversas condições climáticas é possível economizar até $250 \mathrm{~mm}$ de água/ano suspendendo a irrigação cinco meses antes da colheita, sem que haja redução na produção.

Para desenvolver um modelo agrometeorológico de produtividade agroindustrial baseado no modelo proposto por Jensen (1968), em que a produtividade seja dependente da disponibilidade de água no solo, é necessário contar com dados de produtividade real $(\mathrm{Ya})$ e produtividade máxima $(\mathrm{Ym})$, assim como dados meteorológicos 
com os quais poderá ser calculado o balanço hídrico. Além disso é preciso um bom conhecimento sobre os principais componentes utilizados neste cálculo, para que o resultado não tenha algum tipo de erro de procedimento. Isto é importante devido ao fato que esses dados serão correlacionados com a produtividade da cana e ajudarão na confiabilidade do modelo resultante.

\subsection{Balanço hídrico $(B H)$}

$\mathrm{Na}$ interação do sistema solo - planta - atmosfera está envolvida uma certa quantidade de água que entra e sai de cada um desses componentes, fazendo com que a água armazenada no solo esteja em constante variação. Esta variação representa o balanço de entrada e saída do sistema, sendo a intensidade dependente do meio. $O$ estudo desse processo é chamado Balanço Hídrico $(B H)$, sendo o seu conhecimento muito importante, tanto na determinação imediata da necessidade hídrica de uma cultura quanto na tomada de certas dẹcisões num projeto agrícola. Também é caracterizado como indicador de potencial climático de um local, para uma cultura qualquer (Ometto, 1988).

Segundo Pereira et al. (1997), as principais fontes de entradas de água no volume de controle (solo) são basicamente seis: (i) chuva; (ii) orvalho; (iii) escoamento superficial; (iv) drenagem lateral; (v) ascensão capilar e (vi) irrigação. Enquanto que as principais possíveis saídas são: (i) evapotranspiração; (ii) escoamento superficial; (iii) drenagem lateral e (iv) drenagem profunda.

Considerando que o dinamismo desse processo depende das condições climáticas do local; para calcular as necessidades hídricas líquidas nos períodos sazonais, mensais ou inferiores a um mês, além de ter um conceito claro, deve-se determinar primeiro as variáveis que integram o balanço hídrico, sendo o número deles dependente da metodologia utilizada. Um dos métodos mais utilizados para calcular o $B H$, é o de Thornthwaite \& Mather (1955), o qual requer basicamente dados de evapotranspiração de referência $E T o$, coeficiente da cultura $(k c)$, ao longo do período de desenvolvimento, precipitação $(P)$ e a capacidade de água disponível $(C A D)$ para o período considerado. 
Devido à escolha acertada dos valores destas variáveis requerer conhecimentos bem claros, os conceitos sobre os mesmos serão apresentados a seguir.

\subsubsection{Evapotranspiração (ET)}

Evapotranspiração é o termo que foi utilizado por Thornthwaite, no início dos anos 40, para expressar a ocorrência simultânea da evaporação e da transpiração numa superfície vegetada; ela depende da disponibilidade de energia no ambiente, da demanda atmosférica, e do suprimento de água do solo às plantas (Pereira et al. 1997).

Diversos autores, utilizando métodos diferentes de estimativa, deram origem a outros termos como: evapotranspiração potencial, evapotranspiração de referência, evapotranspiração máxima, etc. Descrever com detalhes cada um deles mereceria um tratamento longo; portanto, sintetizando, pode-se dizer que a evapotranspiração de referência (ETo), também chamada potencial pela FAO é a evapotranspiração que ocorre numa superfície vegetada com grama (Paspalum notatum L.) com disponibilidade suficiente de água no solo, em fase de crescimento ativo, cobrindo completamente a superfície do solo e com a bordadura adequada (Ometto, 1988). Outros autores como Jensen (1971), citado por Ometto (1988), definem ETo como o limite superior ou a evapotranspiração máxima que ocorre numa cultura de alfafa (Medicago sativa L.), com altura de 0,3 a 0,5 m, numa dada condição climática, e com aproximadamente $100 \mathrm{~m}$ de área tampão.

Existem numerosos métodos desenvolvidos por diversos autores para estimar ETo. Alguns deles utilizam como variáveis, numerosos elementos climáticos em complicadas equações, sendo que outros utilizam nada mais que uma ou duas variáveis tornando-se na maioria dos casos os mais utilizados devido a sua fácil aplicação. No entanto, a escolha entre uma e outra metodologia depende muito dos dados disponíveis para realizar a estimativa, assim como o grau de precisão que se pretende atingir.

Pereira et al. (1997), de acordo aos princípios envolvidos na sua estimativa, os agruparam em cinco categorias: (i) empíricos; (ii) aerodinâmicos; (iii) 
balanço de energia; (iv) combinados e (v) correlação dos turbilhões. Para trabalhos de pesquisa de alta precisão, por convenção, os cientistas desta área aconselham que o mais adequado para estimar a evapotranspiração de uma cultura na escala diária é o método de Penman-Montheith. Doorenbos \& Pruitt (1997), descreveram amplamente e recomendaram como os mais versáteis para sua utilização nos cálculos das necessidades hídricas os seguintes métodos: (a) Blaney \& Criddle, (b) Radiação, (c) Penman modificado e (d) Tanque de evaporação (Classe A). Este último método, é um dos mais simples e práticos, podendo ser utilizado no cálculo de balanço hídrico, sendo recomendado seu emprego em projetos de irrigação. Ele se baseia na evaporação da água do tanque "Classe A", que ocorre sobre um gramado com suficiente bordadura, em conseqüência de um efeito integrado da radiação solar, temperatura, vento e da umidade do ar. Essa evaporação é relacionada com a evapotranspiração da cultura de referência, que neste caso é o gramado; embora diversos fatores possam introduzir mudanças significativas nessa perda de água. Sendo assim, é aplicado um coeficiente $K p$, que reduz $E C A$ ao valor aproximado da evaporação de um lago, sendo ele igual ao valor da evapotranspiração da cultura de referência (gramado). É comum assumir um valor fixo para $K p$ igual a 0,66 sendo também frequentemente utilizado 0,7 (Pereira et al., 1997). No entanto, Doorenbos \& Pruitt (1997), recomendam utilizar uma tabela de valores de $K p$ para diferentes condições de umidade, vento e tamanho da bordadura. Essa fórmula é detalhada por Snyder (1992) citado por Pereira et al. (1997).

O método de estimativa de Thornthwaite, apesar de utilizar apenas a temperatura do ar como variável independente é considerado como um método adequado na determinação da evapotranspiração de referência, tanto a nível mensal como diário, para um clima como o do Estado de São Paulo (Camargo \& Centelhas, 1997).

Thornthwaite \& Matter (1955) utilizaram este método na determinação do balanço hídrico, embora seja possível a utilização de outro método de determinação de ETo. 
Com base nos numerosos métodos existentes, conclui-se que não existem dificuldades para estimar a evapotranspiração de referência (ETo).

A definição da $E T m$ é similar à de $E T o$, com a diferença de que a primeira trata-se de plantas ou culturas de interesse particular em determinado estádio ou fase vegetativa. No entanto, utilizando um termo mais agrícola, pode-se dizer que a ETm é a evapotranspiração que a planta deve conseguir para potencializar a produção e obter o máximo rendimento.

\subsubsection{Coeficiente de cultura $(k c)$}

Para estimar evapotranspiração máxima da cultura $(E T m)$ é preciso ajustar ETo com a utilização de um coeficiente, denominado coeficiente de cultura $(k c)$.

Os fatores que influenciam o coeficiente de cultura $(k c)$ são principalmente as características da cultura, datas de plantio ou semeadura, desenvolvimento da cultura e da área foliar, a duração do período vegetativo, condições climáticas e, especialmente durante a primeira fase de crescimento, frequência das chuvas ou irrigações (Doorenbos \& Pruitt, 1997). Segundo estes autores, as grandes variações existentes entre os principais grupos de culturas devem-se, principalmente, às diferenças existentes nos mecanismos das plantas à resistência à transpiração; como por exemplo, os estômatos fechados durante o dia (abacaxi) e as folhas cerosa (cítricos). As diferenças de altura, espessura das folhas, albedo e rugosidade da cobertura sombreada, também produzem as variações mencionadas.

Doorenbos \& Pruitt (1997), para a cultura da cana-de-açúcar, encontraram valores de $k c$ com diferentes amplitudes conforme as condições de velocidade média de vento e de umidade.

No entanto, Barbieri (1981), realizando registro diário de evapotranspiração da cana-de-açúcar, variedade NA 56-79, através de um evapotranspirógrafo a nível freático constante, determinou o coeficiente de cultura $(k c)$ ao longo do ciclo, para a região de Araras/SP (Lat. $22^{\circ} 18^{\prime}$ S, Long. $47^{\circ} 23^{\prime}$ ), em relação aos 
diferentes métodos de estimativa de evapotranspiração de referência (ETo). O tempo total de registro foi de 18 meses e o resultado apresentou valores decendiais, com uma variação média entre 0,1 nos primeiros dias após o plantio e 1,5 na época de maior crescimento da cana, com pequenas variações entre os diferentes métodos utilizados. A estimativa de $k c$ pelo método de tanque Classe " $\mathrm{A}$ ", deu como valor médio $k c=0,91$ para o ciclo total da cultura.

\subsubsection{Capacidade de água disponível no solo (CAD)}

A capacidade de água disponível no solo $(C A D)$ é definida, por Doorenbos \& Kassam (1979), como a profundidade ou altura de água, em milímetros por metro de profundidade de solo, entre o conteúdo de água do solo na capacidade de campo $(C C)$ (tensão da água no solo de 0,1 a 0,2 atm.) e o conteúdo de água no solo no ponto de murcha permanente $(P M P)$ (tensão da água no solo de $15 \mathrm{~atm}$.). A $C A D$ para uma cultura seria a altura da água, em $\mathrm{mm}$ contido em aproximadamente $80 \%$ da profundidade onde as raízes estão fixadas.

Considera-se disponibilidade ótima de água no solo, quando a retenção está sob potencial matricial baixo, significando elevada quantidade de água nos capilares da camada do solo onde exploram as raízes das plantas. A quantidade máxima de milímetros de água retida nessa camada depende principalmente das propriedades fisicas do solo e da profundidade do sistema radicular das plantas (Reichardt, 1996). Sousa (1976), citado por Scardua \& Rosenfeld (1987), estudando a irrigação por sulcos de infiltração na cana-de-açúcar, em Araras, concluiu que nos primeiros $60 \mathrm{~cm}$ de solo encontram-se $82 \%$ das raízes da cana irrigada, e $75,2 \%$ das raízes da cana não irrigada. Segundo Doorenbos \& Kassam (1979), em solo de textura pesada pode-se considerar $C A D$ igual a $200 \mathrm{~mm} / \mathrm{m}$, em solo de textura média $140 \mathrm{~mm} / \mathrm{m}$ e em solo de textura grossa $60 \mathrm{~mm} / \mathrm{m}$. Para um experimento, normalmente realizam-se análises de solo para determinar com maior precisão esse parâmetro. 


\subsection{4 Água prontamente disponível $(A P D)$}

Como foi mencionado anteriormente, as plantas evapotranspiram numa taxa máxima enquanto existe água abundante no solo. Se não há suprimento de água por meio de chuva, irrigação ou ascensão capilar, chegará um momento em que a planta terá restrições para absorver a água; a partir desse instante a evapotranspiração real (ETr) será menor que a evapotranspiração máxima $(E T m)$. A porção da $C A D$ que o solo perde por evapotranspiração sem que $E T r$ seja menor que $E T m$ é conhecido como água prontamente disponível $(A P D)$, sendo $p$ uma relação entre $A P D$ e $C A D$, ou seja $p=\frac{A P D}{C A D}$. Admite-se que até que essa fração $p$ da $C A D$ seja utilizada não há redução significativa na produtividade da cultura. Nesse contexto, define-se deficiência hídrica quando 0 armazenamento está abaixo da $A P D$ (Pereira et al., 1997).

Segundo Doorenbos \& Kassam (1979), o valor da fração $p$ depende da: $(i)$ cultura; (ii) magnitude de ETm e (iii) tipo de solo.

(i) - Algumas culturas como as hortaliças, precisam continuamente de solos relativamente úmidos para manter $E T r=E T m$; enquanto que outras como o algodão e o sorgo, podem retirar muito mais água do solo antes que ETr caia abaixo de ETm. A margem tolerável da fração $p$ é estreita para culturas cuja parte coletada é tenra ou fresca, como as frutas, hortaliças ou forragem; no entanto, é mais ampla para culturas cuja parte coletada é seca, como os cereais para grão seco, algodão e sementes oleaginosas.

(ii) - O valor de $p$, também pode variar com a fase de desenvolvimento e, em geral, será maior durante o período de maturação devido ao baixo nível de evapotranspiração (ETm) e ao valor reduzido de kc. Em condições em que ETm é elevada, $p$ é menor; em consequência, a fração $p$ para a qual $E T r$ é igual a $E T m$ varia com o nível de $E T m$ ou seja a intensidade da demanda hídrica ideal.

(iii) - A água infiltrada no solo é absorvida pelas raízes das plantas com maior facilidade nos solos de textura grossa que naqueles de textura fina. Aparentemente o valor de $p$ é 
maior para solos de textura grossa em relação aos de textura fina. Para cana-de-açúcar o valor médio da fração $p$ é de $68 \%$ da $C A D$ num solo de textura média (Ometto, 1988).

Conforme os conceitos mencionados, Doorenbos \& Kassam (1979), agrupam as culturas em 4 categorias de acordo à fração de esgotamento da água do solo (p). Nesta classificação a cana-de-açúcar encontra-se no $4^{\circ}$ grupo, sendo uma das culturas com maior valor da fração $p$.

\subsubsection{Precipitação efetiva (P)}

A precipitação efetiva é apenas uma parte da chuva total. Parte da chuva pode perder-se por escoamento superficial, por percolação profunda além da rizosfera e ainda por evaporação da água interceptada pelas folhas das plantas. Isto se acentua ainda mais quando a precipitação é pequena. Em regiões de chuvas fortes e intensas, somente uma pequena parte pode infiltrar e permanecer armazenada no substrato das plantas e, com isso, a eficiência da chuva será baixa. No caso de chuvas frequentes e leves a interceptação de águas pelas folhas das plantas pode ser muito importante. Neste caso, as plantas molhadas transpiram menos e contrabalançam o aumento da evaporação da água da chuva interceptada pelas folhas. Na prática, em condições de cobertura vegetal completa, pode-se supor seguramente que as chuvas leves são totalmente interceptadas.

$\mathrm{Na}$ estimativa da precipitação efetiva, empregam-se diferentes critérios. Por exemplo, na Índia, utilizando uma metodologia desenvolvida localmente, consideram $60 \%$ das chuvas médias como sendo efetiva; em outro equipara-se a precipitação efetiva à chuva média, porém não levando em consideração as chuvas diárias inferiores a $5 \mathrm{~mm}$ e nem as superiores a $75 \mathrm{~mm} /$ dia e $125 \mathrm{~mm}$ no período de 10 dias, no entanto consideramse efetivas as chuvas caídas após 5 dias da última irrigação (Doorenbos \& Pruitt, 1997).

Cabral et al. (1997), realizando um experimento sobre balanço de água no solo, no município de Sertãozinho (SP), observou que durante a época de maior crescimento da cana-de-açúcar, a evapotranspiração real (ETr) desse cultivo, representa apenas $30 \%$ da precipitação acumulada. 
Considerando todos os fatores que participam na perda da água de chuva observa-se a dificuldade de realizar um cálculo eficiente de determinação da precipitação efetiva para uma região ou lugar específico, o que seria um elemento importante para 0 calculo do balanço hídrico $(B H)$. No entanto, as metodologias utilizadas para o mencionado cálculo, como por exemplo o método de Thornthwaite \& Mather (1955), não se preocupam com boa estimativa dessa variável. Porém, num cálculo de $B H$ climático ou mesmo sequencial, os desvios acabam-se equilibrando, obtendo-se no final uma boa estimativa.

\subsection{Conceitos gerais sobre o cálculo do balanço hídrico pelo método de} Thornthwaite \& Mather (1955)

O balanço hídrico climático, descrito por Thornthwaite \& Mather (1955), é uma das diversas maneiras de monitorar o armazenamento de água no solo. A seguir se apresenta um conceito geral sobre o mesmo.

Partindo-se do suprimento natural de água ao solo, simbolizado pelas chuvas $(P)$, e da demanda atmosférica, simbolizada pela evapotranspiração de referência (ETo), e considerando uma $C A D$ apropriada ao tipo de planta cultivada, o balanço hídrico climático fornece estimativas da evapotranspiração real (ETr), da deficiência hídrica $(D E F)$, do excedente hídrico $(E X C)$, e do armazenamento de água no solo $(A R M)$, tanto na escala diária como mensal.

Para que não haja nem excesso nem deficiência hídrica, a chuva deveria ser igual à ETo. Portanto, ETo representa a chuva ideal. Essa situação só acontece esporadicamente em alguns períodos. Em algumas regiões há excesso praticamente o ano todo, enquanto que em regiões áridas e semi-áridas isso nunca acontece. Em regiões tropicais, é mais comum o excesso numa época e deficiência em outra. A magnitude dos excessos e deficiências depende do conjunto solo - planta - clima.

Embora Thornthwaite (1948) tenha desenvolvido um modo de estimar ETo de um local em função apenas da temperatura do ar, o balanço hídrico de 
Thornthwaite \& Mather (1955) funciona com qualquer método de estimativa de ETo. Outro aspecto pouco conhecido é que este método, parte da premissa básica que a taxa de perda real da água do solo ocorre em função do volume de água armazenado no solo (ARM).

Isto significa que à medida que o solo seca, a perda real diminui proporcionalmente. Thornthwaite \& Mather (1955) apresentam uma tabela que serve para calcular $A R M$ para qualquer valor de $C A D$. Ela foi decifrada por Mendonça (1958), o qual permitiu desenvolver programas computacionais para facilitar o cálculo.A Figura 2 mostra a relação entre $A R M / C A D(=\mathrm{Y})$ e $L / C A D(=\mathrm{X})$.

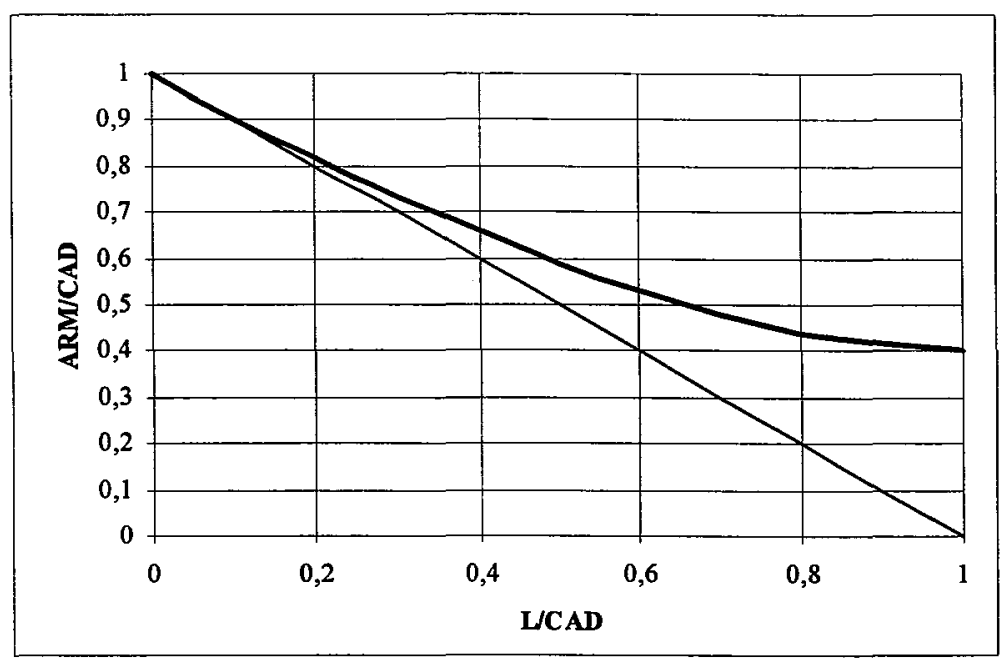

Figura 2 - Relação entre $A R M / C A D$ e $L / C A D$. Fonte: Pereira et al. (1997)

Verifica-se que $A R M / C A D$ desvia substancialmente da linearidade à medida que $L / C A D$ aumenta. Por exemplo, para $L / C A D=0,4$ há um desvio de $11 \%$ com respeito a linearidade. Para $L / C A D=0,5$ o desvio aumenta para $22 \%$. Isso significa que $E T r$ vai se afastando rapidamente de ETo, com consequente prejuízo no crescimento e desenvolvimento das plantas, visto que o solo retém mais firmemente a água à medida que ele se seca. É por esse motivo que se define a fração $p$ da água disponível entre $0,5 \mathrm{e}$ 0,6. Se a cultura for muito sensível ao estresse hídrico, $p=0,6$ é mais recomendado (Pereira et al., 1997). Nesse intervalo de variação do armazenamento (água prontamente disponível, $A P D$ ), o modelo linear pode ser adotado para controlar necessidades de 
irrigação, pois facilita os cálculos e não introduz diferenças significativas, visto que há uma certa variabilidade espacial na estimativa de $C A D$ para um terreno.

O método de Thornthwaite \& Mather (1955), detalhado por Pereira et al. (1997) e exposto com maior detalhe no seguinte capítulo, permite realizar balanço hídrico climático ou sequencial a qualquer escala (mensal, decendial, semanal, etc.). Este método serviu de base para a criação do programa computacional desenvolvido por Barbieri et al. (1991) para escala decendial, o qual foi utilizado no presente trabalho. 


\section{MATERIAL E MÉTODOS}

\subsection{Obtenção dos dados}

Os dados utilizados neste trabalho, tanto meteorológicos como de produtividade da cana-de-açúcar, foram extraídos dos relatórios anuais da PLANALSUCAR-IAA. Os experimentos comparativos durante onze anos (1974-1984) pela Seção de Irrigação e Climatologia, com cana irrigada e não irrigada, foram realizados na Estação-Experimental de Cana-de-açúcar, no município de Araras, SP, com as seguintes coordenadas geográficas: Latitude: $22^{\circ} 18^{\prime} \mathrm{S}$; Longitude: $47^{\circ} 23^{\prime} \mathrm{W}$ e altitude média: $620 \mathrm{~m}$; cuja localização pode ser observada na Figura 3.

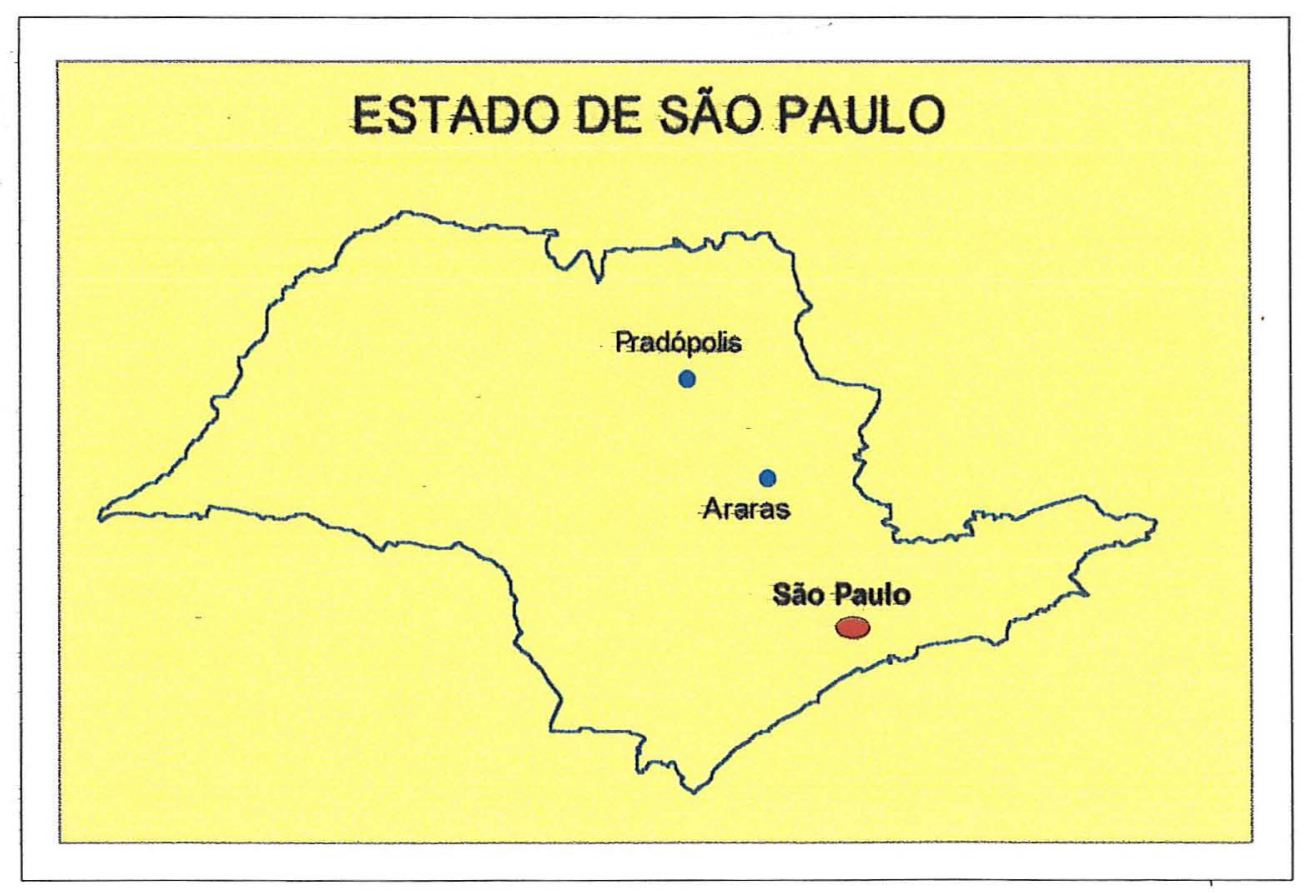

Figura 3 - Localização geográfica dos locais onde foram realizados os experimentos envolvidos no presente trabalho. 
Os experimentos que originaram esses dados não foram instalados para caracterizar exclusivamente a relação das condições hídricas do solo sobre a produtividade da cultura. Por exemplo, o experimento com a variedade CB 41-76, que corresponde à primeira coluna da Tabela 1 , foi instalado em 4 tratamentos e 5 blocos para observar o nível de água no solo utilizando distintas dosagem de água através de irrigação por infiltração. Ele foi observado durante 11 ciclos, entre 1974 até 1985.

Tabela 1. Produtividade de colmo e de açúcar de cinco variedades de canas irrigadas $(\mathrm{Ym})$ e não irrigadas $(\mathrm{Ya})$, em t/ha, cultivadas em Araras, SP, no período de 1974 a 1985.

\begin{tabular}{|c|c|c|c|c|c|c|c|c|c|c|c|c|c|c|c|c|c|c|c|c|}
\hline \multirow{3}{*}{$\begin{array}{l}\text { VAR. } \\
\text { ANO }\end{array}$} & \multicolumn{4}{|c|}{ CB 41-76 } & \multicolumn{4}{|c|}{ NA 56-79 } & \multicolumn{4}{|c|}{ CB 47-355 } & \multicolumn{4}{|c|}{ CB 41-76 } & \multicolumn{4}{|c|}{ CP 51-22 } \\
\hline & \multicolumn{2}{|c|}{$\frac{\text { Irrigada }}{(\mathrm{Ym})}$} & \multicolumn{2}{|c|}{$\frac{\tilde{\mathbf{N}} \text { Irrigada }}{(\mathbf{Y a})}$} & \multicolumn{2}{|c|}{$\frac{\text { |rrigada }}{(Y \mathrm{Ym})}$} & \multicolumn{2}{|c|}{$\frac{\bar{N} \text { Irrigada }}{(\text { Ya) }}$} & \multicolumn{2}{|c|}{$\frac{\text { Irrigada }}{(\mathrm{Ym})}$} & \multicolumn{2}{|c|}{$\frac{\overline{\mathbf{N}} \text { Irrigada }}{\text { (Ya) }}$} & \multicolumn{2}{|c|}{$\frac{\text { Irrigada }}{(Y m)}$} & \multicolumn{2}{|c|}{$\frac{\tilde{\hat{N}} \text { Irrigada }}{(\text { Ya) }}$} & \multicolumn{2}{|c|}{$\frac{\text { |rrigada }}{(Y \mathrm{~m})}$} & \multicolumn{2}{|c|}{$\frac{\tilde{N} \text { Irrigada }}{(\text { Ya })}$} \\
\hline & ${ }^{*} \mathrm{C}$ & $A^{* *}$ & C & A & C & A & C & A & C & A & C & A & C & A & C & A & C & A & C & A \\
\hline 74-75 & 132,4 & 20,8 & 100,7 & 15,8 & & & & & & & & & & & & & & & & \\
\hline 75-76 & 91,8 & 13,9 & 76,0 & 10,9 & & & & & & & & & & & & & & & & \\
\hline 76-77 & 101,0 & 15,6 & 81,5 & 12,4 & & & & & & & & & & & & & & & & \\
\hline $77-78$ & 91,4 & 15,0 & 66,4 & 10,7 & 139,9 & 23,2 & 107,8 & 18,0 & 140,1 & 22,3 & 115,3 & 19,4 & 137,5 & 22,2 & 123,2 & 19,4 & & & & \\
\hline 78-79 & 110,1 & 15,8 & 89,0 & 13,4 & 105,1 & 17,9 & 93,6 & 15,9 & 109,4 & 17,2 & 96,0 & 13,8 & 91,8 & 14,8 & 88,3 & 13,8 & & & & \\
\hline $79-80$ & 93,3 & 14,8 & 82,9 & 12,9 & 99,4 & 15,4 & 98,6 & 15,0 & 101,0 & 15,5 & 93,4 & 15,0 & 97,2 & 15,6 & 91,8 & 15,0 & 133,5 & 22,9 & 123,4 & 20,4 \\
\hline $80-81$ & 82,4 & 12,3 & 64,7 & 9,9 & 100,8 & 15,6 & 92,7 & 15,0 & 92,3 & 13,4 & 74,1 & 12,2 & 92,2 & 14,1 & 76,3 & 12,2 & 79,3 & 11,8 & 69,5 & 10,5 \\
\hline $81-82$ & 85,6 & 13,6 & 75,6 & 12,6 & 99,5 & 15,6 & 85,7 & 13,7 & 98,1 & 14,7 & 87,6 & 13,4 & 91,2 & 14,2 & 88,1 & 13,4 & 91,6 & 13,4 & 76,0 & 11,5 \\
\hline $82-83$ & 73,6 & 11,2 & 68,5 & 10,7 & 105,4 & 17,1 & 101,1 & 16,2 & 95,7 & 13,8 & 91,8 & 13,1 & 89,1 & 13,6 & 87,4 & 13,1 & 85,1 & 12,9 & 77.7 & 12,0 \\
\hline $83-84$ & 90,0 & 13,3 & 65,0 & 9,9 & 105,4 & 18,0 & 90,3 & 15,6 & 97,8 & 14,6 & 68,4 & 11,2 & 94,6 & 13,6 & 72,5 & 11,2 & 100,6 & 14,4 & 74,6 & 12,7 \\
\hline $84-85$ & 88,6 & 10,0 & 83,1 & 9,3 & & & & & & & & & & & & & & & & \\
\hline
\end{tabular}

* Colmo; ** Açúcar

O experimento com as variedades NA 56-79, CB 47-355 e CB 41-76, que correspondem à segunda, terça e quarta colunas da Tabela 1 , foi instalado em blocos casualizados subdivididos, com níveis mínimos de água no solo, correspondendo ao consumo de 58, 69 e $86 \%$ da $\mathrm{CAD}$, aplicado através de irrigação por aspersão, para caracterizar o comportamento da produtividade dessas variedades com relação às dosagens. Foram extraídos dados correspondente a 7 ciclos da cultura (1977 até 1984).

Finalmente, o experimento com a variedade CP 51-22, que corresponde à última coluna da Tabela 1, foi instalado também em blocos casualizados com parcelas subdivididas com 5 tratamentos e 5 blocos para determinar a aspersão mais barata entre 
os distintos distanciamentos dos aspersores. Foram extraídos dados correspondente a 5 ciclos da cultura (1979 até 1984).

Os dados de produtividades, utilizados neste trabalho, foram selecionados arbitrariamente levando em consideração o histórico de cada um desses experimentos. Com foi visto anteriormente, eles foram montados com diferentes sistemas de irrigação, utilizando distintas variedades de cana. Para evitar erros nas escolhas dos dados, foram selecionados aqueles com melhores resultados quanto a produtividade, sem importar a diferença existente entre a produtividade real e a máxima.

\subsection{Generalidades sobre o modelo de Jensen (1968)}

O procedimento seguinte foi ordenar os dados de produtividade e correlacionar com a deficiência hídrica, utilizando o modelo proposto por Jensen (1968), modificado por Meyer et al. (1992) e Camargo (1992).

$$
\frac{Y a}{Y m}=\prod_{i=1}^{n}\left(\frac{E T r}{E T m}\right)_{i}^{\lambda_{i}}
$$

em que: $\Pi$ simboliza a multiplicação entre a evapotranspiração relativa $\left(\frac{E T r}{E T m}\right)$ para cada fase de desenvolvimento da cultura $(i) ; \lambda_{i}$ é o coeficiente de sensibilidade ao déficit hídrico para cada uma das fases $(i)$ consideradas.

Ele considera que a produtividade pode ser relacionada às condições hídricas dos períodos fenológicos, por meio de um modelo multiplicativo.

$$
\frac{Y a}{Y m}=\left(\frac{E T r}{E T m}\right)_{1}^{\lambda_{1}} \cdot\left(\frac{E T r}{E T m}\right)_{2}^{\lambda_{2}} \cdot\left(\frac{E T r}{E T m}\right)_{3}^{\lambda_{3}}
$$

em que: $E T r$ e $E T m$ correspondem a evapotranspiração real e máxima a nível decendial, cuja relação no modelo representa a medida do suprimento hídrico (Ortolani et al. 1996); Ya e Ym são a produtividade real e a potencial. O coeficiente de sensibilidade da cultura, 
representado por $\lambda$, correspondem às seguintes fases: (1) brotação e estabelecimento, (2) crescimento vegetativo e (3) maturação, respectivamente.

Para ajustar o modelo, foi necessário realizar o balanço hídrico, a partir dos dados meteorológicos que foram registrados durante o experimento, para correlacionar com os dados de produtividade.

\subsection{Cálculo do balanço hídrico $(B H)$}

Na obtenção de dados de deficiência hídrica para ajustar o modelo foi necessário calcular o balanço hídrico sequencial decendial, com coeficiente da cultura $(k c)$ e capacidade de água disponível $(C A D)$ variáveis. Para isso foi utilizado o programa elaborado por Barbieri et al. (1991), com o devido cuidado de levar em consideração o ciclo de cada um dos experimentos, tal como se apresentam nas Tabelas 2 e 3 de Anexos. O conceito utilizado foi idealizado por Thornthwaite \& Mather (1955), introduzindo-se algumas alterações, como a variação de $C A D$ e do $k c$ durante o ciclo da cultura, (Barbieri et al. 1997).

É importante esclarecer que o cálculo do $B H$ foi decendial, representando com maior precisão as condições hídricas para cultura, que o $B H$ mensal, que ocasionalmente mascara a deficiência hídrica no solo $(D E F)$, podendo influenciar na precisão do modelo.

O roteiro para o cálculo do balanço hídrico de acordo com a mencionada metodologia é detalhado a seguir:

O primeiro passo é calcular a ETo segundo método de Thornthwaite (1948):

A Evapotranspiração Média padrão (ETop em $\mathrm{mm}$ ) para um mês com 30 dias e 12 horas de fotoperíodo médio diário, é representada pelo seguinte conjunto de equações: 


$$
\begin{aligned}
& \text { ETop }=16\left(10 \frac{T i}{I}\right)^{a} \quad \mathrm{Ti}>0^{\circ} \mathrm{C} \\
& \begin{array}{l}
a=6,75 \cdot 10^{-7} \cdot I^{3}-7,71 \cdot 10^{-5} \cdot I^{2}+1,7912 \cdot 10^{-2} \cdot I+0,49239 \\
I=\sum_{i=1}^{12}(0,2 T i)^{1,514}
\end{array} \quad T i>0^{\circ} \mathrm{C}
\end{aligned}
$$

em que: Ti é a temperatura média mensal $\left({ }^{\circ} \mathrm{C}\right)$ e $I 0$ índice da região, que deve ser calculado com valores normais (média climatológica). $O$ subscrito $i$ representa o mês do ano ( $\mathrm{i}=1$, jan.; $\mathrm{i}=2$, fev.; etc). Como esta fórmula está condicionada para padrão de 12 horas de brilho solar e mês com 30 dias, para estimar a evapotranspiração de referência (ETo), foi necessário que ETop seja ajustada por um fator de correção, isto é:

$$
E T o=E T o p \frac{N}{12} \frac{N D}{30}
$$

sendo $N$ a duração máxima em horas da insolação diária de acordo com o mês e a latitude local, e $N D$ o número de dias do período (dez neste caso).

Posteriormente, segundo os conceitos exposto no item 2.5.2, aplicando os valores de $k c$ determinado por Barbieri (1981) para cana de açúcar, com o auxilio da eq. (7), se obtém a ETm da cultura.

$$
E T m=k c . E T o
$$

A seguir se calcula a diferença entre a precipitação $(P)$ (cujos dados se encontram na Tabela 1 de anexos), e a evapotranspiração máxima decendial (P-ETm), para depois calcular concomitantemente os valores de Negativo Acumulado (NegAc) e Armazenamento ( $A R M)$, levando em consideração os valores de $C A D$ para cada período de desenvolvimento da cultura; que no caso do presente trabalho, esses valores variam entre $30 \mathrm{~mm}$ no começo e $100 \mathrm{~mm}$ no máximo desenvolvimento da cana. Inicia-se quando aparece o primeiro valor negativo de $P$-ETm. Neste decendio, o valor de $N e g A c$ é igual ao valor negativo de $P$-ETm. Nos decendios seguintes se somam os valores de $P$ $E T m$ dos decendios anteriores. De acordo com o valor de $N e g A c$, se obtém o valor 
correspondente do $A R M$ com auxílio da eq. (8). Se depois de um valor ou uma série de valores de $N e g A c$ sobrevier um valor positivo de $(P$-ETm) procede-se da seguinte maneira: soma-se $(P-E T m)$ positivo ao armazenamento $(A R M)$ do decendio anterior e obtém-se o $A R M$ do decendio em questão. Com este valor entra-se na eq. (9) obtendo assim o valor do $N e g A c$ do decendio em questão.

$$
\begin{aligned}
& A R M=C A D \cdot \exp \left[-\frac{L}{C A D}\right] \\
& L=C A D \cdot \operatorname{Ln}\left[\frac{A R M}{C A D}\right]
\end{aligned}
$$

sendo $L$ a perda potencial, chamado também de negativo acumulado (NegAc.) por Camargo, (1978), citado por Pereira et al., (1997).

Conhecendo-se o $A R M$ de cada decendio calcula-se a evapotranspiração real $(E T r)$, a deficiência $(D E F)$, e o excedente $(E X C)$ hídrico para uma determinada $C A D$. No entanto, antes é necessário conhecer a alteração ( $A L T$ ). Ela é a variação no $A R M$ entre decendios consecutivos; isto é, a $A L T$ do decendio é igual ao $A R M$ do decendio em questão menos o $A R M$ do decendio anterior. Portanto, $A L T$ assume valores tanto positivos como negativos. ETr é igual ao valor de $E T m$ quando (P-ETm) é igual ou maior que zero. Nos casos onde $(P$-ETm) é negativo o valor ETr é igual à soma dos valores de $(P+|A L T|)$, sem considerar o sinal de $A L T$. A $D E F$ é obtida com a diferença entre $E T m$ e $E T r$. O EXC é sempre zero no decendio onde não ocorre $A R M$ máximo $(A R M=C A D)$. Quando o armazenamento é máximo o $E X C$ será igual a diferença entre $(P-E T m)$ e $A L T$.

É bom esclarecer que para calcular o balanço hídrico, rodando o programa descrito, foi necessário fazê-lo desde o primeiro decendio do ano, alguns meses antes de começar a primeira fase da cana-de-açúcar. Ele serve para definir principalmente a condição de ARM no solo no momento em que começa a primeira fase da cultura considerada. 
Para facilitar a interpretação acima descrita, um exemplo de cálculo de balanço hídrico é apresentada na Tabela 4 do Anexos.

\subsection{Ajuste do modelo}

Uma vez contando com os dados de balanço hídrico, calculado pela metodologia acima descrita, são calculadas as médias das três fases correspondentes ao ciclo da cultura em questão (Tabela 2), tal como aparece nas Tabelas $5 \mathrm{a}$ até $5 \mathrm{~g}$ de Anexos, de forma a atender o modelo de Jensen (1968).

Tabela 2. Valores de $Y a / Y m$ e $E T r / E T m$ médios, por fase da cultura, observados na localidade de Araras.

\begin{tabular}{|c|c|c|c|c|c|c|}
\hline \multirow[b]{2}{*}{ Variedade } & \multirow{3}{*}{$\begin{array}{l}\text { Ciclo } \\
74-75\end{array}$} & \multicolumn{2}{|c|}{$\underline{Y a / Y m}$} & \multicolumn{3}{|c|}{ ETa/ETm } \\
\hline & & Colmo & Açúcar & $1^{\circ}$ fase & $2^{\circ}$ fase & $3^{\circ}$ fase \\
\hline \multirow{11}{*}{$\begin{array}{l}\frac{0}{T} \\
\frac{1}{8} \\
0 \\
0\end{array}$} & & 0,76 & 0,76 & 0,73 & 0,87 & 0,31 \\
\hline & $75-76$ & 0,83 & 0,78 & 0,94 & 0,94 & 0,90 \\
\hline & $76-77$ & 0,81 & 0,80 & 0,97 & 0,65 & 0,49 \\
\hline & $77-78$ & 0,73 & 0,72 & 0,98 & 0,73 & 0,63 \\
\hline & $78-79$ & 0,81 & 0,85 & 0,96 & 0,80 & 0,72 \\
\hline & $79-80$ & 0,89 & 0,87 & 0,99 & 0,82 & 0,75 \\
\hline & $80-81$ & 0,79 & 0,81 & 0,99 & 0,73 & 0,58 \\
\hline & $81-82$ & 0,88 & 0,93 & 0,98 & 0,85 & 0,78 \\
\hline & $82-83$ & 0,93 & 0,96 & 1,00 & 0,96 & 0,80 \\
\hline & $83-84$ & 0,72 & 0,75 & 0,96 & 0,55 & 0,53 \\
\hline & $84-85$ & 0,94 & 0,93 & 0,97 & 0,91 & 0,42 \\
\hline \multirow{7}{*}{$\begin{array}{l}\stackrel{0}{T} \\
\frac{7}{8} \\
0 \\
0\end{array}$} & $77-78$ & 0,90 & 0,87 & 0,79 & 0,85 & 0,65 \\
\hline & 78-79 & 0,96 & 0,93 & 0,96 & 0,80 & 0,72 \\
\hline & $79-80$ & 0,94 & 0,96 & 0,99 & 0,82 & 0,75 \\
\hline & $80-81$ & 0,83 & 0,87 & 0,99 & 0,73 & 0,58 \\
\hline & $81-82$ & 0,97 & 0,94 & 0,98 & 0,85 & 0,78 \\
\hline & $82-83$ & 0,98 & 0,96 & 1,00 & 0,96 & 0,80 \\
\hline & $83-84$ & 0,77 & 0,82 & 0,96 & 0,55 & 0,53 \\
\hline \multirow{7}{*}{$\begin{array}{l}\text { 号 } \\
\text { ?ै } \\
\text { 吉 } \\
\text { 怘 }\end{array}$} & $77-78$ & 0,82 & 0,87 & 0,79 & 0,85 & 0,65 \\
\hline & $78-79$ & 0,88 & 0,80 & 0,96 & 0,80 & 0,72 \\
\hline & $79-80$ & 0,93 & 0,97 & 0,99 & 0,82 & 0,75 \\
\hline & $80-81$ & 0,80 & 0,91 & 0,99 & 0,73 & 0,58 \\
\hline & $81-82$ & 0,89 & 0,91 & 0,98 & 0,85 & 0,78 \\
\hline & $82-83$ & 0,96 & 0,95 & 1,00 & 0,96 & 0,80 \\
\hline & $83-84$ & 0,70 & 0,77 & 0,96 & 0,55 & 0,53 \\
\hline \multirow{7}{*}{$\begin{array}{l}\frac{\Omega}{7} \\
\dot{8} \\
\mathbf{8} \\
\mathbf{z}\end{array}$} & $77-78$ & 0,77 & 0,78 & 0,79 & 0,85 & 0,65 \\
\hline & $78-79$ & 0,89 & 0,89 & 0,96 & 0,80 & 0,72 \\
\hline & $79-80$ & 0,99 & 0,97 & 0,99 & 0,82 & 0,75 \\
\hline & $80-81$ & 0,92 & 0,96 & 0,99 & 0,73 & 0,58 \\
\hline & $81-82$ & 0,86 & 0,88 & 0,98 & 0,85 & 0,78 \\
\hline & $82-83$ & 0,96 & 0,95 & 1,00 & 0,96 & 0,80 \\
\hline & $83-84$ & 0,86 & 0,87 & 0,96 & 0,55 & 0,53 \\
\hline \multirow{5}{*}{$\begin{array}{l}\frac{Y}{5} \\
\frac{6}{6} \\
\frac{0}{0}\end{array}$} & $79-80$ & 0,92 & 0,89 & 0,89 & 0,94 & 0,76 \\
\hline & $80-81$ & 0,88 & 0,89 & 0,99 & 0,73 & 0,58 \\
\hline & $81-82$ & 0,83 & 0,86 & 0,98 & 0,85 & 0,78 \\
\hline & $82-83$ & 0,91 & 0,93 & 1,00 & 0,96 & 0,80 \\
\hline & $83-84$ & 0,74 & 0,88 & 0,96 & 0,55 & 0,53 \\
\hline
\end{tabular}


$\mathrm{O}$ ajuste dos coeficientes de sensibilidade é feito através do método da regressão linear múltipla (Camargo, 1992). Para tal determinação, aplica-se a regra dos logaritmos.

Tendo-se o modelo de Jensen (1968):

$$
\frac{Y a}{Y m}=\left(\frac{E T r}{E T m}\right)_{1}^{\lambda_{1}}\left(\frac{E T r}{E T m}\right)_{2}^{\lambda_{2}}\left(\frac{E T r}{E T m}\right)_{3}^{\lambda_{3}}
$$

e aplicando a ele o logaritmo neperiano, tem-se:

$$
\operatorname{Ln}\left(\frac{Y a}{Y m}\right)=\lambda_{1} \operatorname{Ln}\left(\frac{E T r}{E T m}\right)_{1}+\lambda_{2} \operatorname{Ln}\left(\frac{E T r}{E T m}\right)_{2}+\lambda_{3} \operatorname{Ln}\left(\frac{E T r}{E T m}\right)_{3}
$$

de onde $\lambda_{1}, \lambda_{2}$ e $\lambda_{3}$ podem ser determinados pelo método dos mínimos quadrados. Esse tipo de determinação dos valores de $\lambda$ impõe a necessidade de um coeficiente linear $(a)$; ficando as estimativas de produtividade dependentes desse coeficiente.

A primeira regressão consiste na plotagem da coluna correspondente ao $\operatorname{Ln}(Y a / Y m)$ de colmo com as três colunas de $\operatorname{Ln}(E T r / E T m)_{1.3 .}$ A segunda regressão é realizada de maneira similar com a diferença de que no lugar da coluna do colmo, utiliza-se a coluna correspondente ao açúcar.

Após a determinação dos valores de $\lambda$, volta-se à equação original; porém, desta vez sendo o modelo dependente de um coeficiente linear $(a)$ :

$$
\left(\frac{Y a}{Y m}\right)=a \cdot\left(\frac{E T r}{E T m}\right)_{1}^{\lambda_{1}} \cdot\left(\frac{E T r}{E T m}\right)_{2}^{\lambda_{2}} \cdot\left(\frac{E T r}{E T m}\right)_{3}^{\lambda_{3}}
$$

sendo este modelo multiplicativo, o resultante para estimativa da produtividade agroindustrial da cana-de-açúcar.

\subsection{Tratamentos estatísticos}

Para o teste do modelo resultante foram utilizados conjuntos de dados independentes, extraídos igualmente dos informes anuais de PLANALSUCAR. Os experimentos foram realizados em Araras e Pradópolis, sendo 12 o total (Tabela 3). 
Pradópolis tem a seguinte coordenada geográfica: Latitude: $21^{\circ} 22^{\prime} \mathrm{S}$, Longitude: $48^{\circ}$ 04' W e Altitude média: $517 \mathrm{~m}$ (ver na figura 3).

Tabela 3. Produtividade de colmo e de açúcar de cinco variedades de canas, irrigadas (Ym) e não irrigadas ( $\mathrm{Ya}$ ), em t/ha, cultivadas em Araras e Pradópolis, SP, no período de 1975 a 1986.

\begin{tabular}{|c|c|c|c|c|c|c|c|c|c|c|c|c|c|c|c|c|c|c|c|}
\hline \multirow{3}{*}{ ANO } & \multicolumn{4}{|c|}{ IAC 51/205 } & \multicolumn{4}{|c|}{ CB41-76 } & \multicolumn{4}{|c|}{ C0775 } & \multicolumn{4}{|c|}{ NA 56-79 } & \multicolumn{3}{|c|}{ RB-725828 } \\
\hline & \multicolumn{2}{|c|}{$\frac{\text { Irrigada }}{(Y m)}$} & \multicolumn{2}{|c|}{$\frac{\overline{\mathbf{N}} \text { Irrigada }}{(\mathrm{Ya})}$} & \multicolumn{2}{|c|}{$\frac{\text { |rrigada }}{(Y \mathrm{Ym})}$} & \multicolumn{2}{|c|}{$\frac{\tilde{N} \text { Irrigada }}{(\text { Ya) }}$} & \multicolumn{2}{|c|}{$\frac{\text { Irrigada }}{(Y \mathrm{~m})}$} & \multicolumn{2}{|c|}{$\frac{\tilde{N} \text { Irrigada }}{(\mathbf{Y a})}$} & \multicolumn{2}{|c|}{$\frac{\text { Irrigada }}{(Y \mathrm{~m})}$} & \multicolumn{2}{|c|}{$\frac{\tilde{N} \text { trrigada }}{(\text { Ya })}$} & \multicolumn{2}{|c|}{$\frac{\text { Irrigada }}{(Y \mathrm{~m})}$} & \multirow{2}{*}{$\frac{\text { N Irrigada }}{\mathrm{c}^{\frac{(Y a)}{A}}}$} \\
\hline & & & & A & & A & & A & & A & & A & & A & & & & & \\
\hline $75 \cdot 76$ & 164,3 & 23,3 & 138,8 & 20,7 & & & & & & & & & & & & & & & \\
\hline 76-77 & 116,9 & 19,0 & 94,2 & 15,5 & & & & & & & & & & & & & & & \\
\hline $77-78$ & 110,8 & 17,9 & 94,3 & 15,6 & & & & & & & & & & & & & & & \\
\hline 78-79 & & & & & 146,5 & 20,6 & 127,9 & 16,7 & & & & & & & & & & & \\
\hline 78-79 & & & & & 128,3 & 16,6 & 111,6 & 14,7 & & & & & & & & & & & \\
\hline $79-80$ & & & & & 104,3 & 15,5 & 93,7 & 13,4 & 118,1 & 20,3 & 105,7 & 17,5 & & & & & & & \\
\hline 79-80 & & & & & & & & & 144,8 & 24,2 & 130,4 & 22,9 & & & & & & & \\
\hline 85-86 & & & & & 86,8 & 14,3 & 65,1 & 10.5 & & & & & 89,9 & 14,0 & 70,2 & 10,3 & 122,5 & 20,3 & 81,9 \\
\hline $85-86$ & & & & & 73,7 & 11,4 & 51,4 & 8,3 & & & & & & & & & & & \\
\hline
\end{tabular}

* $\mathrm{C}=$ colmo; ** $\mathrm{A}=$ açúcar

Assim como foram calculados o balanço hídrico $(B H)$ de cada um dos ciclos das culturas para a realização das regressões múltiplas e criação do modelo, também foram calculados o $B H$ para testar os modelos resultantes (Anexo 6a até $61 \mathrm{de}$ Anexos). Neste processo foi levado em consideração o período de cada um dos ciclos, tal como foi apresentado na Tabela 3 do Anexos.

Posteriormente são calculadas as médias dos valores de $E T r$ e $E T m$ para as três fases de cada um dos ciclos. A seguir eles são ordenados em forma de evapotranspiração relativa (ETr/ETm) e colocados junto com a produtividade máxima $(\mathrm{Ym})$ e produtividade real $(\mathrm{Ya})$ correspondentes, tal como aparece na Tabela 4.

Com estes dados independentes são testados os modelos resultante, e através de tratamentos estatísticos os resultados são avaliados utilizando índices apropriados para este tipo de trabalho. 
Tabela 4. Valores de produtividade agro-industrial da cana e evapotranspiração relativa $(E T r / E T m)$ média, de três fases da cultura, observados nas localidades de Araras e Pradópolis.

\begin{tabular}{lccccccc}
\hline PERIODO & \multicolumn{2}{c}{ COLMO } & \multicolumn{2}{c}{ AÇÚCAR } & \multicolumn{3}{c}{ ETr/ETm } \\
\hline $\begin{array}{l}\text { Ciclo , Local } \\
\text { Variedade }\end{array}$ & $Y m$ & $Y a$ & $Y m$ & $Y a$ & $1^{\circ}$. Período & $2^{\circ}$. Período & $3^{\circ}$. Período \\
\hline $\begin{array}{l}\text { 75-76, Araras } \\
\text { IAC51/205 }\end{array}$ & 164,3 & 138,8 & 23,3 & 20,7 & 0,73 & 0,92 & 0,92 \\
\hline $\begin{array}{l}76-77, \text { Araras } \\
\text { IAC51/205 }\end{array}$ & 116,9 & 94,2 & 19,0 & 15,5 & 0,97 & 0,65 & 0,40 \\
\hline $\begin{array}{l}77-78, \text { Araras } \\
\text { IAC51/205 }\end{array}$ & 110,8 & 94,3 & 17,9 & 15,6 & 0,96 & 0,80 & 0,62 \\
\hline $\begin{array}{l}78-79, \text { Pradopolis } \\
\text { CB 41-76 }\end{array}$ & 146,5 & 127,9 & 20,6 & 16,7 & 0,94 & 0,72 & 0,92 \\
\hline $\begin{array}{l}78-79, \text { Araras, } \\
\text { CB 41-76 }\end{array}$ & 128,3 & 111,6 & 16,6 & 14,7 & 0,85 & 0,83 & 0,76 \\
\hline $\begin{array}{l}79-80, \text { Pradopolis } \\
\text { CB 41-76 }\end{array}$ & 104,3 & 93,7 & 15,5 & 13,4 & 0,81 & 0,94 & 0,90 \\
\hline $\begin{array}{l}85-86 \text { Araras } \\
\text { CB 41-76 }\end{array}$ & 86,8 & 65,1 & 14,3 & 10,5 & 0,71 & 0,88 & 0,60 \\
\hline $\begin{array}{l}85-86, \text { Araras } \\
\text { CB 41-76 }\end{array}$ & 73,7 & 51,4 & 11,4 & 8,3 & 0,71 & 0,88 & 0,60 \\
\hline $\begin{array}{l}79-80, \text { Pradopolis } \\
\text { CO 775 }\end{array}$ & 118,1 & 105,7 & 20,3 & 17,5 & 0,97 & 0,85 & 0,73 \\
\hline $\begin{array}{l}79-80, \text { Pradopolis } \\
\text { CO 775 }\end{array}$ & 144,8 & 130,4 & 24,2 & 22,9 & 0,87 & 0,88 & 0,70 \\
\hline $\begin{array}{l}85-86, \text { Araras } \\
\text { NA 56-79 }\end{array}$ & 89,9 & 70,2 & 14,0 & 10,3 & 0,56 & 0,93 & 0,64 \\
\hline $\begin{array}{l}85-86, \text { Pradopolis } \\
\text { RB-725828 }\end{array}$ & 122,5 & 81,9 & 20,3 & 13,3 & 0,38 & 0,93 & 0,69 \\
\hline
\end{tabular}

Os índices estatísticos utilizados para avaliar a relação entre valores de produtividade de colmo e de açúcar observados e estimados, foram os seguintes:

a) coeficiente de determinação $\left(\mathrm{r}^{2}\right)$, (Pereira \& Arruda, 1987):

$$
r^{2}=1-\frac{\sum(O i-P i)^{2}}{\sum O i^{2}-\frac{\left(\sum O i\right)^{2}}{n}}
$$

em que: $P i$ é o valor estimado pelo modelo proposto, $O i$ o valor observado e $n$ o número de observações.

b) índice de concordância (d), (Willmott, 1981): 


$$
d=1-\left[\sum_{i=1}^{n}(P i-O i)^{2} / \sum_{i=1}^{n}(|P i-\ddot{O}|+\mid O i-\bar{O})^{2}\right]
$$

sendo $\bar{O}$ o valor médio dos dados observados.

Ainda para melhor avaliação dos ajustes, Loague \& Green (1991), citado por Zacharias et al. (1996) sugerem para este tipo de avaliação a utilização dos seguintes índices:

c) erro médio absoluto (EMA)

$$
E M A=\frac{1}{n} \sum|P i-O i|
$$

d) erro máximo (ME)

$$
M E=\operatorname{Max}(|O i-P i|)
$$

e) eficiência do modelo proposto (EF)

$$
E F=\frac{\sum_{i=1}^{n}(O i-\bar{O})^{2}-\sum_{i=1}^{n}(O i-P i)^{2}}{\sum_{i=1}^{n}(O i-\bar{O})^{2}}
$$

Willmott (1981), sugere ainda o cálculo dos seguintes erros:

f) erro sistemático (Es)

$$
E s=\frac{1}{n} \sum_{i=1}^{n}(\hat{P} i-O i)^{2}
$$

g) erro aleatório $(\mathrm{Ea})$,

$$
E a=\frac{1}{n} \sum_{i=1}^{n}\left(P i-\hat{P}_{i}\right)^{2}
$$

em que: $\hat{P} i$ é o valor da produtividade estimada pela equação resultante do ajuste linear, conforme são explicados no item correspondente. 


\section{RESULTADOS E DISCUSSÃO}

\subsection{Resultados preliminares}

Para realizar as regressões, segundo metodologia consultada, foi necessário converter os valores apresentados na Tabela 2 em valores logarítmicos.

Tabela 5. Valores logarítmicos de $Y a / Y m$ e $E T r / E T m$ médios por fase da cultura na localidade de Araras.

\begin{tabular}{|c|c|c|c|c|c|c|}
\hline & \multirow[b]{2}{*}{ Ciclo } & \multicolumn{2}{|c|}{ Ln de Ya/Ym } & \multicolumn{3}{|c|}{ Ln de ETr/Etm } \\
\hline & & Colmo & Açúcar & $1^{\circ}$ fase & $2^{\circ}$ fase & $3^{\circ}$ fase \\
\hline 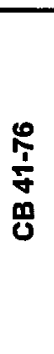 & $\begin{array}{l}74-75 \\
75-76 \\
76-77 \\
77-78 \\
78-79 \\
79-80 \\
80-81 \\
81-82 \\
82-83 \\
83-84 \\
84-85\end{array}$ & $\begin{array}{l}-0,2731 \\
-0,1900 \\
-0,2144 \\
-0,3188 \\
-0,2132 \\
-0,1177 \\
-0,2421 \\
-0,1244 \\
-0,0715 \\
-0,3257 \\
-0,0651\end{array}$ & $\begin{array}{l}-0,2744 \\
-0,2433 \\
-0,2282 \\
-0,3341 \\
-0,1672 \\
-0,1370 \\
-0,2157 \\
-0,0715 \\
-0,0440 \\
-0,2917 \\
-0,0726\end{array}$ & $\begin{array}{c}-0,3191 \\
-0,0609 \\
-0,0337 \\
-0,0244 \\
-0,0450 \\
-0,0141 \\
-0,0124 \\
-0,0166 \\
0,0000 \\
-0,0419 \\
-0,0311\end{array}$ & $\begin{array}{l}-0,1353 \\
-0,0567 \\
-0,4275 \\
-0,3200 \\
-0,2282 \\
-0,2004 \\
-0,3189 \\
-0,1617 \\
-0,0406 \\
-0,5960 \\
-0,0943\end{array}$ & $\begin{array}{l}-1,1849 \\
-0,1100 \\
-0,7219 \\
-0,4599 \\
-0,3227 \\
-0,2836 \\
-0,5494 \\
-0,2510 \\
-0,2222 \\
-0,6311 \\
-0,8615\end{array}$ \\
\hline 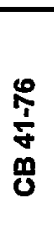 & $\begin{array}{l}77-18 \\
78-79 \\
79-80 \\
80-81 \\
81-82 \\
82-83 \\
83-84\end{array}$ & $\begin{array}{l}-0,1098 \\
-0,0387 \\
-0,0576 \\
-0,1887 \\
-0,0346 \\
-0,0192 \\
-0,2666\end{array}$ & $\begin{array}{l}-0,1347 \\
-0,0704 \\
-0,0387 \\
-0,1450 \\
-0,0576 \\
-0,0377 \\
-0,1936\end{array}$ & $\begin{array}{c}-0,2337 \\
-0,0450 \\
-0,0141 \\
-0,0124 \\
-0,0166 \\
0,0000 \\
-0,0419\end{array}$ & $\begin{array}{l}-0,1604 \\
-0,2282 \\
-0,2004 \\
-0,3189 \\
-0,1617 \\
-0,0406 \\
-0,5960\end{array}$ & $\begin{array}{l}-0,4317 \\
-0,3227 \\
-0,2836 \\
-0,5494 \\
-0,2510 \\
-0,2222 \\
-0,6311\end{array}$ \\
\hline 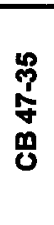 & $\begin{array}{l}77-18 \\
78-79 \\
79-80 \\
80-81 \\
81-82 \\
82-83 \\
83-84\end{array}$ & $\begin{array}{l}-0,1948 \\
-0,1301 \\
-0,0780 \\
-0,2194 \\
-0,1132 \\
-0,0419 \\
-0,3581\end{array}$ & $\begin{array}{l}-0,1393 \\
-0,2206 \\
-0,0325 \\
-0,0943 \\
-0,0921 \\
-0,0523 \\
-0,2653\end{array}$ & $\begin{array}{c}-0,2337 \\
-0,0450 \\
-0,0141 \\
-0,0124 \\
-0,0166 \\
0,0000 \\
-0,0419\end{array}$ & $\begin{array}{l}-0,1604 \\
-0,2282 \\
-0,2004 \\
-0,3189 \\
-0,1617 \\
-0,0406 \\
-0,5960\end{array}$ & $\begin{array}{l}-0,4317 \\
-0,3227 \\
-0,2836 \\
-0,5494 \\
-0,2510 \\
-0,2222 \\
-0,6311\end{array}$ \\
\hline $\begin{array}{l}\mathbf{8} \\
\mathbf{8} \\
\mathbf{8}\end{array}$ & $\begin{array}{l}77-78 \\
78-79 \\
79-80 \\
80-81 \\
81-82 \\
82-83 \\
83-84\end{array}$ & $\begin{array}{l}-0,2601 \\
-0,1154 \\
-0,0080 \\
-0,0834 \\
-0,1497 \\
-0,0419 \\
-0,1543\end{array}$ & $\begin{array}{l}-0,2536 \\
-0,1188 \\
-0,0263 \\
-0,0387 \\
-0,1301 \\
-0,0545 \\
-0,1427\end{array}$ & $\begin{array}{c}-0,2337 \\
-0,0450 \\
-0,0141 \\
-0,0124 \\
-0,0166 \\
0,0000 \\
-0,0419\end{array}$ & $\begin{array}{l}-0,1604 \\
-0,2282 \\
-0,2004 \\
-0,3189 \\
-0,1617 \\
-0,0406 \\
-0,5960\end{array}$ & $\begin{array}{l}-0,4317 \\
-0,3227 \\
-0,2836 \\
-0,5494 \\
-0,2510 \\
-0,2222 \\
-0,6311\end{array}$ \\
\hline $\begin{array}{l}\text { 丈ิ } \\
\frac{1}{0} \\
\frac{0}{0}\end{array}$ & $\begin{array}{l}79-80 \\
80-81 \\
81-82 \\
82-83 \\
83-84\end{array}$ & $\begin{array}{l}-0,0790 \\
-0,1324 \\
-0,1863 \\
-0,0910 \\
-0,2984\end{array}$ & $\begin{array}{l}-0, T 154 \\
-0,1165 \\
-0,1532 \\
-0,0726 \\
-0,1256\end{array}$ & $\begin{array}{c}-0,1779 \\
-0,0124 \\
-0,0166 \\
0,0000 \\
-0,0419\end{array}$ & $\begin{array}{l}-0,0598 \\
-0,3189 \\
-0,1617 \\
-0,0406 \\
-0,5960\end{array}$ & $\begin{array}{l}-0,2731 \\
-0,5494 \\
-0,2510 \\
-0,2222 \\
-0,6311\end{array}$ \\
\hline
\end{tabular}


Posteriormente, com estes valores foram realizadas as regressões lineares múltiplas. A seguir, voltando ao modelo multiplicativo, tem-se como resultado os seguintes modelos de estimativa de produtividade agro-industrial da cana-de-açúcar:

$$
\begin{aligned}
& Y a_{c}=0,97 Y m_{c}\left(\frac{E T r}{E T m}\right)_{1}^{0,43}\left(\frac{E T r}{E T m}\right)_{2}^{0,37}\left(\frac{E T r}{E T m}\right)_{3}^{0,02} \\
& Y a_{a}=0,95 Y m_{a}\left(\frac{E T r}{E T m}\right)_{1}^{0,48}\left(\frac{E T r}{E T m}\right)_{2}^{0,23}\left(\frac{E T r}{E T m}\right)_{3}^{0,01}
\end{aligned}
$$

em que: $Y a_{c}$ é a produtividade estimada de colmo; $Y a_{a}$ a produtividade estimada de açúcar; $Y m_{c}$ a produtividade máxima de colmo; $Y m_{a}$ a produtividade máxima de açúcar. O coeficiente de sensibilidade da cultura $(\lambda)$ são representados pelos valores que eleva à potência a evapotranspiração relativa $\left(\frac{E T r}{E T m}\right)_{i}^{\lambda_{i}}$ para cada fase de desenvolvimento da cultura $(i)$.

Os valores do coeficiente de sensibilidade $\left(\lambda_{l}\right)$, observados nos modelos obtidos, permitem verificar que a deficiência hídrica ocorrida na primeira fase da cultura tem maior influência sobre a produtividade que nas duas últimas fases, tal como fora observado por alguns autores (Vazquez, 1970, citado por Rosenfeld, 1989; Doorenbos \& Kassam, 1979; Rosenfeld \& Leme, 1984; Scardua, 1985 e Rosenfeld, 1989).

Ainda analizando os valores dos coeficientes de sensibilidade, verifica-se que na terceira fase da cultura, tanto para colmo como para açúcar, houve pouca influência das condições hídricas do solo sobre a produtividade final.

Para testar o modelo, foram utilizados valores independentes de produtividade máxima e evapotranspiração relativa, apresentados na Tabela 4. Os resultados são apresentados na Tabela 6. 
Tabela 6. Valores comparativos entre produtividade agro-industrial estimados pelos modelos proposto (eq. 20 e 21 ) e os observados nas localidadades de Araras e Pradópolis, em t/ha de colmo e de açúcar.

\begin{tabular}{ccccc}
\hline No & \multicolumn{2}{c}{ Produtividade de Colmo } & \multicolumn{2}{c}{ Produtividade de Açúcar } \\
observações & Estimada $\left(\mathrm{Ya}_{\mathrm{c}}\right.$ ) & Observada $\left(\mathrm{Ya}^{2}\right)$ & Estimada $\left(\mathrm{Ya}_{a}\right)$ & Observada (Ya) \\
\hline 1 & 134,74 & 138,83 & 18,66 & 20,68 \\
2 & 93,53 & 94,21 & 16,00 & 15,53 \\
3 & 96,28 & 94,29 & 15,79 & 15,64 \\
4 & 107,29 & 111,57 & 14,18 & 14,67 \\
5 & 123,10 & 127,89 & 17,34 & 16,73 \\
6 & 90,19 & 93,67 & 13,14 & 13,42 \\
7 & 58,21 & 51,44 & 8,90 & 8,28 \\
8 & 68,51 & 65,14 & 11,12 & 10,48 \\
9 & 129,59 & 130,41 & 21,72 & 22,94 \\
10 & 101,86 & 105,71 & 17,44 & 17,45 \\
11 & 65,56 & 70,15 & 9,86 & 10,30 \\
12 & 75,79 & 81,90 & 11,91 & 13,30 \\
\hline média & 95,83 & 97,10 & 14,78 & 14,95 \\
\hline
\end{tabular}

Posteriormente, estes valores foram avaliados com relação aos observados, conforme o explicado no item 3.5, utilizando os seguintes índices estatísticos: coeficiente de determinação $\left(\mathrm{r}^{2}\right)$; índice de concordância $(d)$; erro médio absoluto $(E M A)$; erro máximo $(M E)$; eficiência $(E F)$; erro sistemático $(E S)$ e erro aleatório $(E a)$.

Para o cálculo do erro sistemático $E s$ e do erro aleatório $E a$, (eq.18 e 19), foram estimadas a produtividade do colmo e do açúcar através das eq.(22 e 23), as quais são equações lineares das respectivas linhas de tendência dos ajustes dos valores estimados, apresentados nas Figuras 4 e 5.

$$
\begin{gathered}
\hat{P i_{c}}=0,9227 \cdot Y a+5,7949 \\
\hat{P i_{a}}=0,8893 \cdot Y a+1,3755
\end{gathered}
$$

em que: $\hat{P}_{i_{c}}$ e $\hat{P}_{i_{a}}$ são os valores de produtividade de colmo e de açúcar, respectivamente, e $\mathrm{Ya}$ a produtividade observada. 
As Figuras 4 e 5 mostram graficamente a baixa dispersão entre os valores observados e estimados. Assim, o $r^{2}$ foi elevado para ambos os modelos, o que indica estatisticamente, um bom ajuste dos valores estimados com relação aos valores observados.

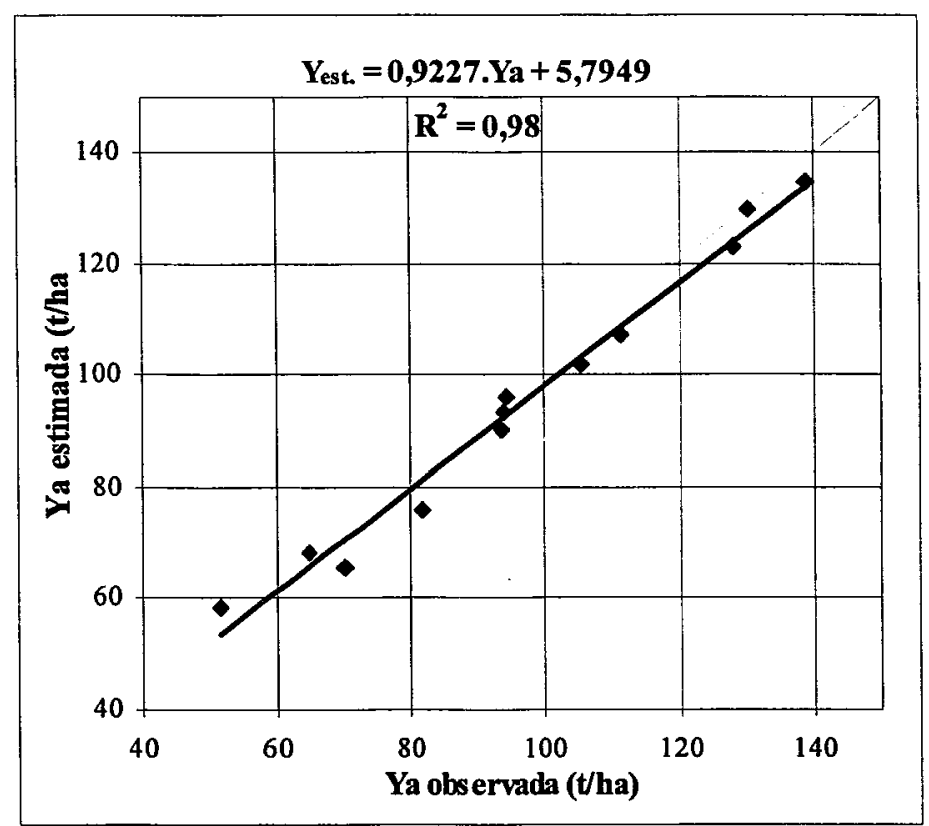

Figura 4 - Análise de regressão entre produtividade observada e produtividade estimada pelo método proposto para colmo (eq. 20).

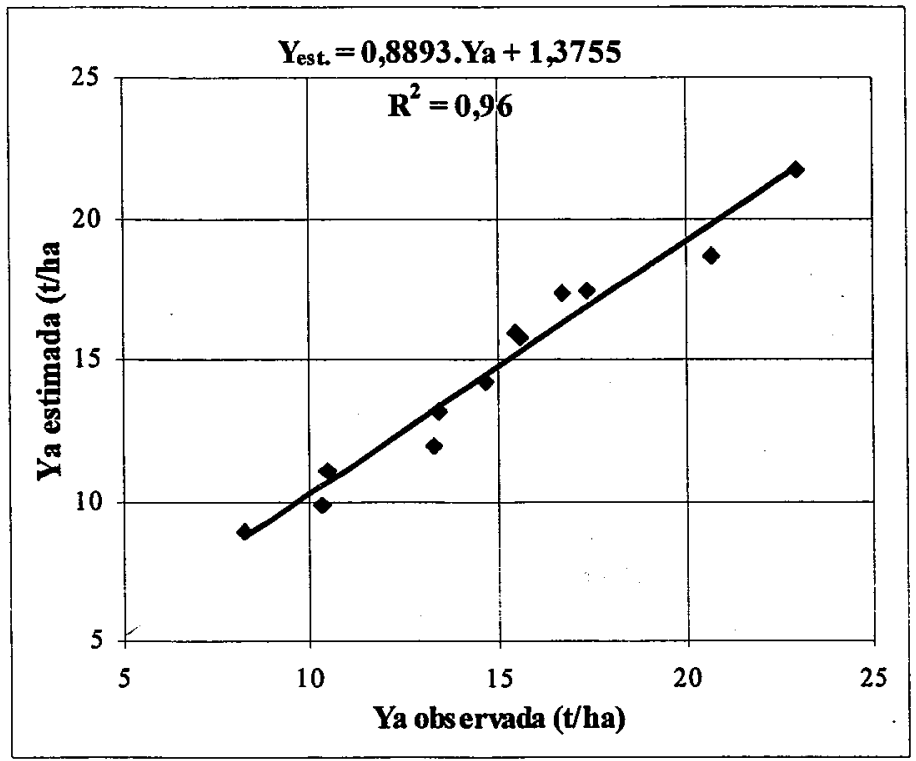

Figura 5 - Análise de regressão entre produtividade observada e produtividade estimada pelo método proposto para açúcar (eq. 21). 
Analisando os valores dos índices estatísticos da Tabela 7, observa-se que, em geral, os resultados obtidos proporcionaram alto grau de confiabilidade nas estimativas.

Tabela 7. Valores dos índices estatísticos utilizados na avaliação dos modelos de estimativa de produtividade de colmo e de açúcar (eq. 20 e 21).

\begin{tabular}{lccccccc}
\hline & $r^{2}$ & $d$ & $\begin{array}{c}E M A \\
(\mathrm{t} / \mathrm{ha})\end{array}$ & $\begin{array}{c}M E \\
(\mathrm{t} / \mathrm{ha})\end{array}$ & $\boldsymbol{E F}$ & $\boldsymbol{E s}$ & $\boldsymbol{E a}$ \\
\hline COLMO & 0,98 & 0,99 & 3,74 & 6,77 & 0,97 & 7,00 & 10,13 \\
\hline AÇÚCAR & 0,96 & 0,99 & 0,70 & 2,02 & 0,95 & 0,28 & 0,50 \\
\hline
\end{tabular}

$r^{2}=$ coeficiente de determinação; $d=$ indice de concordância ou indice de Wilmott; $E M A=$ erro médio absoluto; $M E=$ erro máximo; $E F=$ eficiência; $E S=$ erro sistemático; $E a=$ erro aleatório.

Assim, o valor do índice de concordância (d) foi elevado, alcançando valores próximos a 1 para ambos os casos, o que também indica igualmente, alto grau de ajustes.

Analisando ainda a Tabela 7, pode-se dizer que o erro médio absoluto $(E M A)$ foi baixo, tanto para colmo como para açúcar, representando apenas $3,8 \%$ da produtividade média observada de colmo e $4,7 \%$ da produtividade média observada de açúcar. Por outro lado, os valores proporcionais dos erros máximo $(M E)$ com relação às suas correspondentes produtividades observadas, revelaram que nas estimativas os modelos tiveram um erro de $13 \%$ para colmo e $9,8 \%$ para açúcar, que podem ser considerados relativamente baixos.

Os modelos também apresentam uma eficiência $(E F)$ élevada nas estimativas, permitindo uma ótima confiança. Os valores do erro sistemático (Es) e o erro aleatório $(E a)$, permitem concluir que para os dois casos em questão, o primeiro foi sempre maior que o segundo, não demonstrando assim uma tendência de super ou subestimativa. 


\subsection{Aperfeiçoamento do modelo}

$\mathrm{Na}$ tentativa de melhorar o modelo, foi realizada uma segunda regressão linear múltipla, desta vez com intercepção da linha de tendência passando pela origem $(a=0)$. Os resultados desta regressão são as equações seguintes:

$$
\begin{aligned}
& Y a_{c}=Y m_{c} \cdot\left(\frac{E T r}{E T m}\right)_{1}^{0,43} \cdot\left(\frac{E T r}{E T m}\right)_{2}^{0,39} \cdot\left(\frac{E T r}{E T m}\right)_{3}^{0,07} \\
& Y a_{a}=Y m a \cdot\left(\frac{E T r}{E T m}\right)_{1}^{0,49} \cdot\left(\frac{E T r}{E T m}\right)_{2}^{0,27} \cdot\left(\frac{E T r}{E T m}\right)_{3}^{0,08}
\end{aligned}
$$

Posteriormente, para comparar a confiabilidade com relação aos modelos anteriores, os modelos resultantes foram testados novamente utilizando os dados da Tabela 4. Os resultados são apresentados na Tabela 8.

Tabela 8. Valores comparativos entre produtividade agro-industrial estimados pelos modelos propostos (eq. 24 e 25) e os observados nas localidades de Araras e Pradópolis, em tha de colmo e de açúcar.

\begin{tabular}{ccccc}
\hline No de & \multicolumn{2}{c}{ Produtividade de Colmo } & \multicolumn{2}{c}{ Produtividade de Açúcar } \\
observações & Estimada (Ya $)$ & Observada (Ya) & Estimada (Ya $)$ & Observada (Ya) \\
\hline 1 & 138,10 & 138,83 & 19,39 & 20,68 \\
2 & 91,55 & 94,21 & 15,51 & 15,53 \\
3 & 96,63 & 94,29 & 15,92 & 15,64 \\
4 & 109,33 & 111,57 & 14,63 & 14,67 \\
5 & 124,71 & 127,89 & 17,74 & 16,73 \\
6 & 92,35 & 93,67 & 13,66 & 13,42 \\
7 & 58,40 & 51,44 & 8,95 & 8,28 \\
8 & 68,74 & 65,14 & 11,18 & 10,48 \\
9 & 131,18 & 130,41 & 22,20 & 22,94 \\
10 & 102,97 & 105,71 & 17,78 & 17,45 \\
11 & 66,00 & 70,15 & 9,94 & 10,30 \\
12 & 76,54 & 81,90 & 12,03 & 13,30 \\
\hline média & 96,38 & 97,10 & 14,91 & 14,95 \\
\hline
\end{tabular}


Com a finalidade de avaliar os resultados da nova estimativa utilizou-se similares indicadores aos utilizados nos modelos anteriores, conforme foram detalhados no item 3.5. Observa-se nas Figuras 6 e 7, que os ajustes dos valores estimados pelo novo modelo, revelado pelo $r^{2}$, proporcionaram uma dispersão ligeiramente menor que nas estimativas anteriores.

Para calcular o erro sistemático Es (eq.18) e o erro aleatório $E a$ (eq.19), como parte da avaliação do novo modelo, foram utilizadas as equações resultantes das regressões de ajustes lineares (Fig. 6 e 7), dando as seguintes equações:

$$
\begin{aligned}
& \hat{P i_{c}}=0,9519 \cdot Y a+3,9412 \\
& \hat{P i_{a}}=0,9259 \cdot Y a+1,0659
\end{aligned}
$$

em que: $\hat{P} i_{c}$ e $\hat{P} i_{a}$ são os valores de produtividade de colmo e açúcar, respectivamente e $Y a$, a produtividade observada.

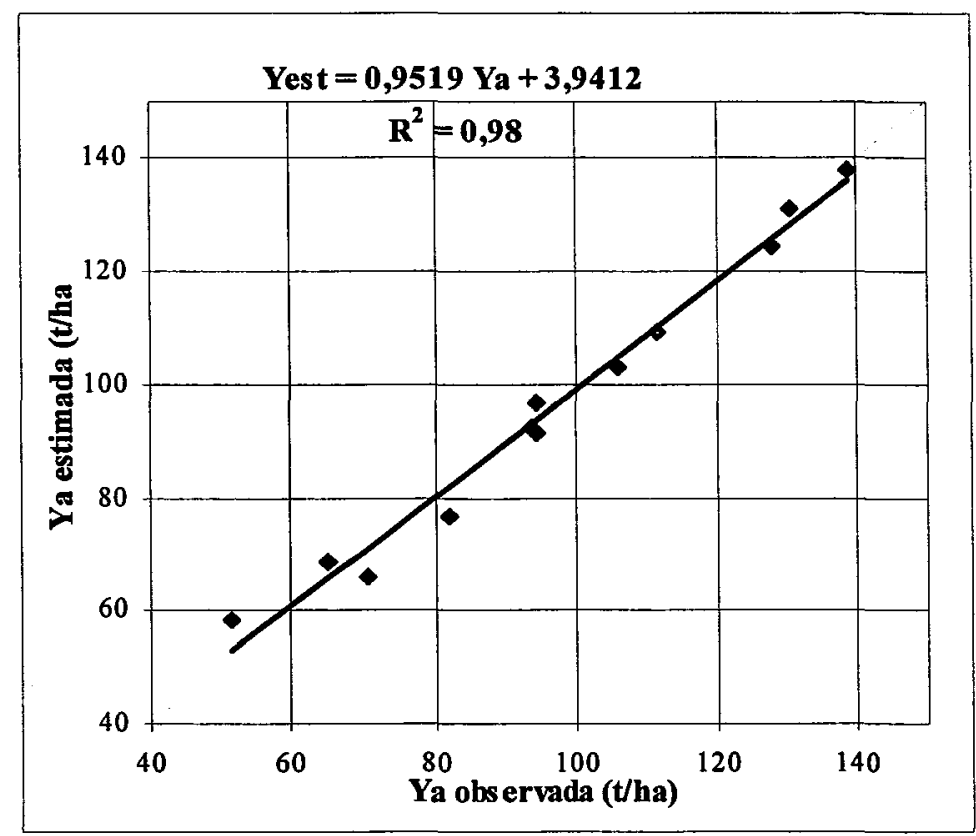

Figura 6 - Análise de regressão entre produtividade observada e produtividade estimada pelo método proposto para colmo (eq.24). 


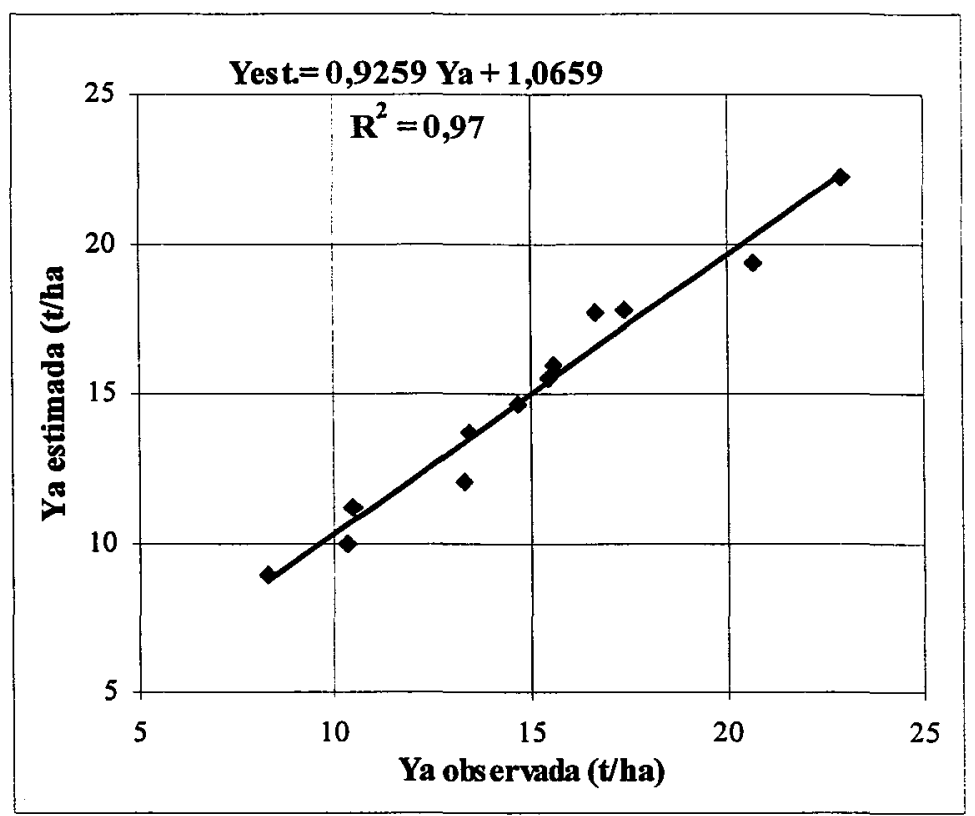

Figura 7 - Análise de regressão entre produtividade observada e produtividade estimada pelo método proposto para açúcar (eq.25).

O resumo dos resultados da avaliação dos novos modelos, apresentado na Tabela 9, permite visualizar que, em geral, foram obtidos melhores ajustes que os modelos originais, o que justifica sua utilização além da sua maior simplicidade.

Tabela 9. Valores dos índices estatísticos utilizados na avaliação dos modelos de estimativa de produtividade de colmo e de açúcar, através das equações $24 \mathrm{e}$ 25 .

\begin{tabular}{lccccccc}
\hline & $\boldsymbol{R}^{2}$ & $\boldsymbol{d}$ & $\begin{array}{c}\boldsymbol{E M A} \\
(\mathrm{t} / \mathrm{ha})\end{array}$ & $\begin{array}{c}M E \\
(\mathrm{t} / \mathrm{ha})\end{array}$ & $\boldsymbol{E F}$ & $\boldsymbol{E s}$ & $\boldsymbol{E a}$ \\
\hline COLMO & 0,98 & 1,0 & 3,01 & 6,96 & 0,98 & 2,11 & 10,02 \\
\hline AÇÚCAR & 0,97 & 0,99 & 0,58 & 1,29 & 0,97 & 0,09 & 0,42 \\
\hline
\end{tabular}

$r^{2}=$ coeficiente de determinação; $d=$ índice de concordância ou índice de Wilmott; $E M A=$ erro médio absoluto; $M E=$ erro máximo; $E F=$ eficiência; $E s=$ erro sistemático; $E a=$ erro aleatório.

\subsection{Simplificação do modelo}

Considerando o pouco peso da deficiência hídrica, na terceira fase, sobre a produtividade final do colmo e do açúcar; e, com a finalidade de simplificar mais ainda, 
em busca de maior utilidade aos modelos propostos, foi realizada uma terceira regressão. Desta vez correlacionando a produtividade máxima observada somente com as duas primeiras fases da cultura, descartando-se assim, o terceiro termo. Os resultados são as seguintes equações:

$$
\begin{aligned}
& Y a_{c}=Y m_{c} \cdot\left(\frac{E T r}{E T m}\right)_{1}^{0,57} \cdot\left(\frac{E T r}{E T m}\right)_{2}^{0,47} \\
& Y a_{a}=Y m_{a} \cdot\left(\frac{E T r}{E T m}\right)_{1}^{0,65} \cdot\left(\frac{E T r}{E T m}\right)_{2}^{0,37}
\end{aligned}
$$

Para avaliar, estes modelos foram testados utilizando os mesmos dados independentes apresentados na Tabela 4. Os resultados são observados na Tabela 10.

Tabela 10. Valores comparativos entre produtividade agro-industrial estimados pelos modelos proposto (eq.28 e 29) e os observados nas localidades de Araras e Pradópolis, em t/ha de colmo e de açúcar.

\begin{tabular}{ccccc}
\hline \multirow{2}{*}{$N^{\circ}$ de } & \multicolumn{2}{c}{ Produtividade de Colmo } & \multicolumn{2}{c}{ Produtividade de Açúcar } \\
observações & Estimada $\left(\mathrm{Ya}_{c}\right)$ & Observada (Ya) & Estimada $\left(\mathrm{Ya}_{a}\right)$ & Observada (Ya) \\
\hline 1 & 132,03 & 138,83 & 18,40 & 20,68 \\
2 & 93,87 & 94,21 & 15,90 & 15,53 \\
3 & 97,55 & 94,29 & 16,06 & 15,64 \\
4 & 106,22 & 111,57 & 14,11 & 14,67 \\
5 & 122,53 & 127,89 & 17,35 & 16,73 \\
6 & 89,90 & 93,67 & 13,23 & 13,42 \\
7 & 57,11 & 51,44 & 8,71 & 8,28 \\
8 & 67,21 & 65,14 & 10,89 & 10,48 \\
9 & 131,79 & 130,41 & 22,29 & 22,94 \\
10 & 102,39 & 105,71 & 17,64 & 17,45 \\
11 & 62,45 & 70,15 & 9,33 & 10,30 \\
12 & 68,20 & 81,90 & 10,54 & 13,30 \\
\hline média & 94,27 & 97,10 & 14,54 & 14,95 \\
\hline
\end{tabular}

Considerando que para calcular o erro sistemático $E s$ e o erro aleatório $E a$, requer-se valores estimados da produtividade de colmo $\left(\hat{P i_{c}}\right)$ e açúcar $\left(\hat{P i_{a}}\right)$, conforme 
já foi explicado anteriormente, foram calculadas as seguintes equações, resultantes das regressões de ajustes lineares e apresentadas nas Fig. 8 e 9.

$$
\begin{gathered}
\hat{P i_{c}}=0,9495 . Y a+2,0803 \\
\hat{P i_{a}}=0,9429 . Y a+0,4402
\end{gathered}
$$

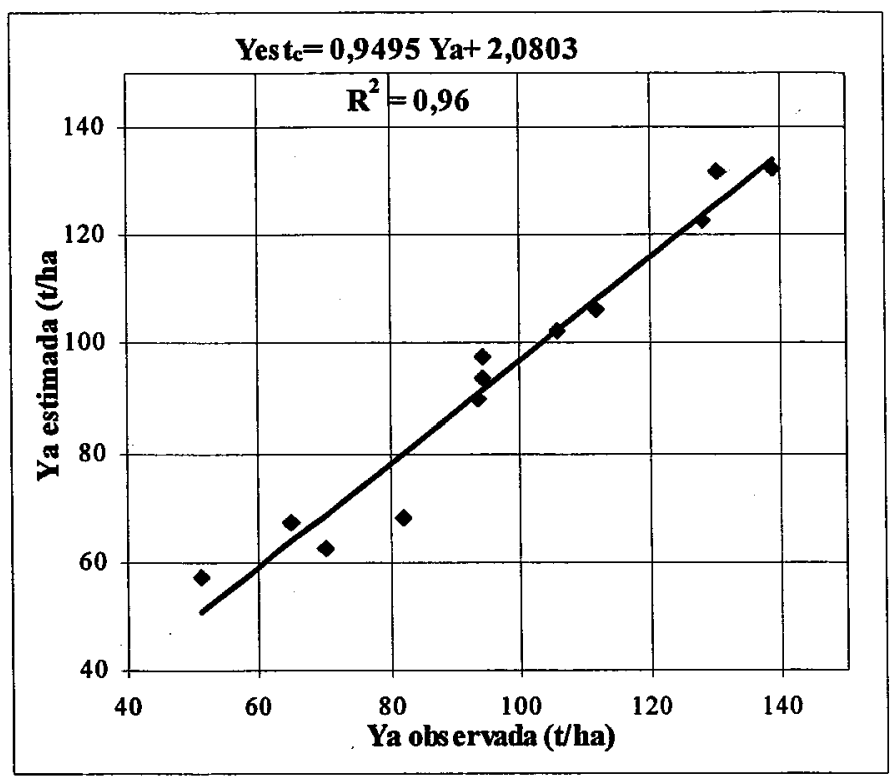

Figura 8 - Análise de regressão entre produtividade observada e produtividade estimada pelo método proposto para colmo (eq.28).

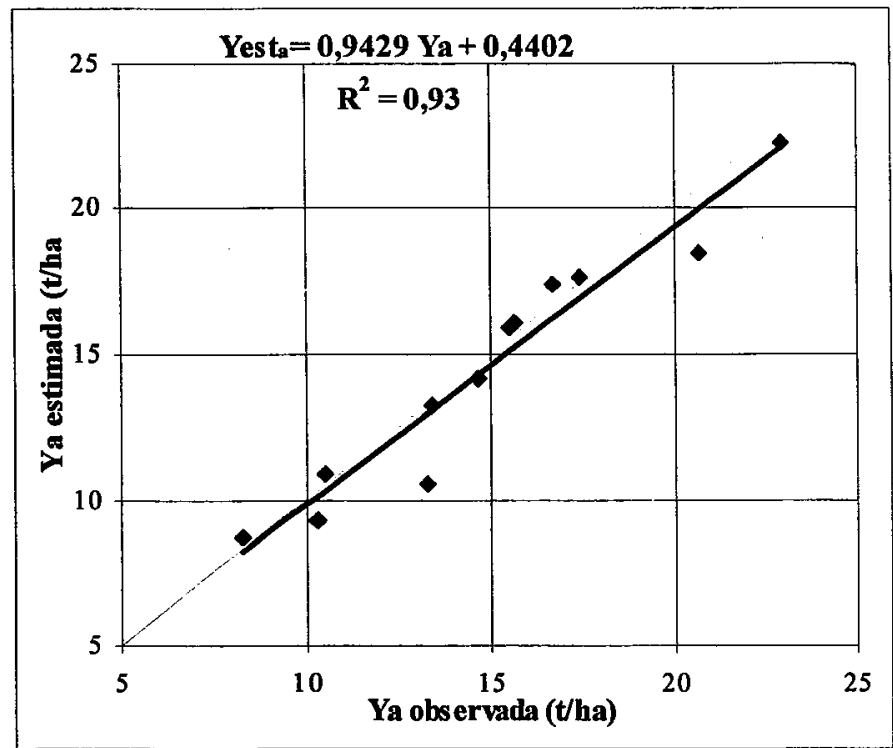

Figura 9 - Análise de regressão entre produtividade observada e produtividade estimada pelo método proposto para açúcar (eq.29). 
Para avaliar os resultados das estimativas, foram realizados tratamentos estatísticos, utilizando índices semelhantes àqueles modelos anteriores. Os resultados se observam na Tabela 11.

Tabela 11. Valores dos indices estatísticos utilizados na avaliação dos modelos de estimativa de produtividade de colmo e de açúcar (eq. 28 e 29).

\begin{tabular}{lccccccc}
\hline & $\mathbf{R}^{2}$ & $d$ & $\begin{array}{c}\text { EMA } \\
(\mathrm{t} / \mathrm{ha})\end{array}$ & $\begin{array}{c}\text { ME } \\
(\mathrm{t} / \mathrm{ha})\end{array}$ & EF & Es & Ea \\
\hline COLMO & 0,96 & 0,99 & 4,89 & 13,70 & 0,95 & 9,71 & 25,65 \\
\hline AÇÚCAR & 0,93 & 0,98 & 0,82 & 2,76 & 0,92 & 0,22 & 1,08 \\
\hline
\end{tabular}

$\mathrm{r}^{2}=$ coeficiente de determinação; $\mathrm{d}=$ índice de concordância ou índice de Wilmott; EMA = erro médio absoluto; $\mathrm{ME}=$ erro máximo; $\mathrm{EF}$ = eficiência; $\mathrm{Es}=$ erro sistemático; $\mathrm{Ea}=$ erro aleatório.

Analisando os valores dos índices estatísticos, pode-se constatar que a precisão da estimativa dos modelos simplificados são ligeiramente inferiores que aquelas obtidas nos modelos anteriores.

\subsection{Modelo definitivo}

Com intuito de melhorar o grau de confiabilidade do modelo simplificado, foram testados os modelos representados pelas equações 24 e 25 . Desta vez descartou-se o último termo, considerando-se que o valor do coeficiente de sensibilidade à deficiência hídrica na última fase da cultura, tem pouca influência no resultado final. Estes novos modelos simplificados são representadas pelas seguintes equações:

$$
\begin{aligned}
& Y a_{c}=Y m_{c} \cdot\left(\frac{E T r}{E T m}\right)_{1}^{0,43} \cdot\left(\frac{E T r}{E T m}\right)_{2}^{0,39} \\
& Y a_{a}=Y m a \cdot\left(\frac{E T r}{E T m}\right)_{1}^{0,49} \cdot\left(\frac{E T r}{E T m}\right)_{2}^{0,27}
\end{aligned}
$$

Neste caso, a eliminação do terceiro termo do modelo se justifica, pois na fase de maturação, a eficiência de assimilação das plantas é muito baixa devido a diversos fatores como: idade das folhas, total de área foliar útil, baixa temperatura nessa 
época e, principalmente, amadurecimento da sacarose assimilada no colmo, a qual requer pouca absorção de água (Camargo, 1976). Portanto, caso ocorra pouca chuva durante essa fase, a evapotranspiração relativa sempre terá um valor alto, e em consequência não comprometerá a confiabilidade das estimativas.

Da mesma forma que os anteriores, estes novos modelos simplificados (modelos definitivo) foram testados, tendo como resultado os valores apresentados na Tabela 12. Posteriormente, estes valores foram avaliados utilizando-se os mesmos índices estatísticos com que foram avaliados os modelos anteriores.

Tabela 12. Valores comparativos entre produtividade agro-industrial estimados pelos modelos proposto (eq.32 e 33) e os observados nas localidades de Araras e Pradópolis, em t/ha de colmo e de açúcar.

\begin{tabular}{ccccc}
\hline No de & \multicolumn{2}{c}{ Produtividade de Colmo } & \multicolumn{2}{c}{ Produtividade de Açúcar } \\
observações & Estimada(Ya $)$ & Observada (Ya) & Estimada (Yaa) & Obsenvada (Ya) \\
\hline 1 & 138,90 & 138,83 & 18,40 & 19,52 \\
2 & 97,58 & 94,21 & 15,90 & 16,68 \\
3 & 99,88 & 94,29 & 16,06 & 16,53 \\
4 & 109,98 & 111,57 & 14,11 & 14,73 \\
5 & 127,17 & 127,89 & 17,35 & 18,13 \\
6 & 93,02 & 93,67 & 13,23 & 13,77 \\
7 & 60,53 & 51,44 & 8,71 & 9,32 \\
8 & 71,24 & 65,14 & 10,89 & 11,65 \\
9 & 134,09 & 130,41 & 22,29 & 22,78 \\
10 & 105,55 & 105,71 & 17,64 & 18,29 \\
11 & 68,13 & 70,15 & 9,33 & 10,31 \\
12 & 78,55 & 81,90 & 10,54 & 12,39 \\
\hline média & 98,72 & 97,10 & 14,54 & 15,34 \\
\hline
\end{tabular}

Para calcular o erro sistemático Es (eq.18) e o erro aleatório $E a(19)$, como parte do teste de validação do modelo definitivo, foram estimadas produtividade do colmo $\left(\hat{P i_{c}}\right)$ e de açúcar $\left(\hat{P i_{a}}\right)$ através das equações 34 e 35 , as quais são equações lineares dos ajustes dos valores estimados pelos novos modelos, segundo as Figuras 10 e 11 . 


$$
\begin{aligned}
& \hat{P i_{c}}=0,9451 \cdot Y a+6,9459 \\
& \hat{P i_{a}}=0,9322 \cdot Y a+1,4024
\end{aligned}
$$

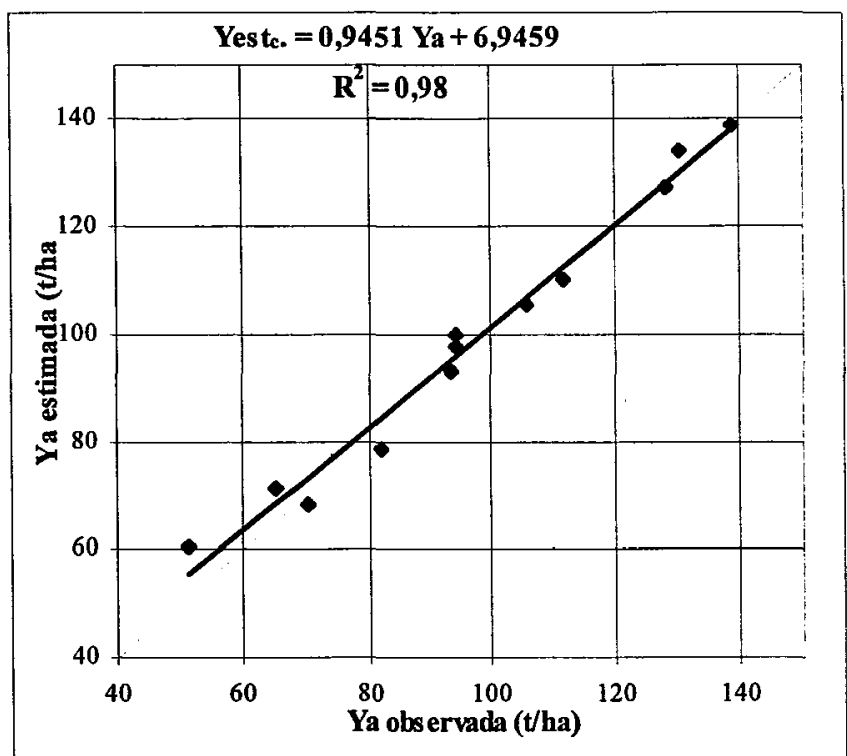

Figura 10 - Análise de regressão entre produtividade observada e produtividade estimada pelo método proposto para colmo (eq.32).

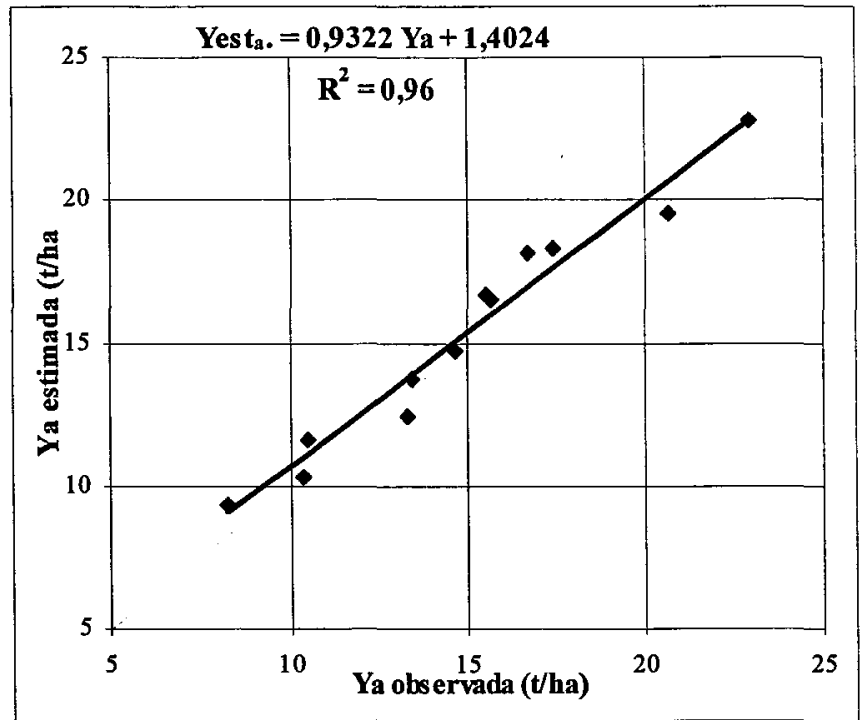

Figura 11 - Análise de regressão entre produtividade observada e produtividade estimada pelo método proposto para açúcar (eq.33).

Após o cálculo de todos os índices estatísticos (Tabela 13), estes foram comparados com os valores obtidos na avaliação dos modelos anteriores (Tabela 11). 
Os resultados revelaram que, as estimativas através destes últimos modelos proporcionaram melhores ajustes que os anteriores modelos simplificados (eq.28 e 29), sendo observado menor dispersão dos valores da reta 1:1, tal como são demostrados nas Figuras 10 e 11.

Tabela 13. Valores dos índices estatísticos utilizados na avaliação dos modelos de estimativa de produtividade de colmo e de açúcar (eq.32 e 33).

\begin{tabular}{lccccccc}
\hline & $\mathbf{R}^{2}$ & $\boldsymbol{d}$ & $\begin{array}{c}\boldsymbol{E M A} \\
(\mathrm{t} / \mathrm{ha})\end{array}$ & $\begin{array}{c}\boldsymbol{M E} \\
(\mathrm{t} / \mathrm{ha})\end{array}$ & $\boldsymbol{E F}$ & $\boldsymbol{E s}$ & $\boldsymbol{E a}$ \\
\hline COLMO & 0,98 & 0,99 & 3,03 & 9,09 & 0,98 & 4,66 & 11,56 \\
\hline AÇÚCAR & 0,96 & 0,99 & 0,76 & 1,40 & 0,95 & 0,23 & 0,57 \\
\hline
\end{tabular}

$\mathrm{r}^{2}=$ coeficiente de determinação; $d=$ índice de concordância ou índice de Wilmott; $E M A=$ erro médio absoluto; $M E=$ erro máximo; $E F=$ eficiência; $E S=$ erro sistemático; $E a=$ erro aleatório.

Em geral, os valores de todos os índices estatísticos (Tabela 13), foram melhores que os anteriores modelos simplificados, revelando ter maior confiabilidade nas estimativas.

Levando em consideração os valores destas análises pode-se, finalmente, aceitar como o resultado principal deste trabalho os modelos de estimativas de produtividade de colmo e de açúcar, representados pelas equações 32 e 33 .

Tendo-se em vista que na validação do modelo foram utilizados dados de outra região, acredita-se que, apesar de empírico, o modelo possa ser empregado em outras regiões do Estado de São Paulo, ou até em outros Estados situados nas mesmas latitudes.

\subsection{Principais utilidades do modelo}

Com base nos dados de balanço hídrico e considerando como único fator restrito a água, estes modelos poderiam ser aproveitados para: 
1- Estimar a produtividade potencial (irrigada) da região e portanto a viabilidade de aplicação de sistema de irrigação.

2- Estudar os efeitos do clima sobre a safra em questão com relação à produtividade média da região.

3- Comparar a produtividade real para duas diferentes épocas de cultivo.

4- Comparar a produtividade real para dois locais diferentes.

5- Estimar a produtividade agro-industrial da cana-de-açúcar (colmo e açúcar), com 4 a 6 meses de antecedência, dependendo da época da colheita.

\subsection{Alguns exemplos de aplicação do modelo}

1) - Numa estação experimental da EMBRAPA, no Mato Grosso do Sul, aplicando-se um sistema de irrigação no cultivo de cana-de-açúcar, pesquisadores obtiveram a produtividade de 120 t/ha de colmo e 15 t/ha de açúcar. Um agricultor da região pretende implantar a mesma cultura, mas sem sistema de irrigação e deseja saber qual produtividade poderá obter. De uma estação meteorológica local foi obtida a média do balanço hídrico climático: para os primeiros 4 meses (primeira fase) $\left(\frac{E T r}{E T m}\right)_{1}=\mathbf{0 , 6 2}$ e para os seguintes 4 meses (segunda fase) $\left(\frac{E T r}{E T m}\right)_{2}=0,68$.

Aplicando os modelos de estimativa de produtividade de colmo e de açúcar, eq.32 e 33 respectivamente, obtém-se:

$$
\begin{aligned}
& Y a_{c}=Y m_{c} \cdot\left(\frac{E T r}{E T m}\right)_{1}^{0,43}\left(\frac{E T r}{E T m}\right)_{2}^{0,39} \rightarrow Y a_{c}=120 \cdot(0,62)^{0,43} \cdot(0,68)^{0,39}=\mathbf{8 4 , 0 6} \mathbf{t} / \mathbf{h a} \text { (colmo) } \\
& Y a_{a}=Y m a \cdot\left(\frac{E T r}{E T m}\right)_{1}^{0,49} \cdot\left(\frac{E T r}{E T m}\right)_{2}^{0,27} \rightarrow Y a_{a}=15 \cdot(0,62)^{0,49} \cdot(0,68)^{0,27}=\mathbf{1 0 , 6 9} \text { t/ha (açúcar) }
\end{aligned}
$$

- Tem-se então que este agricultor pode produzir 84,06 t/ha de colmo e 10,69 t/ha de açúcar. 
2) - Um produtor de cana-de-açúcar do norte do Paraná obteve uma produtividade média de $70 \mathrm{tn} / \mathrm{ha}$. Ele deseja saber qual será sua produtividade no caso de aplicar irrigação em seu cultivo, pois com esse dado, ele poderá estudar a viabilidade econômica da instalação do sistema. Segundo o agrometeorologista do local, a evapotranspiração relativa climática para a primeira e segunda fase de desenvolvimento da cultura são 0,5 e 0,9 respectivamente.

Aplicando o modelo de estimativa de produtividade de colmo (eq. 32), se obtém o seguinte:

$$
Y m_{c}=\frac{Y a_{c}}{\left(\frac{E T r}{E T m}\right)_{1}^{0,43}\left(\frac{E T r}{E T m}\right)_{2}^{0,39}} \rightarrow Y m_{c}=\frac{70}{(0,5)^{0,43}(0,9)^{0,39}}=\mathbf{9 8 , 2 6} \mathbf{t} / \mathbf{h a}
$$

- Desta forma, a produtividade a ser obtida com a irrigação será de 98,26 t de colmo/ha, com um acréscimo de $28,26 \mathrm{t} / \mathrm{ha}$.

3) - Pela experiência de campo, um produtor de cana-de-açúcar sem sistema de irrigação, sabe que num ano chuvoso, em que $\left(\frac{E T r}{E T m}\right)=1$, a produtividade média atinge normalmente 110 tha de colmo. Porém, no presente ano, ele observou uma evapotranspiração relativa de 0,75 e 0,50 na primeira e segunda fase, respectivamente. A dúvida do produtor é de qual será sua produtividade média, pois precisa tomar certas decisões sobre o contrato de transporte e acerto de compromissos da venda com uma usina local, faltando ainda 4 meses para a colheita.

Aplicando o modelo de estimativa de produtividade de colmo (eq.32), se obtém o seguinte:

$$
Y m_{c}=110 \cdot(0,75)^{0,43} \cdot(0,5)^{0,39}=\mathbf{7 4 , 1 8} \mathbf{t} / \mathbf{h a}
$$

- Então, o produtor obterá uma produtividade média de 74,18 t de colmo/ha na próxima safra. 


\section{CONCLUSÕES}

- O modelo de Jensen (1968) modificado, ajustado para a cana-de-açúcar no Estado de São Paulo, permitiu bons ajustes entre os valores estimados e observados de produtividade agro-industrial da cana-de-açúcar, recomendando-se a utilização destes modelos com boa transferibilidade.

- Os modelos propostos podem ser empregados para estimativas de produtividade sob condições de cultivo irrigado e não irrigado.

- O coeficiente de sensibilidade $(\lambda)$, correspondente à primeira fase da cultura, cujos valores são 0,43 para colmo e 0,48 para açúcar, demostraram que nessa primeira fase o déficit hídrico influencia muito mais sobre a produtividade final que nas duas últimas.

- Como a influência da deficiência hídrica na fase de maturação da cana, demostrado pelo coeficiente de sensibilidade, é muito pequena, pode-se desprezar o último termo dos modelos aperfeiçoados (eq.24 e 25), podendo-se utilizar o modelo simplificado (eq.32 e 33) para estimar a produtividade de colmo e de açúcar com no mínimo 4 meses antes da colheita.

- As possibilidades de irrigação estão limitadas pelos níveis do coeficiente de sensibilidade da cultura; sendo assim, no último ciclo ou fase de desenvolvimento, mesmo havendo deficiência hídrica, com a aplicação da irrigação nesse período, os acréscimos na produtividade seriam nulos. 
ANEXOS 
Tabela 1. Dados de temperatura e precipitação utilizados para calcular o balanço hídrico.

\begin{tabular}{|c|c|c|c|c|c|c|c|c|}
\hline & ARARAS & 1974 & ARARAS & 1975 & ARARAS & 1976 & ARARAS & 1977 \\
\hline Decendio & Temp. & Prec. & Temp. & Prec. & Temp. & Prec. & Temp. & Prec. \\
\hline 1 & 23,5 & 106,0 & 22,0 & 50,0 & 22,7 & 66,0 & 23,4 & 81,0 \\
\hline 2 & 22,1 & 74,0 & 23,2 & 95,0 & 25,1 & 65,0 & 23,9 & 141,0 \\
\hline 3 & 23,1 & 124,0 & 24,1 & 8,0 & 23,2 & 80,0 & 25,2 & 206,1 \\
\hline 4 & 24,8 & 19,0 & 23,2 & 159,0 & 22,3 & 123,0 & 25,1 & 4,0 \\
\hline 5 & 24,9 & 16,0 & 25,0 & 43,0 & 22,3 & 99,0 & 24,1 & 0,0 \\
\hline 6 & 23,7 & 15,0 & 23,9 & 87,0 & 22,8 & 138,0 & 24,6 & 18,0 \\
\hline 7 & 23,5 & 24,0 & 24,5 & 0,0 & 24,4 & 48,0 & 24,0 & 33,1 \\
\hline 8 & 22,3 & 236,0 & 22,4 & 0,0 & 24,1 & 143,0 & 24,1 & 37,0 \\
\hline 9 & 22,4 & 13,0 & 22,2 & 17,0 & 24,0 & 16,0 & 23,7 & 64,1 \\
\hline 10 & 22,0 & 16,0 & 21,0 & 28,0 & 22,0 & 11,0 & 20,7 & 55,0 \\
\hline 11 & 20,5 & 13,0 & 21,0 & 18,0 & 21,0 & 61,0 & 22,2 & 17,1 \\
\hline 12 & 19,1 & 2,0 & 21,3 & 0,0 & 19,6 & 5,0 & 19,5 & 0,0 \\
\hline 13 & 17,7 & 0,0 & 20,3 & 17,0 & 18,6 & 11,0 & 20,3 & 10,0 \\
\hline 14 & 19,5 & 4,0 & 19,9 & 0,0 & 22,1 & 52,0 & 16,3 & 1,0 \\
\hline 15 & 18,0 & 0,0 & 18,3 & 0,0 & 22,1 & 113,0 & 17,5 & 0,0 \\
\hline 16 & 18,1 & 3,0 & 18,5 & 2,0 & 16,9 & 49,0 & 17,2 & 32,0 \\
\hline 17 & 17,6 & 60,0 & 17,5 & 0,0 & 17,7 & 3,0 & 18,9 & 0,0 \\
\hline 18 & 15,1 & 76,0 & 19,2 & 0,0 & 17,3 & 0,0 & 18,5 & 7,0 \\
\hline 19 & 15,8 & 0,0 & 15,9 & 27,0 & 14,3 & 106,0 & 17,7 & 0,0 \\
\hline 20 & 18,3 & 0,0 & 16,3 & 0,0 & 16,4 & 0,0 & 18,9 & 1,0 \\
\hline 21 & 19,0 & 0,0 & 17,0 & 0,0 & 18,8 & 0,0 & 20,0 & 7,0 \\
\hline 22 & 18,7 & 0,0 & 22,1 & 0,0 & 19,5 & 15,0 & 20,6 & 0,0 \\
\hline 23 & 17,4 & 4,0 & 17,7 & 0,0 & 18,6 & 49,0 & 20,3 & 0,0 \\
\hline 24 & 21,8 & 0,0 & 22,7 & 0,0 & 19,5 & 12,0 & 19,8 & 30,0 \\
\hline 25 & 21,2 & 1,0 & 20,9 & 35,0 & 16,7 & 30,0 & 18,8 & 55,0 \\
\hline 26 & 22,7 & 3,0 & 20,2 & 0,0 & 16,9 & 47,0 & 22,8 & 7,0 \\
\hline 27 & 23,6 & 53,0 & 20,0 & 53,0 & 18,0 & 26,0 & 21,0 & 24,0 \\
\hline 28 & 21,3 & 38,0 & 21,9 & 48,0 & 19,6 & 67,0 & 21,6 & 30,0 \\
\hline 29 & 23,5 & 29,0 & 20,6 & 25,0 & 21,6 & 12,1 & 23,1 & 6,0 \\
\hline 30 & 25,0 & 88,0 & 21,5 & 18,0 & 24,3 & 44,0 & 23,0 & 18,0 \\
\hline 31 & 21,3 & 4,0 & 21,0 & 24,0 & 22,2 & 18,0 & 23,6 & 16,0 \\
\hline 32 & 24,3 & 49,0 & 21,1 & 14,0 & 23,0 & 90,1 & 21,8 & 84,0 \\
\hline 33 & 24,1 & 28,0 & 21,7 & 21,0 & 23,0 & 11,0 & 23,4 & 72,0 \\
\hline 34 & 21,6 & 95,8 & 23,8 & 16,2 & 23,4 & 7,0 & 22,4 & 89,0 \\
\hline 35 & 22,0 & 152,0 & 21,8 & 63,0 & 22,3 & 39,0 & 21,5 & 18,0 \\
\hline 36 & 23,1 & 141,0 & 22,5 & 94,0 & 23,1 & 128,1 & 21,4 & 56,0 \\
\hline
\end{tabular}


Continuação da Tabela 1.

\begin{tabular}{|c|c|c|c|c|c|c|c|c|}
\hline Decendio & $\begin{array}{l}\text { ARARAS } \\
\text { Temp. }\end{array}$ & $\begin{array}{l}1978 \\
\text { Prec. }\end{array}$ & $\begin{array}{l}\text { ARARAS } \\
\text { Temp. }\end{array}$ & $\begin{array}{l}1979 \\
\text { Prec. }\end{array}$ & $\begin{array}{l}\text { ARARAS } \\
\text { Temp. }\end{array}$ & $\begin{array}{l}1980 \\
\text { Prec. }\end{array}$ & $\begin{array}{l}\text { ARARAS } \\
\text { Temp. }\end{array}$ & $\begin{array}{l}1981 \\
\text { Prec. }\end{array}$ \\
\hline 1 & 21,9 & 141,0 & 21,8 & 25,0 & 22,2 & 23,0 & 20,7 & 80,0 \\
\hline 2 & 24,0 & 56,0 & 22,4 & 10,0 & 23,0 & 93,0 & 21,4 & 156,0 \\
\hline 3 & 25,7 & 14,0 & 22,5 & 41,0 & 23,6 & 110,0 & 23,2 & 49,0 \\
\hline 4 & 23,9 & 88,0 & 24,1 & 38,0 & 24,6 & 47,0 & 23,1 & 35,0 \\
\hline 5 & 24,7 & 43,0 & 23,3 & 101,0 & 22,5 & 94,0 & 21,9 & 19,0 \\
\hline 6 & 22,7 & 25,0 & 24,0 & 3,0 & 22,5 & 106,0 & 22,5 & 24,0 \\
\hline 7 & 22,5 & 81,0 & 23,7 & 1,0 & 24,5 & 43,0 & 24,3 & 34,0 \\
\hline 8 & 24,0 & 0,0 & 22,6 & 14,0 & 24,2 & 81,0 & 20,8 & 10,0 \\
\hline 9 & 25,6 & 2,0 & 23,4 & 12,0 & 24,1 & 0,0 & 19,7 & 14,0 \\
\hline 10 & 21,3 & 8,0 & 20,9 & 60,0 & 21,5 & 109,0 & 20,2 & 5,0 \\
\hline 11 & 21,2 & 0,0 & 21,1 & 1,0 & 22,1 & 42,0 & 19,3 & 24,0 \\
\hline 12 & 20,6 & 48,0 & 18,3 & 34,0 & 20,4 & 0,0 & 19,9 & 13,0 \\
\hline 13 & 17,6 & 0,0 & 20,9 & 144,0 & 18,8 & 5,0 & 19,4 & 27,0 \\
\hline 14 & 19,2 & 49,0 & 20,4 & 0,0 & 20,6 & 18,0 & 19,9 & 0,0 \\
\hline 15 & 16,0 & 2,0 & 17,2 & 25,0 & 21,4 & 0,0 & 18,6 & 4,0 \\
\hline 16 & 15,1 & 25,0 & 15,6 & 0,0 & 17,6 & 19,0 & 15,2 & 54,0 \\
\hline 17 & 17,2 & 0,0 & 17,4 & 0,0 & 15,4 & 3,0 & 15,4 & 46,0 \\
\hline 18 & 18,3 & 0,0 & 16,9 & 0,0 & 12,9 & 107,0 & 16,0 & 0,0 \\
\hline 19 & 17,9 & 0,0 & 18,7 & 7,0 & 16,0 & 0,0 & 15,1 & 10,0 \\
\hline 20 & 16,5 & 52,0 & 13,2 & 15,0 & 18,2 & 0,0 & 15,7 & 0,0 \\
\hline 21 & 20,9 & 22,0 & 17,4 & 5,0 & 18,4 & 0,0 & 16,1 & 0,0 \\
\hline 22 & 18,2 & 0,0 & 19,4 & 0,0 & 18,3 & 0,0 & 17,5 & 0,0 \\
\hline 23 & 15,6 & 0,0 & 19,8 & 37,0 & 20,4 & 1,0 & 18,5 & 4,0 \\
\hline 24 & 18,7 & 0,0 & 19,5 & 18,0 & 19,7 & 16,0 & 19,5 & 0,0 \\
\hline 25 & 18,9 & 28,0 & 18,1 & 22,2 & 21,3 & 20,0 & 21,4 & 0,0 \\
\hline 26 & 19,1 & 41,0 & 18,3 & 63,0 & 19,0 & 54,0 & 23,2 & 0,0 \\
\hline 27 & 20,8 & 0,0 & 22,6 & 36,0 & 16,3 & 29,0 & 22,7 & 6,0 \\
\hline 28 & 22,4 & 3,0 & 22,8 & 51,0 & 20,1 & 36,0 & 19,0 & 74,0 \\
\hline 29 & 23,1 & 37,0 & 20,9 & 21,0 & 21,5 & 58,0 & 20,2 & 114,0 \\
\hline 30 & 25,9 & 54,0 & 24,8 & 16,0 & 24,5 & 5,0 & 22,1 & 121,0 \\
\hline 31 & 23,5 & 110,0 & 22,7 & 92,0 & 20,7 & 90,0 & 23,4 & 73,0 \\
\hline 32 & 21,4 & 67,0 & 22,8 & 0,0 & 20,7 & 25,0 & 23,2 & 40,0 \\
\hline 33 & 23,6 & 32,0 & 21,4 & 32,0 & 23,1 & 98,0 & 24,2 & 36,0 \\
\hline 34 & 23,9 & 113,0 & 24,6 & 50,0 & 21,7 & 171,0 & 22,0 & 108,0 \\
\hline 35 & 21,7 & 34,0 & 23,5 & 65,0 & 22,5 & 43,0 & 23,9 & 29,0 \\
\hline 36 & 22,6 & 104,0 & 22,7 & 61,0 & 24,3 & 21,0 & 23,5 & 60,0 \\
\hline
\end{tabular}


Continuação da Tabela 1.

\begin{tabular}{|c|c|c|c|c|c|c|c|c|}
\hline Decendio & $\begin{array}{l}\text { ARARAS } \\
\text { Temp }\end{array}$ & $\begin{array}{l}1982 \\
\text { Predu }\end{array}$ & $\begin{array}{l}\text { ARARAS } \\
\text { Temo }\end{array}$ & $\begin{array}{l}1983 \\
\mathrm{Prec}\end{array}$ & $\begin{array}{l}\text { ARARAS } \\
\text { Temp }\end{array}$ & $\begin{array}{l}1984 \\
\text { Prec }\end{array}$ & $\begin{array}{l}\text { ARARAS } \\
\text { Temp }\end{array}$ & $\begin{array}{l}1985 \\
\text { Prect }\end{array}$ \\
\hline 1 & 22,5 & 45,0 & 22,7 & 96,0 & 25,0 & 35,0 & 22,8 & 144,0 \\
\hline 2 & 23,6 & 64,0 & 25,0 & 122,0 & 26,5 & 4,0 & 23,4 & 30,0 \\
\hline 3 & 21,7 & 74,0 & 23,9 & $82 ; 0$ & 23,8 & 63,0 & 23,1 & 156,0 \\
\hline 4 & 23,1 & 36,0 & 22,5 & 154,0 & 26,0 & 24,0 & 24,6 & 59,0 \\
\hline 5 & 24,6 & 8,0 & 24,8 & 96,0 & 26,0 & 5,0 & 25,0 & 54,0 \\
\hline 6 & 24,8 & 82,0 & 24,7 & 104,0 & 26,6 & 5,0 & 23,6 & 32,0 \\
\hline 7 & 22,9 & 105,0 & 24,3 & 303,0 & 24,6 & 48,0 & 22,7 & 32,0 \\
\hline 8 & 23,5 & 113,0 & 23,4 & 45,0 & 23,6 & 0,0 & 23,2 & 81,0 \\
\hline 9 & 22,6 & 60,4 & 23,0 & 28,0 & 23,1 & 22,0 & 25,5 & 0,0 \\
\hline 10 & 21,1 & 0,0 & 22,2 & 45,0 & 21,9 & 49,0 & 24,1 & 44,0 \\
\hline 11 & 20,4 & 29,0 & 22,3 & 7,0 & 22,2 & 17,0 & 22,6 & 113,0 \\
\hline 12 & 19,6 & 0,0 & 21,4 & 52,0 & 22,1 & 26,0 & 21,1 & 18,0 \\
\hline 13 & 16,8 & 0,0 & 21,9 & 10,0 & 22,0 & 7,0 & 19,0 & 0,0 \\
\hline 14 & 19,6 & 8,0 & 20,8 & 39,0 & 21,3 & 19,0 & 18,6 & 0,0 \\
\hline 15 & 17,4 & 28,0 & 18,1 & 144,0 & 20,2 & 0,0 & 19,2 & 35,0 \\
\hline 16 & 17,9 & 18,4 & 17,5 & 84,1 & 19,3 & 0,0 & 14,1 & 21,0 \\
\hline 17 & 18,8 & 30,0 & 18,4 & 0,0 & 19,9 & 0,0 & 14,0 & 0,0 \\
\hline 18 & 17,5 & 65,0 & 19,7 & 20,0 & 18,4 & 0,0 & 18,6 & 0,0 \\
\hline 19 & 17,6 & 0,0 & 20,8 & 0,0 & 20,4 & 0,0 & 17,2 & 0,0 \\
\hline 20 & 17,2 & 14,0 & 19,0 & 36,0 & 20,4 & 0,0 & 15,5 & 0,0 \\
\hline 21 & 18,4 & 4,0 & 18,9 & 20,0 & 17,3 & 3,0 & 16,4 & 0,0 \\
\hline 22 & 18,6 & 7,0 & 15,6 & 0,0 & 21,7 & 47,0 & 20,3 & 0,0 \\
\hline 23 & 18,5 & 18,0 & 20,5 & 0,0 & 18,9 & 23,0 & 18,9 & 0,0 \\
\hline 24 & 21,5 & 45,0 & 19,9 & 0,0 & 17,1 & 114,0 & 19,3 & 9,0 \\
\hline 25 & 19,6 & 0,0 & 16,2 & 94,0 & 19,3 & 19,0 & 18,4 & 28,0 \\
\hline 26 & 21,8 & 0,0 & 17,5 & 113,0 & 21,9 & 28,0 & 23,7 & 0,0 \\
\hline 27 & 19,5 & 23,0 & 21,1 & 49,0 & 19,8 & 30,0 & 21,3 & 5,0 \\
\hline 28 & 20,6 & 199,2 & 22,4 & 0,0 & 23,4 & 0,0 & 22,1 & 0,0 \\
\hline 29 & 20,0 & 86,0 & 21,8 & 52,0 & 22,4 & 24,0 & 24,9 & 0,0 \\
\hline 30 & 23,2 & 40,0 & 20,3 & 52,0 & 24,4 & 0,0 & 24,5 & 4,0 \\
\hline 31 & 25,0 & 34,0 & 22,8 & 164,0 & 26,2 & 32,0 & 22,3 & 45,0 \\
\hline 32 & 22,6 & 38,0 & 23,2 & 70,0 & 21,8 & 34,0 & 26,5 & 19,0 \\
\hline 33 & 24,3 & 117,0 & 22,7 & 32,0 & 22,0 & 87,0 & 22,4 & 120,0 \\
\hline 34 & 21,6 & 61,0 & 23,0 & 46,0 & 23,1 & 31,0 & 23,0 & 68,0 \\
\hline 35 & 22,9 & 86,0 . & 23,5 & 164,0 & 22,6 & 77,0 & 25,7 & 9,0 \\
\hline 36 & 22,5 & 73,0 & 22,3 & 120,0 & 23,0 & 69,0 & 23,9 & 85,0 \\
\hline
\end{tabular}


Continuação da Tabela 1.

ARARAS 1986

PRADOPOLIS

1978

Decendio Temo. Prec.

$24,0 \quad 64,0$

Temp.

$24,8 \quad 75,0$

21,9

$24,9 \quad 137,0$

24,0

25,7

$24,4 \quad 66,0$

15

16

17

18

19

20

21

22

23

24

25

26

27

28

29

30

31

32

33

34

35

36
$24,2 \quad 137,0$

$24,4 \quad 41,0$

$23,2160,0$

$24,8 \quad 2,0$

$22,7 \quad 65,0$

0,0

24,3

16,0

21,2

9,0

19,6

21,3

38,0

49,0

20,0

15,5

19,1

17,8

16,5

17,0

17,1

19,2

18,6

19,5

19,0

22,0

20,7

3,0

0,0

0,0

0,0

0,0

0,0

28,0

0,0

75,0

35,0

0,0

0,0

28,0

$24,7 \quad 55,0$

$22,5 \quad 25,0$

$24,0 \quad 180,0$

25,6

5,0

21,3

30,0

5,0

0,0

32,0

10,0

80,0

10,0

30,0

5,0

0,0

5,0

70,0

10,0

0,0

0,0

0,0

10,0

23,0

0,0

31,0

40,0

29,0

23,5

21,4

$21,4100,0$

$23,6 \quad 10,0$

$23,940,0$

21,7

22,6

98,0

97,0

$21,8 \quad 102,0$
PRADOPOLIS

1979

PRADOPOLIS

1980

Temp. Prec.

$21,870,0$

$22,4 \quad 10,0$

$22,5 \quad 128,0$

$24,1 \quad 41,0$

$23,3 \quad 124,0$

$24,0 \quad 25,0$

$23,7 \quad 8,0$

42,0

$\begin{array}{ll}23,4 & 10,0 \\ 20,9 & 55,0\end{array}$

Temp. Prec.

$22,2 \quad 18,0$

$23,0 \quad 59,0$

$23,6 \quad 83,0$

$24,6 \quad 94,0$

$22,5 \quad 116,0$

$22,5 \quad 49,0$

$24,2 \quad 78,0$

$24,1 \quad 0,0$

$21,5 \quad 45,0$

$21,1 \quad 2,0$

22,1

24,0

18,3

25,0

20,4

0,0

$20,9 \quad 69,0$

20,9

0,0

$20,4 \quad 0,0$

20,4

2,0

$17,2 \quad 28,0$

17,2

0,0

15,6

0,0

15,6

0,0

17,4

0,0

17,4

5,0

16,9

0,0

16,9

85,0

18,7

0,0

18,7

13,2

17,4

19,4

19,8

0,0

17,4

25,0

0,0

25,0

19,5

$19,5 \quad 10,0$

19,4

19,8

$18,3 \quad 133,0$

22,6

22,7

15,0

28,0

$22,8 \quad 57,0$

$21,4 \quad 6,0$

$24,6 \quad 123,0$

$23,5 \quad 34,0$

$22,7 \quad 50,0$

$24,6 \quad 80,0$

$22,7 \quad 130,0$

$23,5191,0$ 
Continuação da Tabela 1.

\begin{tabular}{|c|c|c|c|c|}
\hline \multirow[b]{2}{*}{ Decendio } & \multicolumn{2}{|c|}{$\begin{array}{l}\text { PRADOPOLIS } \\
1985\end{array}$} & \multicolumn{2}{|c|}{$\begin{array}{c}\text { PRADOPOLIS } \\
1986\end{array}$} \\
\hline & Temp. & Prec. & Temp. & Prec. \\
\hline 1 & 22,8 & 132,0 & 24,0 & 16,0 \\
\hline 2 & 23,4 & 118,0 & 24,8 & 135,0 \\
\hline 3 & 23,1 & 115,0 & 24,9 & 30,0 \\
\hline 4 & 24,6 & 23,0 & 24,4 & 34,0 \\
\hline 5 & 25,0 & 4,0 & 24,2 & 127,0 \\
\hline 6 & 23,6 & 58,0 & 24,4 & 32,0 \\
\hline 7 & 22,7 & 45,0 & 23,2 & 100,0 \\
\hline 8 & 23,2 & 125,0 & 24,8 & 58,0 \\
\hline 9 & 25,5 & 16,0 & 22,7 & 66,0 \\
\hline 10 & 24,1 & 15,0 & 24,3 & 0,0 \\
\hline 11 & 22,6 & 59,0 & 22,2 & 21,0 \\
\hline 12 & 21,1 & 11,0 & 21,2 & 0,0 \\
\hline 13 & 19,0 & 0,0 & 19,6 & 32,0 \\
\hline 14 & 18,6 & 0,0 & 21,3 & 58,0 \\
\hline 15 & 19,2 & 6,0 & 20,0 & 4,0 \\
\hline 16 & 14,1 & 0,0 & 15,5 & 0,0 \\
\hline 17 & 14,0 & 0,0 & 19,1 & 0,0 \\
\hline 18 & 18,6 & 0,0 & 17,8 & 0,0 \\
\hline 19 & 17,2 & 0,0 & 16,5 & 0,0 \\
\hline 20 & 15,5 & 0,0 & 17,0 & 0,0 \\
\hline 21 & 16,4 & 0,0 & 17,1 & 34,0 \\
\hline 22 & 20,3 & 0,0 & & \\
\hline 23 & 18,9 & 0,0 & & \\
\hline 24 & 19,3 & 0,0 & & \\
\hline 25 & 18,4 & 0,0 & & \\
\hline 26 & 23,7 & 0,0 & & \\
\hline 27 & 21,3 & 0,0 & & \\
\hline 28 & 22,1 & 2,0 & & \\
\hline 29 & 24,9 & 0,0 & & \\
\hline 30 & 24,5 & 48,0 & & \\
\hline 31 & 22,3 & 76,0 & & \\
\hline 32 & 26,5 & 8,0 & & \\
\hline 33 & 22,4 & 69,0 & & \\
\hline 34 & 23,0 & 57,0 & & \\
\hline 35 & 25,7 & 22,0 & & \\
\hline 36 & 23,9 & 112,0 & & \\
\hline
\end{tabular}


Tabela 2 Ciclo das variedades de cana-de-açúcar cultivadas em Araras, cujos valores de produtividade, apresentados na pagina 21 , foram utilizados para correlacionar com os valores do balanço hídrico.

\begin{tabular}{cccccc}
\hline Ano & CB 41-76 & NA 56-79 & CB 47-355 & CB 41-76 & CP 5122 \\
\hline $74-75$ & Abril - Agosto & & & & \\
$75-76$ & Setembro - Agosto & & & & \\
$76-77$ & Outubro - Setembro & & Abril - Setembro & \\
$77-78$ & Outubro - Setembro & Abril - Setembro & Abril - Setembro & Outubro - Setembro & \\
$78-79$ & Outubro - Setembro & Outubro - Setembro & Outubro - Setembro & Abril - Agosto \\
$79-80$ & Novembro - & Novembro - Outubro & Novembro - Outubro & Novembro - & Outubro \\
& Outubro & & & Novembro - & Novembro - \\
$80-81$ & Novembro - & Novembro - Outubro & Novembro - Outubro & Outubro & Outubro \\
& Outubro & & & Novembro - & Novembro - \\
$81-82$ & Novembro - & Novembro - Outubro & Novembro - Outubro & Outubro & Outubro \\
& Outubro & & & Outubro - Setembro & Outubro - Setembro \\
$82-83$ & Outubro - Setembro & Outubro - Setembro & Outubro - Setembro & Outubro - Setembro \\
$83-84$ & Outubro - Setembro & Outubro - Setembro & Outubro - Setembro & Outubro - Setembro & Outuro \\
$84-85$ & Outubro - Setembro & & & & \\
\hline
\end{tabular}

Tabela 3 Ciclo das variedades de cana-de-açúcar, cujos valores de produtividade, apresentados na pagina 28 , foram utilizados para o teste estatístico do modelo proposto.

\begin{tabular}{|c|c|c|c|c|c|}
\hline Ano & IAC 51/205 & CB 41-76 & CO 775 & NA 56-79 & RB 725828 \\
\hline \multirow[t]{2}{*}{$75-76$} & Junho - Setembro & & & & \\
\hline & Araras & & & & \\
\hline \multirow[t]{2}{*}{ 76-77 } & Outubro - Agosto & & & & \\
\hline & Araras & & & & \\
\hline \multirow{3}{*}{ 78-78 } & Setembro - & & & & \\
\hline & Setembro & & & & \\
\hline & Araras & & & & \\
\hline \multirow[t]{2}{*}{ 78-79 } & & Fevereiro - Agosto & & & \\
\hline & & Araras & & & \\
\hline \multirow[t]{2}{*}{$78-79$} & & Março - Maio & & & \\
\hline & & Pradópolis & & & \\
\hline \multirow[t]{2}{*}{$79-80$} & & Junho - Julho & Março - Setembro & & \\
\hline & & Pradópolis & Pradópolis & & \\
\hline \multirow[t]{2}{*}{$79-80$} & & & Fevereiro - Agosto & & \\
\hline & & & Pradópolis & & \\
\hline \multirow[t]{2}{*}{$85-86$} & & Setembro - Setembro & & Julho - Julho & Julho - Julho \\
\hline & & Araras & & Araras & Pradólis \\
\hline \multirow[t]{2}{*}{$85-86$} & & Setembro - Setembro & & & \\
\hline & & Araras & & & \\
\hline
\end{tabular}


Tabela 4 Balanço hídrico sequencial, método de Thornthwaite-Mather (1955), para cana-de açúcar no período de setembro/1977 a julho/1978 na localidade de Araras.

\begin{tabular}{|c|c|c|c|c|c|c|c|c|c|c|c|c|c|c|}
\hline ANO & DEC & $\mathbf{T}^{\circ}$ & $\mathbf{P}$ & kc & CAD & ETo & ETm & P-ETm & NegAc & ARM & ALT & ETr & $\begin{array}{ll}\text { DEF } 1 \\
\end{array}$ & EXC \\
\hline 1977 & 1 & 23,4 & 81 & 1 & 30 & 37,9 & 37,9 & 43,1 & 0,0 & 30,0 & 0,0 & 37,9 & 0,0 & $\overline{43,1}$ \\
\hline 1977 & 2 & 23,9 & 141 & 1 & 30 & 39,5 & 39,5 & 101,6 & 0,0 & 30,0 & 0,0 & 39,5 & 0,0 & 101,6 \\
\hline 1977 & 3 & 25,2 & 206 & 1 & 30 & 48,2 & 48,2 & 157,8 & 0,0 & 30,0 & 0,0 & 48,2 & 0,0 & 157,8 \\
\hline 1977 & 4 & 25,1 & 4 & 1 & 30 & 42,8 & 42,8 & $-38,8$ & $-38,8$ & 8,2 & $-21,8$ & 25,8 & 17,1 & 0,0 \\
\hline 1977 & 5 & 24,1 & 0 & 1 & 30 & 38,7 & 38,7 & $-38,7$ & $-77,5$ & 2,3 & $-6,0$ & 6,0 & 32,7 & 0,0 \\
\hline 1977 & 6 & 24,6 & 18 & 1 & 30 & 31,8 & 31,8 & $-13,8$ & $-91,3$ & 1,4 & $-0,8$ & 18,8 & 13,0 & 0,0 \\
\hline 1977 & 7 & 24 & 33 & 1 & 30 & 37,2 & 37,2 & $-4,2$ & $-95,5$ & 1,2 & $-0,2$ & 33,2 & 4,0 & 0,0 \\
\hline 1977 & 8 & 24,1 & 37 & 1 & 30 & 36,8 & 36,8 & 0,2 & $-91,6$ & 1,4 & 0,2 & 36,8 & 0,0 & 0,0 \\
\hline 1977 & 9 & 23,7 & 64 & 1 & 30 & 38,4 & 38,4 & 25,6 & $-3,2$ & 27,0 & 25,6 & 38,4 & 0,0 & 0,0 \\
\hline 1977 & 10 & 20,7 & 55 & 1 & 30 & 25,5 & 25,5 & 29,5 & 0,0 & 30,0 & 3,0 & 25,5 & 0,0 & 26,5 \\
\hline 1977 & 11 & 22,2 & 17 & 1 & 30 & 29,2 & 29,2 & $-12,2$ & $-12,2$ & 20,0 & $-10,0$ & 27,0 & 2,2 & 0,0 \\
\hline 1977 & 12 & 19,5 & 0 & 1 & 30 & 21,7 & 21,7 & $-21,7$ & $-33,8$ & 9,7 & $-10,3$ & 10,3 & 11,4 & 0,0 \\
\hline 1977 & 13 & 20,3 & 10 & 1 & 30 & 23,3 & 23,3 & $-13,3$ & $-47,1$ & 6,3 & $-3,5$ & 13,5 & 9,8 & 0,0 \\
\hline 1977 & 14 & 16,3 & 1 & 1 & 30 & 14,1 & 14,1 & $-13,1$ & $-60,2$ & 4,0 & $-2,2$ & 3,2 & 10,9 & 0,0 \\
\hline 1977 & 15 & 17,5 & 0 & 1 & 30 & 18,1 & 18,1 & $-18,1$ & $-78,3$ & 2,2 & $-1,8$ & 1,8 & 16,2 & 0,0 \\
\hline 1977 & 16 & 17,2 & 32 & 1 & 30 & 15,7 & 15,7 & 16,4 & $-14,4$ & 18,6 & 16,4 & 15,7 & 0,0 & 0,0 \\
\hline 1977 & 17 & 18,9 & 0 & 1 & 30 & 19,1 & 19,1 & $-19,1$ & $-33,5$ & 9,8 & $-8,7$ & 8,7 & 10,4 & 0,0 \\
\hline 1977 & 18 & 18,5 & 7 & 1 & 30 & 18,2 & 18,2 & $-11,2$ & $-44,7$ & 6,8 & $-3,1$ & 10,1 & 8,2 & 0,0 \\
\hline 1977 & 19 & 17,7 & 0 & 1 & 30 & 16,6 & 16,6 & $-16,6$ & $-61,3$ & 3,9 & $-2,9$ & 2,9 & 13,7 & 0,0 \\
\hline 1977 & 20 & 18,9 & 1 & 1 & 30 & 19,3 & 19,3 & $-18,3$ & $-79,6$ & 2,1 & $-1,8$ & 2,8 & 16,5 & 0,0 \\
\hline 1977 & 21 & 20 & 7 & 1 & 30 & 24,2 & 24,2 & $-17,2$ & $-96,9$ & 1,2 & $-0,9$ & 7,9 & 16,3 & 0,0 \\
\hline 1977 & 22 & 20,6 & 0 & 1 & 30 & 23,9 & 23,9 & $-23,9$ & $-120,7$ & 0,5 & $-0,7$ & 0,7 & 23,2 & 0,0 \\
\hline 1977 & 23 & 20,3 & 0 & 1 & 30 & 23,5 & 23,5 & $-23,5$ & $-144,2$ & 0,3 & $-0,3$ & 0,3 & 23,2 & 0,0 \\
\hline 1977 & 24 & 19,8 & 30 & 1 & 30 & 24,9 & 24,9 & 5,2 & $-51,5$ & 5,4 & 5,2 & 24,9 & 0,0 & 0,0 \\
\hline 1977 & 25 & 18,8 & 55 & 0,18 & 30 & 20,6 & 3,7 & 51,3 & 0,0 & 30,0 & 24,6 & 3,7 & 0,0 & 26,7 \\
\hline 1977 & 26 & 22,8 & 7 & 0,3 & 30 & 31,9 & 9,6 & $-2,6$ & $-2,6$ & 27,5 & $-2,5$ & 9,5 & 0,1 & 0,0 \\
\hline 1977 & 27 & 21 & 24 & 0,42 & 30 & 27,1 & 11,4 & 12,6 & 0,0 & 30,0 & 2,5 & 11,4 & 0,0 & 10,2 \\
\hline 1977 & 28 & 21,6 & 30 & 0,52 & 40 & 29,3 & 15,3 & 14,8 & 0,0 & 40,0 & 0,0 & 15,3 & 0,0 & 14,8 \\
\hline 1977 & 29 & 23,1 & 6 & 0,61 & 40 & 34,5 & 21,1 & $-15,1$ & $-15,1$ & 27,4 & $-12,6$ & 18,6 & 2,5 & 0,0 \\
\hline 1977 & 30 & 23 & 18 & 0,71 & 40 & 38,2 & 27,1 & $-9,1$ & $-24,2$ & 21,8 & $-5,6$ & 23,6 & 3,5 & 0,0 \\
\hline 1977 & 31 & 23,6 & 16 & 0,8 & 50 & 37,3 & 29,9 & $-13,9$ & $-36,4$ & 24,1 & $-7,7$ & 23,7 & 6,2 & 0,0 \\
\hline 1977 & 32 & 21,8 & 84 & 0,87 & 50 & 31,9 & 27,7 & 56,3 & 0,0 & 50,0 & 25,9 & 27,7 & 0,0 & 30,4 \\
\hline 1977 & 33 & 23,4 & 72 & 0,94 & 50 & 37,6 & 35,3 & 36,7 & 0,0 & 50,0 & 0,0 & 35,3 & 0,0 & 36,7 \\
\hline 1977 & 34 & 22,4 & 89 & 1,01 & 60 & 34,4 & 34,8 & 54,2 & 0,0 & 60,0 & 0,0 & 34,8 & 0,0 & 54,2 \\
\hline 1977 & 35 & 21,5 & 18 & 1,06 & 60 & 31,7 & 33,6 & $-15,6$ & $-15,6$ & 46,3 & $-13,7$ & 31,7 & 1,9 & 0,0 \\
\hline 1977 & 36 & 21,4 & 56 & 1,12 & 60 & 34,5 & 38,6 & 17,4 & 0,0 & 60,0 & 13,7 & 38,6 & 0,0 & 3,7 \\
\hline 1978 & 1 & 21,9 & 141 & 1,16 & 70 & 32,9 & 38,1 & 102,9 & 0,0 & 70,0 & 0,0 & 38,1 & 0,0 & 102,9 \\
\hline 1978 & 2 & 24 & 56 & 1,2 & 70 & 39,8 & 47,8 & 8,2 & 0,0 & 70,0 & 0,0 & 47,8 & 0,0 & 8,2 \\
\hline 1978 & 3 & 25,7 & 14 & 1,23 & 70 & 50,3 & 61,9 & $-47,9$ & $-47,9$ & 35,3 & $-34,7$ & 48,7 & 13,2 & 0,0 \\
\hline 1978 & 4 & 23,9 & 88 & 1,26 & 80 & 38,5 & 48,5 & 39,5 & 0,0 & 80,0 & 34,7 & 48,5 & 0,0 & 4 , \\
\hline 1978 & 5 & 24,7 & 43 & 1,29 & 80 & 40,8 & 52,6 & $-9,6$ & $-9,6$ & 71,0 & $-9,1$ & 52,1 & 0,6 & 0,0 \\
\hline 1978 & 6 & 22,7 & 25 & 1,31 & 80 & 26,7 & 35,0 & $-10,0$ & $-19,6$ & 62,6 & $-8,3$ & 33,3 & 1,7 & 0,0 \\
\hline 1978 & 7 & 22,5 & 81 & 1,33 & 90 & 32,3 & 43,0 & 38,0 & 0,0 & 90,0 & 17,4 & 43,0 & 0,0 & 20,6 \\
\hline 1978 & 8 & 24 & 0 & 1,34 & 90 & 36,5 & 48,9 & $-48,9$ & $-48,9$ & 52,3 & $-37,7$ & 37,7 & 11,2 & 0,0 \\
\hline 1978 & 9 & 25,6 & 2 & 1,35 & 90 & 45,4 & 61,3 & $-59,3$ & $-108,2$ & 27,0 & $-25,2$ & 27,2 & 34,1 & 0,0 \\
\hline 1978 & 10 & 21,3 & 8 & 1,35 & 100 & 27,2 & 36,7 & $-28,7$ & $-128,0$ & 27,8 & $-9,2$ & 17,2 & 19,4 & 0,0 \\
\hline 1978 & 11 & 21,2 & 0 & 1,35 & 100 & 26,4 & 35,6 & $-35,6$ & $-163,6$ & 19,5 & $-8,3$ & 8,3 & 27,3 & 0,0 \\
\hline 1978 & 12 & 20,6 & 48 & 1,35 & 100 & 24,4 & 32,9 & 15,1 & $-106,3$ & 34,5 & 15,1 & 32,9 & 0,0 & 0,0 \\
\hline 1978 & 13 & 17,6 & 0 & 1,35 & 100 & 17,1 & 23,0 & $-23,0$ & $-129,3$ & 27,4 & $-7,1$ & 7,1 & 15,9 & 0 , \\
\hline 1978 & 14 & 19,2 & 49 & 1,34 & 100 & 20,2 & 27,0 & 22,0 & $-70,5$ & 49,4 & 22,0 & 27,0 & 0,0 & 0,0 \\
\hline 1978 & 15 & 16 & 2 & 1,33 & 100 & 14,9 & 19,8 & $-17,8$ & $-88,3$ & 41,4 & $-8,0$ & 10,0 & 9,7 & 0,0 \\
\hline 1978 & 16 & 15,1 & 25 & 1,32 & 100 & 11,8 & 15,6 & 9,4 & $-67,7$ & 50,8 & 9,4 & 15,6 & 0,0 & 0 , \\
\hline 1978 & 17 & 17,2 & 0 & 1,32 & 100 & 15,6 & 20,6 & $-20,6$ & $-88,3$ & 41,4 & $-9,4$ & 9,4 & 11,1 & 0 \\
\hline 1978 & 18 & 18,3 & 0 & 1,31 & 100 & 17,8 & 23,3 & $-23,3$ & $-111,6$ & 32,8 & $-8,6$ & 8,6 & 14,7 & 0,0 \\
\hline 1978 & 19 & 17,9 & 0 & 1,29 & 100 & 17,0 & 22,0 & $-22,0$ & $-133,6$ & 26,3 & $-6,5$ & 6,5 & 15,5 & 0, \\
\hline 1978 & 20 & 16,5 & 52 & 1,28 & 100 & 14,4 & 18,4 & 33,6 & $-51,2$ & 59,9 & 33,6 & 18,4 & 0,0 & 0 , \\
\hline 1978 & 21 & 20,9 & 22 & 1,26 & 100 & 26,7 & 33,6 & $-11,6$ & $-62,9$ & 53,3 & $-6,6$ & 28,6 & 5,0 & 0, \\
\hline
\end{tabular}


Tabela 5 a. Dados de ETr e ETm durante o ciclo da cana planta, variedade CB 41-76, período 1974 - 1975, em Araras.

\begin{tabular}{|c|c|c|c|c|c|}
\hline ANO & $\mathrm{DEC}$ & $\begin{array}{c}E T m \\
\mathrm{~mm}\end{array}$ & $\begin{array}{l}E T r \\
\mathrm{~mm}\end{array}$ & $E T r / E T m$ & $\begin{array}{c}E T r / E T m \\
\text { médio }\end{array}$ \\
\hline 1974 & 10 & 1,22 & 1,22 & 1,00 & \\
\hline 1974 & 11 & 1,03 & 1,03 & 1,00 & \\
\hline 1974 & 12 & 0,87 & 0,87 & 1,00 & \\
\hline 1974 & 13 & 3,11 & 2,95 & 0,95 & \\
\hline 1974 & 14 & 6,26 & 5,96 & 0,95 & \\
\hline 1974 & 15 & 8,06 & 5,91 & 0,73 & \\
\hline 1974 & 16 & 9,09 & 7,12 & 0,78 & \\
\hline 1974 & 17 & 9,98 & 9,98 & 1,00 & \\
\hline 1974 & 18 & 8,33 & 8,33 & 1,00 & \\
\hline 1974 & 19 & 10,39 & 9,38 & 0,90 & \\
\hline 1974 & 20 & 15,66 & 10,92 & 0,70 & \\
\hline 1974 & 21 & 20,39 & 9,95 & 0,49 & \\
\hline 1974 & 22 & 19,52 & 8,27 & 0,42 & \\
\hline 1974 & 23 & 17,82 & 8,42 & 0,47 & \\
\hline 1974 & 24 & 34,30 & 7,43 & 0,22 & \\
\hline 1974 & 25 & 30,98 & 7,84 & 0,25 & \\
\hline 1974 & 26 & 37,89 & 8,02 & 0,21 & \\
\hline 1974 & 27 & 42,95 & 42,95 & 1,00 & 0,73 \\
\hline 1974 & 28 & 35,84 & 35,84 & 1,00 & \\
\hline 1974 & 29 & 46,25 & 34,82 & 0,75 & \\
\hline 1974 & 30 & 59,98 & 59,98 & 1,00 & \\
\hline 1974 & 31 & 39,75 & 24,39 & 0,61 & \\
\hline 1974 & 32 & 54,06 & 51,29 & 0,95 & \\
\hline 1974 & 33 & 54,04 & 37,93 & 0,70 & \\
\hline 1974 & 34 & 42,95 & 42,95 & 1,00 & \\
\hline 1974 & 35 & 44,92 & 44,92 & 1,00 & \\
\hline 1974 & 36 & 54,97 & 54,97 & 1,00 & \\
\hline 1975 & 1 & 44,80 & 44,80 & 1,00 & \\
\hline 1975 & 2 & 49,56 & 49,56 & 1,00 & \\
\hline 1975 & 3 & 58,17 & 47,45 & 0,82 & \\
\hline 1975 & 4 & 47,66 & 47,66 & 1,00 & \\
\hline 1975 & 5 & 55,26 & 54,54 & 0,99 & \\
\hline 1975 & 6 & 39,14 & 39,14 & 1,00 & \\
\hline 1975 & 7 & 50,16 & 39,45 & 0,79 & \\
\hline 1975 & 8 & 40,22 & 20,05 & 0,50 & \\
\hline 1975 & 9 & 42,01 & 25,96 & 0,62 & 0,87 \\
\hline 1975 & 10 & 32,92 & 29,52 & 0,90 & \\
\hline 1975 & 11 & 32,04 & 21,93 & 0,68 & \\
\hline 1975 & 12 & 32,26 & 7,19 & 0,22 & \\
\hline 1975 & 13 & 28,14 & 18,99 & 0,67 & \\
\hline 1975 & 14 & 26,16 & 3,89 & 0,15 & \\
\hline 1975 & 15 & 23,66 & 2,74 & 0,12 & \\
\hline 1975 & 16 & 21,63 & 3,83 & 0,18 & \\
\hline 1975 & 17 & 19,07 & 1,47 & 0,08 & \\
\hline 1975 & 18 & 23,11 & 1,44 & 0,06 & \\
\hline 1975 & 19 & 15,40 & 15,40 & 1,00 & \\
\hline 1975 & 20 & 16,38 & 2,59 & 0,16 & \\
\hline 1975 & 21 & 19,94 & 2,63 & 0,13 & \\
\hline 1975 & 22 & 32,78 & 3,33 & 0,10 & \\
\hline 1975 & 23 & 20,76 & 1,61 & 0,08 & \\
\hline 1975 & 24 & 40,12 & 2,31 & 0,06 & 0,31 \\
\hline
\end{tabular}

Tabela 5 b. Dados de ETr e ETm durante o ciclo da cana soca, variedade CB 41-76, período 1974 - 1975, em Araras.

\begin{tabular}{lccccc}
\hline ANO & DEC & $\begin{array}{c}E T m \\
\mathrm{~mm}\end{array}$ & $\begin{array}{c}E T r \\
\mathrm{~mm}\end{array}$ & $\begin{array}{c}E T r / E T m \\
\text { ETr } / E T m \\
\text { médio }\end{array}$ \\
\hline 1975 & 25 & 7,77 & 7,77 & 1,00 & \\
1975 & 26 & 7,35 & 6,15 & 0,84 & \\
1975 & 27 & 7,32 & 7,32 & 1,00 & \\
1975 & 28 & 18,43 & 18,43 & 1,00 & \\
1975 & 29 & 17,51 & 17,51 & 1,00 & \\
1975 & 30 & 23,10 & 22,83 & 0,99 & \\
1975 & 31 & 25,22 & 25,08 & 0,99 & \\
1975 & 32 & 26,73 & 23,91 & 0,89 & \\
1975 & 33 & 31,88 & 28,03 & 0,88 & \\
1975 & 34 & 41,63 & 29,03 & 0,70 & \\
1975 & 35 & 35,23 & 35,23 & 1,00 & \\
1975 & 36 & 44,23 & 44,23 & 1,00 & 0,94 \\
\hline 1976 & 1 & 42,62 & 42,62 & 1,00 & \\
1976 & 2 & 53,97 & 53,97 & 1,00 & \\
1976 & 3 & 49,53 & 49,53 & 1,00 & \\
1976 & 4 & 42,74 & 42,74 & 1,00 & \\
1976 & 5 & 42,14 & 42,14 & 1,00 & \\
1976 & 6 & 34,80 & 34,80 & 1,00 & \\
1976 & 7 & 51,65 & 51,57 & 1,00 & \\
1976 & 8 & 49,35 & 49,35 & 1,00 & \\
1976 & 9 & 52,91 & 46,28 & 0,87 & \\
1976 & 10 & 39,33 & 28,20 & 0,72 & \\
1976 & 11 & 34,89 & 34,89 & 1,00 & \\
1976 & 12 & 29,56 & 22,12 & 0,75 & 0,94 \\
\hline 1976 & 13 & 25,77 & 19,45 & 0,75 & \\
1976 & 14 & 36,68 & 36,68 & 1,00 & \\
1976 & 15 & 40,13 & 40,13 & 1,00 & \\
1976 & 16 & 19,88 & 19,88 & 1,00 & \\
1976 & 17 & 21,87 & 20,19 & 0,92 & \\
1976 & 18 & 20,79 & 15,55 & 0,75 & \\
1976 & 19 & 13,38 & 13,38 & 1,00 & \\
1976 & 20 & 18,16 & 16,61 & 0,91 & \\
1976 & 21 & 27,13 & 19,82 & 0,73 & \\
1976 & 22 & 26,25 & 21,77 & 0,83 & \\
1976 & 23 & 24,09 & 24,09 & 1,00 & \\
1976 & 24 & 29,81 & 25,34 & 0,85 & 0,90 \\
\hline & & & & & \\
\hline
\end{tabular}


Tabela 5 c. Dados de ETr e ETm durante o ciclo da cana soca, variedade CB 41-76, período 1976 - 1977, em Araras.

\begin{tabular}{lccccc}
\hline ANO & DEC & $\begin{array}{c}E T m \\
\mathrm{~mm}\end{array}$ & $\begin{array}{c}E T r \\
\mathrm{~mm}\end{array}$ & $\begin{array}{c}E T r / E T m \\
\text { ETr } / E T m \\
\text { médio }\end{array}$ \\
\hline 1976 & 28 & 4,27 & 4,27 & 1,00 & \\
1976 & 29 & 8,96 & 8,96 & 1,00 & \\
1976 & 30 & 18,08 & 18,08 & 1,00 & \\
1976 & 31 & 17,00 & 17,00 & 1,00 & \\
1976 & 32 & 21,84 & 21,84 & 1,00 & \\
1976 & 33 & 25,68 & 23,29 & 0,91 & \\
1976 & 34 & 30,28 & 21,04 & 0,69 & \\
1976 & 35 & 29,81 & 29,81 & 1,00 & \\
1976 & 36 & 38,28 & 38,28 & 1,00 & \\
1977 & 1 & 38,32 & 38,32 & 1,00 & \\
1977 & 2 & 41,82 & 41,82 & 1,00 & \\
1977 & 3 & 53,97 & 53,97 & 1,00 & 0,97 \\
\hline 1977 & 4 & 49,68 & 37,55 & 0,76 & \\
1977 & 5 & 46,39 & 17,66 & 0,38 & \\
1977 & 6 & 39,13 & 22,89 & 0,58 & \\
1977 & 7 & 46,85 & 36,87 & 0,79 & \\
1977 & 8 & 47,50 & 39,48 & 0,83 & \\
1977 & 9 & 50,33 & 50,33 & 1,00 & \\
1977 & 10 & 33,95 & 33,95 & 1,00 & \\
1977 & 11 & 39,07 & 30,63 & 0,78 & \\
1977 & 12 & 29,24 & 13,57 & 0,46 & \\
1977 & 13 & 31,39 & 18,74 & 0,60 & \\
1977 & 14 & 19,09 & 7,06 & 0,37 & \\
1977 & 15 & 24,36 & 6,61 & 0,27 & 0,65 \\
1977 & 16 & 21,12 & 21,12 & 1,00 & \\
1977 & 17 & 25,59 & 7,86 & 0,31 & \\
1977 & 18 & 24,23 & 11,27 & 0,47 & \\
1977 & 19 & 21,92 & 4,47 & 0,20 & \\
1977 & 20 & 25,48 & 4,96 & 0,19 & \\
1977 & 21 & 31,76 & 10,13 & 0,32 & \\
1977 & 22 & 30,76 & 2,95 & 0,10 & \\
1977 & 23 & 30,06 & 2,13 & 0,07 & \\
1977 & 24 & 31,32 & 30,08 & 0,96 & \\
1977 & 25 & 25,72 & 25,72 & 1,00 & \\
1977 & 26 & 39,53 & 16,79 & 0,42 & \\
1977 & 27 & 33,34 & 26,27 & 0,79 & 0,49 \\
\hline & & & & & \\
\hline
\end{tabular}

Tabela 5 d. Dados de ETr e ETm durante o ciclo da cana soca, variedade CB 41-76, período 1977 - 1978, em Araras.

\begin{tabular}{|c|c|c|c|c|c|}
\hline ANO & DEC & $\begin{array}{c}E T m \\
\mathrm{~mm}\end{array}$ & $\begin{array}{l}E T r \\
\mathrm{~mm}\end{array}$ & $E T r / E T m$ & $\begin{array}{c}E T r / E T m \\
\text { médio }\end{array}$ \\
\hline 1977 & 28 & 5,28 & 5,28 & 1,00 & \\
\hline 1977 & 29 & 10,36 & 10,06 & 0,97 & \\
\hline 1977 & 30 & 16,05 & 16,05 & 1,00 & \\
\hline 1977 & 31 & 19,42 & 19,10 & 0,98 & \\
\hline 1977 & 32 & 19,45 & 19,45 & 1,00 & \\
\hline 1977 & 33 & 26,66 & 26,66 & 1,00 & \\
\hline 1977 & 34 & 27,54 & 27,54 & 1,00 & \\
\hline 1977 & 35 & 27,54 & 26,68 & 0,97 & . \\
\hline 1977 & 36 & 32,43 & 32,43 & 1,00 & \\
\hline 1978 & 1 & 33,18 & 33,18 & 1,00 & \\
\hline 1978 & 2 & 42,20 & 42,20 & 1,00 & \\
\hline 1978 & 3 & 56,32 & 44,36 & 0,79 & 0,98 \\
\hline 1978 & 4 & 44,67 & 44,67 & 1,00 & \\
\hline 1978 & 5 & 48,94 & 48,69 & 0,99 & \\
\hline 1978 & 6 & 32,87 & 31,83 & 0,97 & \\
\hline 1978 & 7 & 40,73 & 40,73 & 1,00 & \\
\hline 1978 & 8 & 47,08 & 35,59 & 0,76 & \\
\hline 1978 & 9 & 59,50 & 24,77 & 0,42 & \\
\hline 1978 & 10 & 36,13 & 16,49 & 0,46 & \\
\hline 1978 & 11 & 35,35 & 7,52 & 0,21 & \\
\hline 1978 & 12 & 32,93 & 32,93 & 1,00 & \\
\hline 1978 & 13 & 23,03 & 8,37 & 0,36 & \\
\hline 1978 & 14 & 27,23 & 27,23 & 1,00 & \\
\hline 1978 & 15 & 20,06 & 10,94 & 0,55 & 0,73 \\
\hline 1978 & 16 & 15,92 & 15,92 & 1,00 & \\
\hline 1978 & 17 & 20,86 & 10,21 & 0,49 & \\
\hline 1978 & 18 & 23,67 & 9,28 & 0,39 & \\
\hline 1978 & 19 & 22,47 & 6,99 & 0,31 & \\
\hline 1978 & 20 & 18,97 & 18,97 & 1,00 & \\
\hline 1978 & 21 & 34,94 & 29,38 & 0,84 & \\
\hline 1978 & 22 & 23,51 & 11,19 & 0,48 & \\
\hline 1978 & 23 & 16,97 & 6,59 & 0,39 & \\
\hline 1978 & 24 & 27,66 & 8,61 & 0,31 & \\
\hline 1978 & 25 & 26,02 & 26,02 & 1,00 & \\
\hline 1978 & 26 & 26,92 & 26,92 & 1,00 & \\
\hline 1978 & 27 & 32,66 & 12,00 & 0,37 & 0,63 \\
\hline
\end{tabular}


Tabela 5 e. Dados de ETr e ETm durante o ciclo da cana planta, variedades NA 56-79; CB47-355 e CB41-76, período 1977 - 1978, em Araras.

\begin{tabular}{|c|c|c|c|c|c|}
\hline ANO & $\overline{\mathrm{DEC}}$ & $\begin{array}{l}E T m \\
\mathrm{~mm}\end{array}$ & $\begin{array}{l}E T r \\
\mathrm{~mm}\end{array}$ & $E T r / E T m$ & $\begin{array}{c}E T r / E T m \\
\text { médio }\end{array}$ \\
\hline 1977 & 10 & 1,07 & 1,07 & 1,00 & \\
\hline 1977 & 11 & 1,22 & 1,22 & 1,00 & \\
\hline 1977 & 12 & 0,91 & 0,90 & 0,99 & \\
\hline 1977 & 13 & 4,19 & 4,19 & 1,00 & \\
\hline 1977 & 14 & 4,24 & 4,07 & 0,96 & \\
\hline 1977 & 15 & 7,58 & 6,01 & 0,79 & \\
\hline 1977 & 16 & 8,14 & 8,14 & 1,00 & \\
\hline 1977 & 17 & 11,65 & 10,11 & 0,87 & \\
\hline 1977 & 18 & 12,94 & 11,12 & 0,86 & \\
\hline 1977 & 19 & 13,29 & 8,35 & 0,63 & \\
\hline 1977 & 20 & 16,79 & 8,43 & 0,50 & \\
\hline 1977 & 21 & 22,79 & 12,41 & 0,54 & \\
\hline 1977 & 22 & 24,09 & 8,13 & 0,34 & \\
\hline 1977 & 23 & 24,89 & 5,59 & 0,22 & \\
\hline 1977 & 24 & 27,84 & 27,84 & 1,00 & \\
\hline 1977 & 25 & 23,87 & 23,87 & 1,00 & \\
\hline 1977 & 26 & 38,25 & 26,50 & 0,69 & \\
\hline 1977 & 27 & 33,34 & 28,33 & 0,85 & 0,79 \\
\hline 1977 & 28 & 36,95 & 33,35 & 0,90 & \\
\hline 1977 & 29 & 44,56 & 20,14 & 0,45 & \\
\hline 1977 & 30 & 50,05 & 25,54 & 0,51 & \\
\hline 1977 & 31 & 49,66 & 23,89 & 0,48 & \\
\hline 1977 & 32 & 42,72 & 42,72 & 1,00 & \\
\hline 1977 & 33 & 50,69 & 50,69 & 1,00 & \\
\hline 1977 & 34 & 46,48 & 46,48 & 1,00 & \\
\hline 1977 & 35 & 42,73 & 39,91 & 0,93 & \\
\hline 1977 & 36 & 46,57 & 46,57 & 1,00 & \\
\hline 1978 & 1 & 44,36 & 44,36 & 1,00 & \\
\hline 1978 & 2 & 53,35 & 53,35 & 1,00 & \\
\hline 1978 & 3 & 66,88 & 55,07 & 0,82 & \\
\hline 1978 & 4 & 50,84 & 50,84 & 1,00 & \\
\hline 1978 & 5 & 53,83 & 52,86 & 0,98 & \\
\hline 1978 & 6 & 35,00 & 33,21 & 0,95 & \\
\hline 1978 & 7 & 41,70 & 41,70 & 1,00 & \\
\hline 1978 & 8 & 46,71 & 37,32 & 0,80 & \\
\hline 1978 & 9 & 57,23 & 28,60 & 0,50 & 0,85 \\
\hline 1978 & 10 & 33,95 & 16,25 & 0,48 & \\
\hline 1978 & 11 & 32,71 & 7,77 & 0,24 & \\
\hline 1978 & 12 & 30,01 & 30,01 & 1,00 & \\
\hline 1978 & 13 & 20,64 & 7,10 & 0,34 & \\
\hline 1978 & 14 & 24,21 & 24,21 & 1,00 & \\
\hline 1978 & 15 & 17,68 & 10,09 & 0,57 & \\
\hline 1978 & 16 & 13,92 & 13,92 & 1,00 & \\
\hline 1978 & 17 & 18,37 & 9,86 & 0,54 & \\
\hline 1978 & 18 & 20,82 & 9,19 & 0,44 & \\
\hline 1978 & 19 & 19,91 & 7,17 & 0,36 & \\
\hline 1978 & 20 & 16,82 & 16,82 & 1,00 & \\
\hline 1978 & 21 & 31,21 & 27,96 & 0,90 & \\
\hline 1978 & 22 & 21,51 & 11,95 & 0,56 & \\
\hline 1978 & 23 & 15,78 & 7,27 & 0,46 & \\
\hline
\end{tabular}

Continuação da Tabela 5 e.

\begin{tabular}{cccccc}
\hline ANO & DEC & $\begin{array}{c}E T m \\
\mathrm{~mm}\end{array}$ & $\begin{array}{c}E T r \\
\mathrm{~mm}\end{array}$ & ETr/ETm & $\begin{array}{c}E T r / E T m \\
\text { médio }\end{array}$ \\
\hline 1978 & 24 & 26,35 & 9,85 & 0,37 & \\
1978 & 25 & 24,98 & 24,98 & 1,00 & \\
1978 & 26 & 26,05 & 26,05 & 1,00 & \\
1978 & 27 & 31,86 & 13,82 & 0,43 & 0,65 \\
\hline
\end{tabular}

Tabela 5 f. Dados de ETr e ETm durante o ciclo da cana soca, variedades NA 56-79; CB47-355 e CB41-76, período 1978 - 1979, em Araras.

\begin{tabular}{|c|c|c|c|c|c|}
\hline ANO & $\overline{\mathrm{DEC}}$ & $\begin{array}{c}E T m \\
\mathrm{~mm}\end{array}$ & $\begin{array}{l}\text { ETr } \\
\mathrm{mm}\end{array}$ & $E T r / E T m$ & $\begin{array}{c}E T r / E T m \\
\text { médio }\end{array}$ \\
\hline 1978 & 28 & 5,71 & 4,07 & 0,71 & \\
\hline 1978 & 29 & 10,36 & 10,36 & 1,00 & \\
\hline 1978 & 30 & 20,76 & 20,76 & 1,00 & \\
\hline 1978 & 31 & 19,24 & 19,24 & 1,00 & \\
\hline 1978 & 32 & 18,68 & 18,68 & 1,00 & \\
\hline 1978 & 33 & 27,16 & 27,16 & 1,00 & \\
\hline 1978 & 34 & 31,70 & 31,70 & 1,00 & \\
\hline 1978 & 35 & 28,10 & 28,10 & 1,00 & \\
\hline 1978 & 36 & 36,50 & 36,50 & 1,00 & \\
\hline 1979 & 1 & 32,86 & 32,36 & 0,98 & \\
\hline 1979 & 2 & 36,33 & 28,70 & 0,79 & \\
\hline 1979 & 3 & 42,20 & 41,67 & 0,99 & 0,96 \\
\hline 1979 & 4 & 45,49 & 42,39 & 0,93 & \\
\hline 1979 & 5 & 43,12 & 43,12 & 1,00 & \\
\hline 1979 & 6 & 37,09 & 29,99 & 0,81 & \\
\hline 1979 & 7 & 45,59 & 23,65 & 0,52 & \\
\hline 1979 & 8 & 41,32 & 22,78 & 0,55 & \\
\hline 1979 & 9 & 48,96 & 19,98 & 0,41 & \\
\hline 1979 & 10 & 34,67 & 34,67 & 1,00 & \\
\hline 1979 & 11 & 34,99 & 16,39 & 0,47 & \\
\hline 1979 & 12 & 25,47 & 25,47 & 1,00 & \\
\hline 1979 & 13 & 33,44 & 33,44 & 1,00 & \\
\hline 1979 & 14 & 31,06 & 26,70 & 0,86 & \\
\hline 1979 & 15 & 23,47 & 23,47 & 1,00 & 0,80 \\
\hline 1979 & 16 & 17,09 & 11,76 & 0,69 & \\
\hline 1979 & 17 & 21,39 & 12,15 & 0,57 & \\
\hline 1979 & 18 & 19,91 & 9,20 & 0,46 & \\
\hline 1979 & 19 & 24,70 & 13,77 & 0,56 & \\
\hline 1979 & 20 & 11,69 & 11,69 & 1,00 & \\
\hline 1979 & 21 & 23,48 & 11,46 & 0,49 & \\
\hline 1979 & 22 & 27,01 & 7,53 & 0,28 & \\
\hline 1979 & 23 & 28,48 & 28,48 & 1,00 & \\
\hline 1979 & 24 & 30,29 & 21,80 & 0,72 & \\
\hline 1979 & 25 & 23,69 & 22,63 & 0,96 & \\
\hline 1979 & 26 & 24,53 & 24,53 & 1,00 & \\
\hline 1979 & 27 & 39,10 & 38,05 & 0,97 & 0,72 \\
\hline
\end{tabular}


Tabela 5 g. Dados de ETr e Etm durante o ciclo a cana soca, variedades NA 56-79; CB47-355 e CB41-76, período 1979 - 1980, em Araras.

\begin{tabular}{|c|c|c|c|c|c|}
\hline ANO & DEC & $\begin{array}{c}E T m \\
\mathrm{~mm}\end{array}$ & $\begin{array}{l}\text { ETr } \\
\mathrm{mm}\end{array}$ & ETr/ETm & $\begin{array}{c}E T r / E T m \\
\text { médio }\end{array}$ \\
\hline 1979 & 31 & 6,18 & 6,18 & 1,00 & \\
\hline 1979 & 32 & 10,54 & 8,89 & 0,84 & \\
\hline 1979 & 33 & 12,99 & 12,99 & 1,00 & \\
\hline 1979 & 34 & 21,94 & 21,94 & 1,00 & \\
\hline 1979 & 35 & 23,42 & 23,42 & 1,00 & \\
\hline 1979 & 36 & 27,83 & 27,83 & 1,00 & \\
\hline 1980 & 1 & 27,07 & 26,91 & 0,99 & \\
\hline 1980 & 2 & 31,58 & 31,58 & 1,00 & \\
\hline 1980 & 3 & 39,29 & 39,29 & 1,00 & \\
\hline 1980 & 4 & 41,41 & 41,41 & 1,00 & \\
\hline 1980 & 5 & 35,31 & 35,31 & 1,00 & \\
\hline 1980 & 6 & 29,36 & 29,36 & 1,00 & 0,99 \\
\hline 1980 & 7 & 45,11 & 45,08 & 1,00 & \\
\hline 1980 & 8 & 44,59 & 44,59 & 1,00 & \\
\hline 1980 & 9 & 49,00 & 35,24 & 0,72 & \\
\hline 1980 & 10 & 34,93 & 34,93 & 1,00 & \\
\hline 1980 & 11 & 37,24 & 37,24 & 1,00 & \\
\hline 1980 & 12 & 31,29 & 25,89 & 0,83 & \\
\hline 1980 & 13 & 26,18 & 18,44 & 0,70 & \\
\hline 1980 & 14 & 31,49 & 25,05 & 0,80 & \\
\hline 1980 & 15 & 37,70 & 14,92 & 0,40 & \\
\hline 1980 & 16 & 22,20 & 20,22 & 0,91 & \\
\hline 1980 & 17 & 16,53 & 7,74 & 0,47 & \\
\hline 1980 & 18 & 11,25 & 11,25 & 1,00 & 0,82 \\
\hline 1980 & 19 & 18,01 & 16,48 & 0,92 & \\
\hline 1980 & 20 & 23,83 & 17,71 & 0,74 & \\
\hline 1980 & 21 & 26,91 & 15,53 & 0.58 & \\
\hline 1980 & 22 & 24,35 & 10,87 & 0,45 & \\
\hline 1980 & 23 & 31,33 & 11,31 & 0,36 & \\
\hline 1980 & 24 & 32,20 & 20,35 & 0,63 & \\
\hline 1980 & 25 & 34,81 & 23,41 & 0,67 & \\
\hline 1980 & 26 & 27,47 & 27,47 & 1,00 & \\
\hline 1980 & 27 & 19,71 & 19,71 & 1,00 & \\
\hline 1980 & 28 & 31,35 & 31,35 & 1,00 & \\
\hline 1980 & 29 & 36,66 & 36,66 & 1,00 & \\
\hline 1980 & 30 & 53,90 & 37,16 & 0,69 & 0,75 \\
\hline
\end{tabular}

Tabela 5 h. Dados de ETr e ETm durante o ciclo da cana planta, variedades CP51-22, período 1979 - 1980, em Araras.

\begin{tabular}{|c|c|c|c|c|c|}
\hline ANO & $\overline{\mathrm{DEC}}$ & $\begin{array}{c}E T m \\
\mathrm{~mm}\end{array}$ & $\begin{array}{l}\text { ETr } \\
\mathrm{mm}\end{array}$ & $E T r / E T m$ & $\begin{array}{c}E T r / E T m \\
\text { médio }\end{array}$ \\
\hline 1979 & 10 & 1,09 & 1,09 & 1,00 & \\
\hline 1979 & 11 & 1,10 & 1,10 & 1,00 & \\
\hline 1979 & 12 & 0,79 & 0,79 & 1,00 & \\
\hline 1979 & 13 & 4,46 & 4,46 & 1,00 & \\
\hline 1979 & 14 & 6,90 & 6,17 & 0,89 & \\
\hline 1979 & 15 & 7,30 & 7,30 & 1,00 & \\
\hline 1979 & 16 & 6,58 & 6,07 & 0,92 & \\
\hline 1979 & 17 & 9,74 & 7,33 & 0,75 & \\
\hline 1979 & 18 & 10,63 & 6,21 & 0,58 & \\
\hline 1979 & 19 & 14,97 & 11,48 & 0,77 & \\
\hline 1979 & 20 & 7,71 & 7,71 & 1,00 & \\
\hline 1979 & 21 & 16,85 & 12,00 & 0,71 & \\
\hline 1979 & 22 & 21,15 & 10,75 & 0,51 & \\
\hline 1979 & 23 & 23,58 & 23,58 & 1,00 & \\
\hline 1979 & 24 & 26,93 & 23,37 & 0,87 & \\
\hline 1979 & 25 & 21,98 & 21,98 & 1,00 & \\
\hline 1979 & 26 & 23,74 & 23,74 & 1,00 & \\
\hline 1979 & 27 & 39,10 & 39,03 & 1,00 & 0,89 \\
\hline 1979 & 28 & 41,55 & 41,55 & 1,00 & \\
\hline 1979 & 29 & 35,12 & 33,95 & 0,97 & \\
\hline 1979 & 30 & 58,94 & 43,85 & 0,74 & \\
\hline 1979 & 31 & 45,64 & 45,64 & 1,00 & \\
\hline 1979 & 32 & 47,08 & 36,66 & 0,78 & \\
\hline 1979 & 33 & 41,76 & 37,48 & 0,90 & \\
\hline 1979 & 34 & 56,96 & 53,89 & 0,95 & \\
\hline 1979 & 35 & 51,83 & 51,83 & 1,00 & \\
\hline 1980 & 36 & 52,93 & 52,93 & 1,00 & \\
\hline 1980 & 1 & 45,69 & 38,27 & 0,84 & \\
\hline 1980 & 2 & 48,64 & 48,64 & 1,00 & \\
\hline 1980 & 3 & 55,59 & 55,59 & 1,00 & \\
\hline 1980 & 4 & 54,12 & 53,87 & 1,00 & \\
\hline 1980 & 5 & 43,97 & 43,97 & 1,00 & \\
\hline 1980 & 6 & 34,34 & 34,34 & 1,00 & \\
\hline 1980 & 7 & 50,16 & 49,91 & 1,00 & \\
\hline 1980 & 8 & 47,56 & 47,56 & 1,00 & \\
\hline 1980 & 9 & 50,20 & 39,47 & 0,79 & 0,94 \\
\hline 1980 & 10 & 34,65 & 34,65 & 1,00 & \\
\hline 1980 & 11 & 35,80 & 35,80 & 1,00 & \\
\hline 1980 & 12 & 29,38 & 25,46 & 0,87 & \\
\hline 1980 & 13 & 23,82 & 17,79 & 0,75 & \\
\hline 1980 & 14 & 28,20 & 23,99 & 0,85 & \\
\hline 1980 & 15 & 33,23 & 15,77 & 0,47 & \\
\hline 1980 & 16 & 19,41 & 19,16 & 0,99 & \\
\hline 1980 & 17 & 14,45 & 7,31 & 0,51 & \\
\hline 1980 & 18 & 9,75 & 9,75 & 1,00 & \\
\hline 1980 & 19 & 15,61 & 14,45 & 0,93 & \\
\hline 1980 & 20 & 20,81 & 16,07 & 0,77 & \\
\hline 1980 & 21 & 23,67 & 14,64 & 0,62 & \\
\hline 1980 & 22 & 21,77 & 10,73 & 0,49 & \\
\hline 1980 & 23 & 28,25 & 11,52 & 0,41 & 0,76 \\
\hline
\end{tabular}


Tabela 5 i. Dados de ETr e ETm durante o ciclo a cana soca, variedades CB41-76; NA 56-79; CB47-355 e CP51-22, período 1980 - 1981, em Araras.

\begin{tabular}{|c|c|c|c|c|c|}
\hline NO & $\mathrm{DEC}$ & $\begin{array}{l}E T m \\
\text { mm }\end{array}$ & $\begin{array}{l}E T r \\
\text { mm }\end{array}$ & $E T r / E T m$ & $\begin{array}{c}E T r / E T m \\
\text { médio }\end{array}$ \\
\hline 1980 & 31 & 5,06 & 5,06 & 1,00 & \\
\hline 1980 & 32 & 8,55 & 8,55 & 1,00 & \\
\hline 1980 & 33 & 15,34 & 15,34 & 1,00 & \\
\hline 1980 & 34 & 16,71 & 16,71 & 1,00 & \\
\hline 1980 & 35 & 21,31 & 21,31 & 1,00 & \\
\hline 1980 & 36 & 32,27 & 30,82 & 0,96 & \\
\hline 1981 & 1 & 23,26 & 23,26 & 1,00 & \\
\hline 1981 & 2 & 27,01 & 27,01 & 1,00 & \\
\hline 1981 & 3 & 37,86 & 37,86 & 1,00 & \\
\hline 1981 & 4 & 36,13 & 36,12 & 1,00 & \\
\hline 1981 & 5 & 33,30 & 31,48 & 0,95 & \\
\hline 1981 & 6 & 29,36 & 27,96 & 0,95 & 0,99 \\
\hline 1981 & 7 & 44,31 & 41,18 & 0,93 & \\
\hline 1981 & 8 & 32,10 & 22,25 & 0,69 & \\
\hline 1981 & 9 & 31,64 & 21,35 & 0,67 & \\
\hline 1981 & 10 & 30,50 & 14,73 & 0,48 & \\
\hline 1981 & 11 & 27,76 & 25,19 & 0,91 & \\
\hline 1981 & 12 & 29,65 & 17,65 & 0,60 & \\
\hline 1981 & 13 & 28,03 & 27,34 & 0,98 & \\
\hline 1981 & 14 & 29,22 & 8,24 & 0,28 & \\
\hline 1981 & 15 & 27,81 & 9,00 & 0,32 & \\
\hline 1981 & 16 & 16,15 & 16,15 & 1,00 & \\
\hline 1981 & 17 & 16,53 & 16,53 & 1,00 & \\
\hline 1981 & 18 & 17,95 & 15,42 & 0,86 & 0,73 \\
\hline 1981 & 19 & 15,88 & 14,48 & 0,91 & \\
\hline 1981 & 20 & 17,29 & 11,74 & 0,68 & \\
\hline 1981 & 21 & 20,14 & 11,34 & 0,56 & \\
\hline 1981 & 22 & 22,10 & 10,08 & 0,46 & \\
\hline 1981 & 23 & 25,34 & 11,83 & 0,47 & \\
\hline 1981 & 24 & 31,50 & 8,90 & 0,28 & \\
\hline 1981 & 25 & 35,16 & 7,12 & 0,20 & \\
\hline 1981 & 26 & 42,37 & 5,84 & 0,14 & \\
\hline 1981 & 27 & 40,44 & 9,22 & 0,23 & \\
\hline 1981 & 28 & 27,75 & 27,75 & 1,00 & \\
\hline 1981 & 29 & 32,02 & 32,02 & 1,00 & \\
\hline 1981 & 30 & 43,10 & 43,10 & 1,00 & 0,58 \\
\hline
\end{tabular}

Tabela 5 j. Dados de ETr e ETm durante o ciclo da cana soca, variedades CB41-76; NA 56-79; CB47-355 e CP51-22, período 1981 - 1982, em Araras.

\begin{tabular}{|c|c|c|c|c|c|}
\hline ANO & DEC & $\begin{array}{c}E T m \\
\mathrm{~mm}\end{array}$ & $\begin{array}{l}E T r \\
\mathrm{~mm}\end{array}$ & ETr/ETm & $\begin{array}{c}E T r / E T m \\
\text { médio }\end{array}$ \\
\hline 1981 & 31 & 6,60 & 6,60 & 1,00 & \\
\hline 1981 & 32 & 10,95 & 10,95 & 1,00 & \\
\hline 1981 & 33 & 16,96 & 16,96 & 1,00 & \\
\hline 1981 & 34 & 17,22 & 17,22 & 1,00 & \\
\hline 1981 & 35 & 24,29 & 24,29 & 1,00 & \\
\hline 1981 & 36 & 30,01 & 30,01 & 1,00 & \\
\hline 1982 & 1 & 27,87 & 27,87 & 1,00 & \\
\hline 1982 & 2 & 33,40 & 33,40 & 1,00 & \\
\hline 1982 & 3 & 32,74 & 32,74 & 1,00 & \\
\hline 1982 & 4 & 36,13 & 36,13 & 1,00 & \\
\hline 1982 & 5 & 42,85 & 34,38 & 0,80 & \\
\hline 1982 & 6 & 36,26 & 36,26 & 1,00 & 0,98 \\
\hline 1982 & 7 & 38,96 & 38,96 & 1,00 & \\
\hline 1982 & 8 & 41,84 & 41,84 & 1,00 & \\
\hline 1982 & 9 & 42,63 & 42,63 & 1,00 & \\
\hline 1982 & 10 & 33,53 & 27,39 & 0,82 & \\
\hline 1982 & 11 & 31,30 & 30,49 & 0,97 & \\
\hline 1982 & 12 & 28,69 & 15,40 & 0,54 & \\
\hline 1982 & 13 & 20,51 & 9,32 & 0,45 & \\
\hline 1982 & 14 & 28,27 & 15,34 & 0,54 & \\
\hline 1982 & 15 & 24,06 & 24,06 & 1,00 & \\
\hline 1982 & 16 & 23,03 & 20,35 & 0,88 & \\
\hline 1982 & 17 & 25,49 & 25,49 & 1,00 & \\
\hline 1982 & 18 & 21,80 & 21,80 & 1,00 & 0,85 \\
\hline 1982 & 19 & 22,15 & 17,63 & 0,80 & \\
\hline 1982 & 20 & 21,08 & 18,86 & 0,89 & \\
\hline 1982 & 21 & 26,91 & 17,57 & 0,65 & \\
\hline 1982 & 22 & 25,22 & 15,78 & 0,63 & \\
\hline 1982 & 23 & 25,34 & 21,11 & 0,83 & \\
\hline 1982 & 24 & 38,93 & 38,93 & 1,00 & \\
\hline 1982 & 25 & 29,06 & 11,82 & 0,41 & \\
\hline 1982 & 26 & 37,02 & 10,85 & 0,29 & \\
\hline 1982 & 27 & 29,08 & 24,43 & 0,84 & \\
\hline 1982 & 28 & 33,07 & 33,07 & 1,00 & \\
\hline 1982 & 29 & 31,33 & 31,33 & 1,00 & \\
\hline 1982 & 30 & 47,89 & 47,59 & 0,99 & 0,78 \\
\hline
\end{tabular}


Tabela 5 k. Dados de ETr e ETm durante o ciclo da cana soca, variedades CB41-76; NA 56-79; CB47-355 e CP51-22, período 1982 - 1983, em Araras.

\begin{tabular}{|c|c|c|c|c|c|}
\hline ANO & $\overline{\mathrm{DEC}}$ & $\begin{array}{c}E T m \\
\mathrm{~mm}\end{array}$ & $\begin{array}{l}E T r \\
\text { mm }\end{array}$ & $E T r / E T m$ & $\begin{array}{c}\text { ETr } / E T m \\
\text { médio }\end{array}$ \\
\hline 1982 & 28 & 4,76 & 4,76 & 1,00 & \\
\hline 1982 & 29 & 7,58 & 7,58 & 1,00 & \\
\hline 1982 & 30 & 16,35 & 16,35 & 1,00 & \\
\hline 1982 & 31 & 22,00 & 22,00 & 1,00 & \\
\hline 1982 & 32 & 21,03 & 21,03 & 1,00 & \\
\hline 1982 & 33 & 28,94 & 28,94 & 1,00 & \\
\hline 1982 & 34 & 25,45 & 25,45 & 1,00 & \\
\hline 1982 & 35 & 31,58 & 31,58 & 1,00 & \\
\hline 1982 & 36 & 36,15 & 36,15 & 1,00 & \\
\hline 1983 & 1 & 35,87 & 35,87 & 1,00 & \\
\hline 1983 & 2 & 46,11 & 46,11 & 1,00 & \\
\hline 1983 & 3 & 48,11 & 48,11 & 1,00 & 1,00 \\
\hline 1983 & 4 & 39,19 & 39,19 & 1,00 & \\
\hline 1983 & 5 & 49,37 & 49,37 & 1,00 & \\
\hline 1983 & 6 & 39,47 & 39,47 & 1,00 & \\
\hline 1983 & 7 & 48,13 & 48,13 & 1,00 & \\
\hline 1983 & 8 & 44,56 & 44,56 & 1,00 & \\
\hline 1983 & 9 & 47,16 & 45,04 & 0,96 & \\
\hline 1983 & 10 & 39,52 & 39,52 & 1,00 & \\
\hline 1983 & 11 & 39,45 & 30,75 & 0,78 & \\
\hline 1983 & 12 & 35,77 & 35,77 & 1,00 & \\
\hline 1983 & 13 & 37,01 & 29,15 & 0,79 & \\
\hline 1983 & 14 & 32,40 & 32,40 & 1,00 & \\
\hline 1983 & 15 & 26,21 & 26,21 & 1,00 & 0,96 \\
\hline 1983 & 16 & 21,93 & 21,93 & 1,00 & \\
\hline 1983 & 17 & 24,15 & 21,45 & 0,89 & \\
\hline 1983 & 18 & 27,77 & 25,88 & 0,93 & \\
\hline 1983 & 19 & 31,12 & 19,43 & 0,62 & \\
\hline 1983 & 20 & 25,77 & 25,77 & 1,00 & \\
\hline 1983 & 21 & 28,09 & 24,93 & 0,89 & \\
\hline 1983 & 22 & 16,83 & 9,07 & 0,54 & \\
\hline 1983 & 23 & 30,71 & 13,08 & 0,43 & \\
\hline 1983 & 24 & 31,66 & 9,88 & 0,31 & \\
\hline 1983 & 25 & 18,62 & 18,62 & 1,00 & \\
\hline 1983 & 26 & 22,26 & 22,26 & 1,00 & \\
\hline 1983 & 27 & 33,69 & 33,69 & 1,00 & 0,80 \\
\hline
\end{tabular}

Tabela 5 1. Dados de ETr e ETm durante o ciclo da cana soca, variedades CB41-76; NA 56-79; CB47-355 e CP51-22, período 1983 - 1984, em Araras.

\begin{tabular}{|c|c|c|c|c|c|}
\hline ANO & $\overline{\mathrm{DEC}}$ & $\begin{array}{c}E T m \\
\mathrm{~mm}\end{array}$ & $\begin{array}{l}\text { ETr } \\
\mathrm{mm}\end{array}$ & $E T r / E T m$ & $\begin{array}{c}E T r / E T m \\
\text { médio }\end{array}$ \\
\hline 1983 & 28 & 5,71 & 5,20 & 0,91 & \\
\hline 1983 & 29 & 9,14 & 9,14 & 1,00 & \\
\hline 1983 & 30 & 12,24 & 12,24 & 1,00 & \\
\hline 1983 & 31 & 18,02 & 18,02 & 1,00 & \\
\hline 1983 & 32 & 22,26 & 22,26 & 1,00 & \\
\hline 1983 & 33 & 24,96 & 24,96 & 1,00 & \\
\hline 1983 & 34 & 29,17 & 29,17 & 1,00 & \\
\hline 1983 & 35 & 33,40 & 33,40 & 1,00 & \\
\hline 1983 & 36 & 35,46 & 35,46 & 1,00 & \\
\hline 1984 & 1 & 44,23 & 43,55 & 0,98 & \\
\hline 1984 & 2 & 52,85 & 32,65 & 0,62 & \\
\hline 1984 & 3 & 47,67 & 47,67 & 1,00 & 0,96 \\
\hline 1984 & 4 & 53,63 & 40,61 & 0,76 & \\
\hline 1984 & 5 & 54,70 & 21,02 & 0,38 & \\
\hline 1984 & 6 & 46,72 & 11,96 & 0,26 & \\
\hline 1984 & 7 & 49,43 & 48,33 & 0,98 & \\
\hline 1984 & 8 & 45,39 & 7,88 & 0,17 & \\
\hline 1984 & 9 & 47,61 & 24,83 & 0,52 & \\
\hline 1984 & 10 & 38,37 & 38,37 & 1,00 & \\
\hline 1984 & 11 & 39,07 & 23,12 & 0,59 & \\
\hline 1984 & 12 & 38,36 & 28,82 & 0,75 & \\
\hline 1984 & 13 & 37,38 & 14,65 & 0,39 & \\
\hline 1984 & 14 & 34,11 & 22,02 & 0,65 & \\
\hline 1984 & 15 & 33,26 & 5,24 & 0,16 & 0,55 \\
\hline 1984 & 16 & 27,12 & 3,15 & 0,12 & \\
\hline 1984 & 17 & 28,62 & 2,52 & 0,09 & \\
\hline 1984 & 18 & 23,95 & 1,62 & 0,07 & \\
\hline 1984 & 19 & 29,83 & 1,54 & 0,05 & \\
\hline 1984 & 20 & 30,07 & 1,15 & 0,04 & \\
\hline 1984 & 21 & 23,18 & 3,60 & 0,16 & \\
\hline 1984 & 22 & 34,44 & 34,44 & 1,00 & \\
\hline 1984 & 23 & 25,74 & 23,41 & 0,91 & \\
\hline 1984 & 24 & 22,78 & 22,78 & 1,00 & \\
\hline 1984 & 25 & 27,23 & 26,90 & 0,99 & \\
\hline 1984 & 26 & 36,22 & 35,27 & 0,97 & \\
\hline 1984 & 27 & 29,34 & 29,34 & 1,00 & 0,53 \\
\hline
\end{tabular}


Tabela 5 g. Dados de $E T r$ e ETm durante o ciclo da cana soca, variedade CB41-76, período 1984 - 1985, em Araras.

\begin{tabular}{|c|c|c|c|c|c|}
\hline ANO & $\overline{\mathrm{DEC}}$ & $\begin{array}{c}\text { ETm } \\
\mathrm{mm}\end{array}$ & $\begin{array}{l}E T r \\
\mathrm{~mm}\end{array}$ & $E T r / E T m$ & $\begin{array}{c}E T r / E T m \\
\text { médio }\end{array}$ \\
\hline 1984 & 28 & 6,28 & 5,67 & 0,90 & \\
\hline 1984 & 29 & 9,69 & 9,69 & 1,00 & \\
\hline 1984 & 30 & 18,24 & 13,67 & 0,75 & \\
\hline 1984 & 31 & 24,36 & 24,36 & 1,00 & \\
\hline 1984 & 32 & 19,45 & 19,45 & 1,00 & \\
\hline 1984 & 33 & 23,32 & 23,32 & 1,00 & \\
\hline 1984 & 34 & 29,45 & 29,45 & 1,00 & \\
\hline 1984 & 35 & 30,69 & 30,69 & 1,00 & \\
\hline 1984 & 36 & 37,92 & 37,92 & 1,00 & \\
\hline 1985 & 1 & 36,22 & 36,22 & 1,00 & \\
\hline 1985 & 2 & 39,94 & 39,16 & 0,98 & \\
\hline 1985 & 3 & 44,68 & 44,68 & 1,00 & 0,97 \\
\hline 1985 & 4 & 47,56 & 47,56 & 1,00 & \\
\hline 1985 & 5 & 50,24 & 50,24 & 1,00 & \\
\hline 1985 & 6 & 35,76 & 35,66 & 1,00 & \\
\hline 1985 & 7 & 41,52 & 40,56 & 0,98 & \\
\hline 1985 & 8 & 43,74 & 43,74 & 1,00 & \\
\hline 1985 & 9 & 59,00 & 41,73 & 0,71 & \\
\hline 1985 & 10 & 47,23 & 45,70 & 0,97 & \\
\hline 1985 & 11 & 40,61 & 40,61 & 1,00 & \\
\hline 1985 & 12 & 34,69 & 33,24 & 0,96 & \\
\hline 1985 & 13 & 27,19 & 20,18 & 0,74 & \\
\hline 1985 & 14 & 25,42 & 14,50 & 0,57 & \\
\hline 1985 & 15 & 29,79 & 29,79 & 1,00 & 0,91 \\
\hline 1985 & 16 & 13,72 & 13,72 & 1,00 & \\
\hline 1985 & 17 & 13,34 & 7,82 & 0,59 & \\
\hline 1985 & 18 & 24,52 & 11,91 & 0,49 & \\
\hline 1985 & 19 & 20,60 & 7,98 & 0,39 & \\
\hline 1985 & 20 & 16,57 & 5,32 & 0,32 & \\
\hline 1985 & 21 & 20,65 & 5,51 & 0,27 & \\
\hline 1985 & 22 & 29,80 & 6,19 & 0,21 & \\
\hline 1985 & 23 & 25,74 & 4,05 & 0,16 & \\
\hline 1985 & 24 & 29,62 & 11,57 & 0,39 & 0,42 \\
\hline
\end{tabular}


Tabela 6 a. Dados de ETr e ETm durante o ciclo da cana planta, variedade IAC 51/205, periodo 1975-1976, em Araras.
Tabela 6 b. Dados de $E T r$ e $E T m$ durante o ciclo da cana soca, variedade IAC 51/205, período 1976 - 1977, em Araras.

\begin{tabular}{|c|c|c|c|c|c|}
\hline ANO & $\overline{\mathrm{DEC}}$ & $\begin{array}{c}E T m \\
\mathrm{~mm}\end{array}$ & $\begin{array}{l}E T r \\
\mathrm{~mm}\end{array}$ & $\overline{E T r} / E T m$ & $\begin{array}{c}E T r / E T m \\
\text { médio }\end{array}$ \\
\hline 1975 & 16 & 0,77 & 0,77 & 1,00 & \\
\hline 1975 & 17 & 0,68 & 0,04 & 0,06 & \\
\hline 1975 & 18 & 0,83 & 0,31 & 0,37 & \\
\hline 1975 & 19 & 2,37 & 2,37 & 1,00 & \\
\hline 1975 & 20 & 4,20 & 3,92 & 0,93 & \\
\hline 1975 & 21 & 7,16 & 5,54 & 0,77 & \\
\hline 1975 & 22 & 14,44 & 9,26 & 0,64 & \\
\hline 1975 & 23 & 10,64 & 4,97 & 0,47 & \\
\hline 1975 & 24 & 23,74 & 7,30 & 0,31 & \\
\hline 1975 & 25 & 20,72 & 20,72 & 1,00 & \\
\hline 1975 & 26 & 21,32 & 10,68 & 0,50 & \\
\hline 1975 & 27 & 22,92 & 22,92 & 1,00 & \\
\hline 1975 & 28 & 30,52 & 30,52 & 1,00 & \\
\hline 1975 & 29 & 28,56 & 28,43 & 1,00 & \\
\hline 1975 & 30 & 36,97 & 32,70 & 0,88 & \\
\hline 1975 & 31 & 33,62 & 29,58 & 0,88 & \\
\hline 1975 & 32 & 35,64 & 23,23 & 0,65 & \\
\hline 1975 & 33 & 39,21 & 27,22 & 0,69 & 0,73 \\
\hline 1975 & 34 & 49,48 & 25,07 & 0,51 & \\
\hline 1975 & 35 & 42,08 & 42,08 & 1,00 & \\
\hline 1975 & 36 & 50,38 & 50,38 & 1,00 & \\
\hline 1976 & 1 & 47,24 & 47,24 & 1,00 & \\
\hline 1976 & 2 & 58,80 & 58,80 & 1,00 & \\
\hline 1976 & 3 & 54,37 & 54,37 & 1,00 & \\
\hline 1976 & 4 & 44,73 & 44,73 & 1,00 & \\
\hline 1976 & 5 & 44,10 & 44,10 & 1,00 & \\
\hline 1976 & 6 & 36,42 & 36,42 & 1,00 & \\
\hline 1976 & 7 & 52,03 & 51,94 & 1,00 & \\
\hline 1976 & 8 & 49,35 & 49,35 & 1,00 & \\
\hline 1976 & 9 & 52,91 & 46,28 & 0,87 & \\
\hline 1976 & 10 & 39,33 & 28,20 & 0,72 & \\
\hline 1976 & 11 & 34,89 & 34,89 & 1,00 & \\
\hline 1976 & 12 & 29,56 & 22,12 & 0,75 & \\
\hline 1976 & 13 & 25,77 & 19,45 & 0,75 & \\
\hline 1976 & 14 & 36,68 & 36,68 & 1,00 & \\
\hline 1976 & 15 & 40,13 & 40,13 & 1,00 & 0,92 \\
\hline 1976 & 16 & 19,88 & 19,88 & 1,00 & \\
\hline 1976 & 17 & 21,87 & 20,19 & 0,92 & \\
\hline 1976 & 18 & 20,79 & 15,55 & 0,75 & \\
\hline 1976 & 19 & 13,38 & 13,38 & 1,00 & \\
\hline 1976 & 20 & 18,16 & 16,61 & 0,91 & \\
\hline 1976 & 21 & 27,13 & 19,82 & 0,73 & \\
\hline 1976 & 22 & 26,25 & 21,77 & 0,83 & \\
\hline 1976 & 23 & 24,09 & 24,09 & 1,00 & \\
\hline 1976 & 24 & 29,81 & 25,34 & 0,85 & \\
\hline 1976 & 25 & 19,73 & 19,73 & 1,00 & \\
\hline 1976 & 26 & 20,64 & 20,64 & 1,00 & \\
\hline 1976 & 27 & 24,06 & 24,06 & 1,00 & 0,92 \\
\hline
\end{tabular}

\begin{tabular}{|c|c|c|c|c|c|}
\hline ANO & $\overline{\mathrm{DEC}}$ & $\begin{array}{c}E T m \\
\mathrm{~mm}\end{array}$ & $\begin{array}{l}E T r \\
\mathrm{~mm}\end{array}$ & $E T r / E T m$ & $\begin{array}{c}E T r / E T m \\
\text { médio }\end{array}$ \\
\hline 1976 & 28 & 4,27 & 4,27 & 1,00 & \\
\hline 1976 & 29 & 8,96 & 8,96 & 1,00 & \\
\hline 1976 & 30 & 18,08 & 18,08 & 1,00 & \\
\hline 1976 & 31 & 17,00 & 17,00 & 1,00 & \\
\hline 1976 & 32 & 21,84 & 21,84 & 1,00 & \\
\hline 1976 & 33 & 25,68 & 23,29 & 0,91 & \\
\hline 1976 & 34 & 30,28 & 21,04 & 0,69 & \\
\hline 1976 & 35 & 29,81 & 29,81 & 1,00 & \\
\hline 1976 & 36 & 38,28 & 38,28 & 1,00 & \\
\hline 1977 & 1 & 38,32 & 38,32 & 1,00 & \\
\hline 1977 & 2 & 41,82 & 41,82 & 1,00 & \\
\hline 1977 & 3 & 53,97 & 53,97 & 1,00 & 0,97 \\
\hline 1977 & 4 & 49,68 & 37,55 & 0,76 & \\
\hline 1977 & 5 & 46,39 & 17,66 & 0,38 & \\
\hline 1977 & 6 & 39,13 & 22,89 & 0,58 & \\
\hline 1977 & 7 & 46,85 & 36,80 & 0,79 & \\
\hline 1977 & 8 & 47,50 & 39,47 & 0,83 & \\
\hline 1977 & 9 & 50,33 & 50,33 & 1,00 & \\
\hline 1977 & 10 & 33,95 & 33,95 & 1,00 & \\
\hline 1977 & 11 & 39,07 & 30,55 & 0,78 & \\
\hline 1977 & 12 & 29,24 & 13,53 & 0,46 & \\
\hline 1977 & 13 & 31,39 & 18,71 & 0,60 & \\
\hline 1977 & 14 & 19,09 & 7,05 & 0,37 & \\
\hline 1977 & 15 & 24,36 & 6,59 & 0,27 & 0,65 \\
\hline 1977 & 16 & 21,12 & 21,12 & 1,00 & \\
\hline 1977 & 17 & 25,59 & 7,85 & 0,31 & \\
\hline 1977 & 18 & 24,23 & 11,26 & 0,46 & \\
\hline 1977 & 19 & 21,92 & 4,46 & 0,20 & \\
\hline 1977 & 20 & 25,48 & 4,95 & 0,19 & \\
\hline 1977 & 21 & 31,76 & 10,12 & 0,32 & \\
\hline 1977 & 22 & 30,76 & 2,95 & 0,10 & \\
\hline 1977 & 23 & 30,06 & 2,12 & 0,07 & \\
\hline 1977 & 24 & 31,32 & 30,08 & 0,96 & 0,40 \\
\hline
\end{tabular}


Tabela 6 c. Dados de $E T r$ e $E T m$ durante o ciclo da cana soca, variedade IAC 51/205, período 1977 - 1978 , em Araras.

\begin{tabular}{|c|c|c|c|c|c|}
\hline ANO & DEC & $\begin{array}{l}E T m \\
\mathrm{~mm}\end{array}$ & $\begin{array}{l}E T r \\
\mathrm{~mm}\end{array}$ & $E T r / E T m$ & $\begin{array}{c}\text { ETr/ETm } \\
\text { médio }\end{array}$ \\
\hline 1977 & 25 & 3,70 & 3,70 & 1,00 & \\
\hline 1977 & 26 & 9,56 & 9,46 & 0,99 & \\
\hline 1977 & 27 & 11,38 & 11,38 & 1,00 & \\
\hline 1977 & 28 & 15,25 & 15,25 & 1,00 & \\
\hline 1977 & 29 & 21,07 & 18,56 & 0,88 & \\
\hline 1977 & 30 & 27,13 & 23,60 & 0,87 & \\
\hline 1977 & 31 & 29,87 & 23,71 & 0,79 & \\
\hline 1977 & 32 & 27,73 & 27,73 & 1,00 & \\
\hline 1977 & 33 & 35,30 & 35,30 & 1,00 & \\
\hline 1977 & 34 & 34,77 & 34,77 & 1,00 & \\
\hline 1977 & 35 & 33,55 & 31,70 & 0,94 & \\
\hline 1977 & 36 & 38,63 & 38,63 & 1,00 & 0,96 \\
\hline 1978 & 1 & 38,11 & 38,11 & 1,00 & \\
\hline 1978 & 2 & 47,77 & 47,77 & 1,00 & \\
\hline 1978 & 3 & 61,85 & 48,66 & 0,79 & \\
\hline 1978 & 4 & 48,52 & 48,52 & 1,00 & \\
\hline 1978 & 5 & 52,61 & 52,05 & 0,99 & \\
\hline 1978 & 6 & 35,00 & 33,34 & 0,95 & \\
\hline 1978 & 7 & 42,99 & 42,99 & 1,00 & \\
\hline 1978 & 8 & 48,90 & 37,73 & 0,77 & \\
\hline 1978 & 9 & 61,32 & 27,23 & 0,44 & \\
\hline 1978 & 10 & 36,67 & 17,23 & 0,47 & \\
\hline 1978 & 11 & 35,61 & 8,33 & 0,23 & \\
\hline 1978 & 12 & 32,93 & 32,93 & 1,00 & 0,80 \\
\hline 1978 & 13 & 23,03 & 7,11 & 0,31 & \\
\hline 1978 & 14 & 27,03 & 27,03 & 1,00 & \\
\hline 1978 & 15 & 19,76 & 10,04 & 0,51 & \\
\hline 1978 & 16 & 15,57 & 15,57 & 1,00 & \\
\hline 1978 & 17 & 20,55 & 9,43 & 0,46 & \\
\hline 1978 & 18 & 23,31 & 8,60 & 0,37 & \\
\hline 1978 & 19 & 21,95 & 6,46 & 0,29 & \\
\hline 1978 & 20 & 18,40 & 18,40 & 1,00 & \\
\hline 1978 & 21 & 33,61 & 28,57 & 0,85 & \\
\hline 1978 & 22 & 22,78 & 10,87 & 0,48 & \\
\hline 1978 & 23 & 16,44 & 6,44 & 0,39 & \\
\hline 1978 & 24 & 27,00 & 8,53 & 0,32 & \\
\hline 1978 & 25 & 25,61 & 25,61 & 1,00 & \\
\hline 1978 & 26 & 26,70 & 26,70 & 1,00 & \\
\hline 1978 & 27 & 32,66 & 12,31 & 0,38 & 0,62 \\
\hline
\end{tabular}

Tabela 6 d. Dados de $E T r$ e $E T m$ durante o ciclo da cana planta, variedade CB41-76, período 1978 - 1979, em Araras.

\begin{tabular}{|c|c|c|c|c|c|}
\hline ANO & $\mathrm{DEC}$ & $\begin{array}{c}E T m \\
\mathrm{~mm}\end{array}$ & $\begin{array}{l}\text { ETr } \\
\mathrm{mm}\end{array}$ & $E T r / E T m$ & $\begin{array}{c}E T r / E T m \\
\text { médio }\end{array}$ \\
\hline 1978 & 4 & 1,62 & 1,62 & 1,00 & \\
\hline 1978 & 5 & 1,71 & 1,71 & 1,00 & \\
\hline 1978 & 6 & 1,12 & 1,12 & 1,00 & \\
\hline 1978 & 7 & 5,82 & 5,82 & 1,00 & \\
\hline 1978 & 8 & 10,95 & 9,17 & 0,84 & \\
\hline 1978 & 9 & 19,08 & 11,04 & 0,58 & \\
\hline 1978 & 10 & 14,12 & 11,09 & 0,79 & \\
\hline 1978 & 11 & 16,09 & 6,19 & 0,38 & \\
\hline 1978 & 12 & 17,32 & 17,32 & 1,00 & \\
\hline 1978 & 13 & 13,65 & 11,94 & 0,87 & \\
\hline 1978 & 14 & 17,55 & 17,55 & 1,00 & \\
\hline 1978 & 15 & 13,97 & 12,64 & 0,90 & \\
\hline 1978 & 16 & 11,91 & 11,91 & 1,00 & \\
\hline 1978 & 17 & 16,50 & 14,43 & 0,87 & \\
\hline 1978 & 18 & 19,93 & 12,88 & 0,65 & \\
\hline 1978 & 19 & 19,74 & 10,49 & 0,53 & \\
\hline 1978 & 20 & 17,25 & 17,25 & 1,00 & \\
\hline 1978 & 21 & 32,81 & 31,58 & 0,96 & 0,85 \\
\hline 1978 & 22 & 22,97 & 16,81 & 0,73 & \\
\hline 1978 & 23 & 17,11 & 9,73 & 0,57 & \\
\hline 1978 & 24 & 28,76 & 12,33 & 0,43 & \\
\hline 1978 & 25 & 27,69 & 27,69 & 1,00 & \\
\hline 1978 & 26 & 29,09 & 29,09 & 1,00 & \\
\hline 1978 & 27 & 35,84 & 16,66 & 0,46 & \\
\hline 1978 & 28 & 42,84 & 17,48 & 0,41 & \\
\hline 1978 & 29 & 46,63 & 39,72 & 0,85 & \\
\hline 1978 & 30 & 66,74 & 57,21 & 0,86 & \\
\hline 1978 & 31 & 49,94 & 49,94 & 1,00 & \\
\hline 1978 & 32 & 41,34 & 41,34 & 1,00 & \\
\hline 1978 & 33 & 51,64 & 49,83 & 0,96 & \\
\hline 1978 & 34 & 53,50 & 53,50 & 1,00 & \\
\hline 1978 & 35 & 43,60 & 43,15 & 0,99 & \\
\hline 1978 & 36 & 52,42 & 52,42 & 1,00 & \\
\hline 1979 & 1 & 43,92 & 42,24 & 0,96 & \\
\hline 1979 & 2 & 45,93 & 34,98 & 0,76 & \\
\hline 1979 & 3 & 50,12 & 46,03 & 0,92 & 0,83 \\
\hline 1979 & 4 & 51,76 & 44,78 & 0,87 & \\
\hline 1979 & 5 & 47,43 & 47,43 & 1,00 & \\
\hline 1979 & 6 & 39,50 & 33,44 & 0,85 & \\
\hline 1979 & 7 & 46,68 & 26,34 & 0,56 & \\
\hline 1979 & 8 & 41,00 & 24,36 & 0,59 & \\
\hline 1979 & 9 & 47,09 & 21,89 & 0,46 & \\
\hline 1979 & 10 & 32,58 & 32,58 & 1,00 & \\
\hline 1979 & 11 & 32,38 & 14,72 & 0,45 & \\
\hline 1979 & 12 & 23,21 & 23,21 & 1,00 & \\
\hline 1979 & 13 & 29,97 & 29,97 & 1,00 & \\
\hline 1979 & 14 & 27,61 & 24,13 & 0,87 & \\
\hline 1979 & 15 & 20,69 & 20,69 & 1,00 & \\
\hline 1979 & 16 & 14,94 & 11,13 & 0,74 & \\
\hline 1979 & 17 & 18,83 & 11,86 & 0,63 & \\
\hline 1979 & 18 & 17,52 & 9,19 & 0,52 & \\
\hline 1979 & 19 & 21,89 & 13,64 & 0,62 & \\
\hline 1979 & 20 & 10,36 & 10,36 & 1,00 & \\
\hline 1979 & 21 & 20,97 & 11,79 & 0,56 & \\
\hline
\end{tabular}


Continuação da Tabela 6 d.

\begin{tabular}{|c|c|c|c|c|c|}
\hline ANO & DEC & $\begin{array}{c}E T m \\
\mathrm{~mm}\end{array}$ & $\begin{array}{l}\text { ETr } \\
\mathrm{mm}\end{array}$ & $\mathrm{ETr} / \mathrm{ETm}$ & $\begin{array}{c}E T r / E T m \\
\text { médio }\end{array}$ \\
\hline 1979 & 22 & 24,70 & 8,58 & 0,35 & \\
\hline 1979 & 23 & 26,47 & 26,47 & 1,00 & \\
\hline 1979 & 24 & 28,85 & 22,23 & 0,77 & 0,76 \\
\hline
\end{tabular}

Tabela 6 e. Dados da ETr e ETm durante o ciclo de cana soca, variedade NA56-79, período 1985-1986, em Araras.

\begin{tabular}{lccccc}
\hline ANO & DEC & $\begin{array}{c}E T m \\
\text { mm }\end{array}$ & $\begin{array}{c}E T r \\
\text { mm }\end{array}$ & ETr/ETm & ETr/ETm \\
médio
\end{tabular}

Tabela 6 f. Dados de ETr e ETm durante o ciclo de cana soca, variedade CB41-76, período 1985-1986, em Araras.

\begin{tabular}{cccccc}
\hline ANO & DEC & $\begin{array}{c}E T m \\
\text { mm }\end{array}$ & $\begin{array}{c}E T r \\
\text { mm }\end{array}$ & $E T r / E T m$ & $E T r / E T m$ \\
médio
\end{tabular}


Tabela 6 g. Dados de ETr e ETm durante o ciclo da cana soca, variedade CB41-76, período 1985-1986, em Araras.

\begin{tabular}{|c|c|c|c|c|c|}
\hline ANO & $\mathrm{DEC}$ & $\begin{array}{l}E T m \\
\mathrm{~mm}\end{array}$ & $\begin{array}{l}E T r \\
\mathrm{~mm}\end{array}$ & ETr/ETm & $\begin{array}{c}E T r / E T m \\
\text { medio }\end{array}$ \\
\hline 1985 & 25 & 5,89 & 5,89 & 1,00 & \\
\hline 1985 & 26 & 10,40 & 8,11 & 0,78 & \\
\hline 1985 & 27 & 8,39 & 7,34 & 0,87 & \\
\hline 1985 & 28 & 18,80 & 11,08 & 0,59 & \\
\hline 1985 & 29 & 26,42 & 8,93 & 0,34 & \\
\hline 1985 & 30 & 30,68 & 10,50 & 0,34 & \\
\hline 1985 & 31 & 28,73 & 28,73 & 1,00 & \\
\hline 1985 & 32 & 44,26 & 30,63 & 0,69 & \\
\hline 1985 & 33 & 34,15 & 34,15 & 1,00 & \\
\hline 1985 & 34 & 38,65 & 38,65 & 1,00 & \\
\hline 1985 & 35 & 50,35 & 38,88 & 0,77 & \\
\hline 1985 & 36 & 50,42 & 50,42 & 1,00 & 0,71 \\
\hline 1986 & 1 & 48,09 & 48,09 & 1,00 & \\
\hline 1986 & 2 & 52,58 & 52,58 & 1,00 & \\
\hline 1986 & 3 & 57,75 & 57,75 & 1,00 & \\
\hline 1986 & 4 & 51,96 & 51,96 & 1,00 & \\
\hline 1986 & 5 & 50,32 & 50,32 & 1,00 & \\
\hline 1986 & 6 & 40,32 & 40,32 & 1,00 & \\
\hline 1986 & 7 & 46,29 & 46,29 & 1,00 & \\
\hline 1986 & 8 & 52,51 & 40,65 & 0,77 & \\
\hline 1986 & 9 & 46,89 & 46,89 & 1,00 & \\
\hline 1986 & 10 & 48,81 & 30,69 & 0,63 & \\
\hline 1986 & 11 & 39,36 & 26,16 & 0,66 & \\
\hline 1986 & 12 & 35,05 & 17,86 & 0,51 & 0,88 \\
\hline 1986 & 13 & 28,87 & 28,87 & 1,00 & \\
\hline 1986 & 14 & 33,86 & 33,86 & 1,00 & \\
\hline 1986 & 15 & 32,31 & 16,73 & 0,52 & \\
\hline 1986 & 16 & 16,48 & 6,12 & 0,37 & \\
\hline 1986 & 17 & 25,79 & 7,77 & 0,30 & \\
\hline 1986 & 18 & 22,12 & 5,24 & 0,24 & \\
\hline 1986 & 19 & 18,26 & 3,53 & 0,19 & \\
\hline 1986 & 20 & 19,63 & 3,14 & 0,16 & \\
\hline 1986 & 21 & 22,09 & 22,09 & 1,00 & \\
\hline 1986 & 22 & 25,38 & 4,57 & 0,18 & \\
\hline 1986 & 23 & 24,09 & 24,09 & 1,00 & \\
\hline 1986 & 24 & 29,81 & 29,81 & 1,00 & \\
\hline 1986 & 25 & 26,11 & 16,53 & 0,63 & \\
\hline 1986 & 26 & 36,58 & 16,97 & 0,46 & \\
\hline 1986 & 27 & 32,58 & 29,72 & 0,91 & 0,60 \\
\hline
\end{tabular}

Tabela 6 h. Dados de ETr e ETm durante o ciclo da cana planta, variedade CB41-76, período 1978 - 1979, em Pradópolis.

\begin{tabular}{|c|c|c|c|c|c|}
\hline ANO & $\overline{D E C}$ & $\begin{array}{c}E T m \\
\mathrm{~mm}\end{array}$ & $\begin{array}{l}E T r \\
\mathrm{~mm}\end{array}$ & $E T r / E T m$ & $\begin{array}{c}E T r / E T m \\
\text { medio }\end{array}$ \\
\hline 1978 & 7 & 1,56 & 1,56 & 1,00 & \\
\hline 1978 & 8 & 1,76 & 1,76 & 1,00 & \\
\hline 1978 & 9 & 5,49 & 5,49 & 1,00 & \\
\hline 1978 & 10 & 8,16 & 8,00 & 0,98 & \\
\hline 1978 & 11 & 10,43 & 7,93 & 0,76 & \\
\hline 1978 & 12 & 9,04 & 9,04 & 1,00 & \\
\hline 1978 & 13 & 12,62 & 12,53 & 0,99 & \\
\hline 1978 & 14 & 9,69 & 9,69 & 1,00 & \\
\hline 1978 & 15 & 10,54 & 10,53 & 1,00 & \\
\hline 1978 & 16 & 13,69 & 13,69 & 1,00 & \\
\hline 1978 & 17 & 16,84 & 15,41 & 0,92 & \\
\hline 1978 & 18 & 17,24 & 11,01 & 0,64 & 0,94 \\
\hline 1978 & 19 & 15,21 & 10,28 & 0,68 & \\
\hline 1978 & 20 & 27,04 & 27,04 & 1,00 & \\
\hline 1978 & 21 & 23,03 & 21,47 & 0,93 & \\
\hline 1978 & 22 & 15,72 & 10,39 & 0,66 & \\
\hline 1978 & 23 & 24,25 & 11,81 & 0,49 & \\
\hline 1978 & 24 & 28,38 & 9,92 & 0,35 & \\
\hline 1978 & 25 & 27,52 & 14,15 & 0,51 & \\
\hline 1978 & 26 & 34,24 & 25,74 & 0,75 & \\
\hline 1978 & 27 & 41,47 & 8,72 & 0,21 & \\
\hline 1978 & 28 & 45,41 & 33,01 & 0,73 & \\
\hline 1978 & 29 & 59,67 & 42,15 & 0,71 & \\
\hline 1978 & 30 & 53,91 & 33,45 & 0,62 & \\
\hline 1978 & 31 & 40,63 & 40,63 & 1,00 & \\
\hline 1978 & 32 & 50,92 & 38,65 & 0,76 & \\
\hline 1978 & 33 & 52,84 & 47,04 & 0,89 & \\
\hline 1978 & 34 & 42,87 & 42,87 & 1,00 & \\
\hline 1978 & 35 & 47,04 & 47,04 & 1,00 & 0,72 \\
\hline 1978 & 36 & 48,24 & 48,24 & 1,00 & \\
\hline 1979 & 1 & 46,36 & 46,36 & 1,00 & \\
\hline 1979 & 2 & 46,52 & 40,28 & 0,87 & \\
\hline 1979 & 3 & 58,38 & 58,38 & 1,00 & \\
\hline 1979 & 4 & 48,67 & 48,38 & 0,99 & \\
\hline 1979 & 5 & 51,20 & 51,20 & 1,00 & \\
\hline 1979 & 6 & 38,65 & 37,76 & 0,98 & \\
\hline 1979 & 7 & 43,02 & 33,78 & 0,79 & \\
\hline 1979 & 8 & 45,58 & 44,16 & 0,97 & \\
\hline 1979 & 9 & 37,45 & 24,23 & 0,65 & \\
\hline 1979 & 10 & 34,11 & 34,11 & 1,00 & \\
\hline 1979 & 11 & 27,60 & 17,60 & 0,64 & \\
\hline 1979 & 12 & 31,31 & 28,20 & 0,90 & \\
\hline 1979 & 13 & 20,20 & 20,20 & 1,00 & \\
\hline 1979 & 14 & 28,07 & 23,97 & 0,85 & \\
\hline 1979 & 15 & 21,67 & 21,67 & 1,00 & 0,92 \\
\hline
\end{tabular}


Tabela 6 i. Dados de ETr e ETm durante o ciclo da cana soca, variedade CB41-76, período 1979-1980, em Pradópolis.

\begin{tabular}{lccccc}
\hline ANO & DEC & $\begin{array}{c}E T m \\
\text { mm }\end{array}$ & $\begin{array}{c}E T r \\
\text { mm }\end{array}$ & $\begin{array}{c}E T / E T m \\
E T r / E T m \\
\text { medio }\end{array}$ \\
\hline 1979 & 16 & 2,29 & 1,80 & 0,79 & \\
1979 & 17 & 4,82 & 3,35 & 0,70 & \\
1979 & 18 & 6,33 & 3,66 & 0,58 & \\
1979 & 19 & 9,79 & 5,56 & 0,57 & \\
1979 & 20 & 5,43 & 5,43 & 1,00 & \\
1979 & 21 & 12,79 & 12,79 & 1,00 & \\
1979 & 22 & 16,82 & 14,28 & 0,85 & \\
1979 & 23 & 19,42 & 19,42 & 1,00 & \\
1979 & 24 & 22,66 & 19,24 & 0,85 & 0,81 \\
\hline 1979 & 25 & 19,17 & 13,85 & 0,72 & \\
1979 & 26 & 20,98 & 20,98 & 1,00 & \\
1979 & 27 & 35,60 & 32,44 & 0,91 & \\
1979 & 28 & 37,85 & 34,90 & 0,92 & \\
1979 & 29 & 40,22 & 40,22 & 1,00 & \\
1979 & 30 & 40,09 & 30,07 & 0,75 & \\
1979 & 31 & 51,31 & 51,31 & 1,00 & \\
1979 & 32 & 48,21 & 47,02 & 0,98 & \\
1979 & 33 & 45,86 & 45,86 & 1,00 & \\
1979 & 34 & 55,86 & 55,86 & 1,00 & \\
1979 & 35 & 47,49 & 47,49 & 1,00 & \\
1979 & 36 & 56,78 & 56,78 & 1,00 & 0,94 \\
\hline 1980 & 1 & 45,47 & 42,02 & 0,92 & \\
1980 & 2 & 48,79 & 48,79 & 1,00 & \\
1980 & 3 & 56,20 & 56,20 & 1,00 & \\
1980 & 4 & 55,17 & 55,17 & 1,00 & \\
1980 & 5 & 44,51 & 44,51 & 1,00 & \\
1980 & 6 & 34,79 & 34,79 & 1,00 & \\
1980 & 7 & 51,26 & 40,11 & 0,78 & \\
1980 & 8 & 49,03 & 49,03 & 1,00 & \\
1980 & 9 & 52,21 & 36,14 & 0,69 & \\
1980 & 10 & 35,80 & 35,80 & 1,00 & \\
1980 & 11 & 37,04 & 31,57 & 0,85 & \\
1980 & 12 & 30,18 & 14,16 & 0,47 & 0,90 \\
\hline & & & & & \\
\hline
\end{tabular}

Tabela 6 j. Dados de ETr e ETm durante o ciclo da cana planta, variedade CO775, período 1979 - 1980, em Pradópolis.

\begin{tabular}{|c|c|c|c|c|c|}
\hline ANO & $\mathrm{DEC}$ & $\begin{array}{c}E T m \\
\mathrm{~mm}\end{array}$ & $\begin{array}{l}E T r \\
\mathrm{~mm}\end{array}$ & $E T r / E T m$ & $\begin{array}{c}E T r / E T m \\
\text { medio }\end{array}$ \\
\hline 1979 & 4 & 1,64 & $1, \overline{64}$ & 1,00 & \\
\hline 1979 & 5 & 1,51 & 1,51 & 1,00 & \\
\hline 1979 & 6 & 1,26 & 1,26 & 1,00 & \\
\hline 1979 & 7 & 6,50 & 6,50 & 1,00 & \\
\hline 1979 & 8 & 9,61 & 9,61 & 1,00 & \\
\hline 1979 & 9 & 15,70 & 15,19 & 0,97 & \\
\hline 1979 & 10 & 13,57 & 13,57 & 1,00 & \\
\hline 1979 & 11 & 15,96 & 13,79 & 0,86 & \\
\hline 1979 & 12 & 13,44 & 13,44 & 1,00 & \\
\hline 1979 & 13 & 19,89 & 19,89 & 1,00 & \\
\hline 1979 & 14 & 20,12 & 16,56 & 0,82 & \\
\hline 1979 & 15 & 16,43 & 16,43 & 1,00 & \\
\hline 1979 & 16 & 12,86 & 10,61 & 0,83 & \\
\hline 1979 & 17 & 17,02 & 10,97 & 0,64 & \\
\hline 1979 & 18 & 16,87 & 8,20 & 0,49 & 0,97 \\
\hline 1979 & 19 & 21,84 & 9,44 & 0,43 & \\
\hline 1979 & 20 & 10,69 & 10,69 & 1,00 & \\
\hline 1979 & 21 & 22,15 & 22,15 & 1,00 & \\
\hline 1979 & 22 & 26,49 & 12,11 & 0,46 & \\
\hline 1979 & 23 & 28,79 & 26,43 & 0,92 & \\
\hline 1979 & 24 & 31,58 & 16,95 & 0,54 & \\
\hline 1979 & 25 & 25,25 & 11,54 & 0,46 & \\
\hline 1979 & 26 & 26,52 & 26,52 & 1,00 & \\
\hline 1979 & 27 & 42,91 & 39,00 & 0,91 & \\
\hline 1979 & 28 & 44,05 & 39,27 & 0,89 & \\
\hline 1979 & 29 & 45,25 & 45,25 & 1,00 & \\
\hline 1979 & 30 & 44,00 & 30,18 & 0,69 & \\
\hline 1979 & 31 & 54,98 & 54,98 & 1,00 & \\
\hline 1979 & 32 & 50,46 & 49,17 & 0,97 & \\
\hline 1979 & 33 & 47,26 & 47,26 & 1,00 & \\
\hline 1979 & 34 & 56,70 & 56,70 & 1,00 & \\
\hline 1979 & 35 & 47,85 & 47,85 & 1,00 & \\
\hline 1979 & 36 & 56,78 & 56,78 & 1,00 & 0,85 \\
\hline 1980 & 1 & 45,47 & 42,02 & 0,92 & \\
\hline 1980 & 2 & 48,43 & 48,43 & 1,00 & \\
\hline 1980 & 3 & 55,36 & 55,36 & 1,00 & \\
\hline 1980 & 4 & 53,94 & 53,94 & 1,00 & \\
\hline 1980 & 5 & 43,85 & 43,85 & 1,00 & \\
\hline 1980 & 6 & 34,27 & 34,27 & 1,00 & \\
\hline 1980 & 7 & 50,10 & 39,41 & 0,79 & \\
\hline 1980 & 8 & 47,54 & 47,54 & 1,00 & \\
\hline 1980 & 9 & 50,22 & 35,95 & 0,72 & \\
\hline 1980 & 10 & 34,69 & 34,69 & 1,00 & \\
\hline
\end{tabular}


Continuação da Tabela 6 j.

\begin{tabular}{cccccc}
\hline ANO & DEC & $\begin{array}{c}\text { ETm } \\
\mathrm{mm}\end{array}$ & $\begin{array}{c}\text { ETr } \\
\mathrm{mm}\end{array}$ & $\begin{array}{c}\text { ETr/ETm } \\
\text { ETr/ETm } \\
\text { médio }\end{array}$ \\
\hline 1980 & 11 & 35,88 & 31,33 & 0,87 & \\
1980 & 12 & 29,47 & 14,83 & 0,50 & \\
1980 & 13 & 30,09 & 11,24 & 0,37 & \\
1980 & 14 & 27,75 & 9,27 & 0,33 & \\
1980 & 15 & 20,79 & 4,65 & 0,22 & \\
1980 & 16 & 15,03 & 2,81 & 0,19 & \\
1980 & 17 & 18,95 & 7,25 & 0,38 & \\
1980 & 18 & 17,63 & 17,63 & 1,00 & \\
1980 & 19 & 22,02 & 16,29 & 0,74 & \\
1980 & 20 & 10,42 & 6,54 & 0,63 & \\
1980 & 21 & 21,07 & 11,32 & 0,54 & \\
1980 & 22 & 24,81 & 10,60 & 0,43 & \\
1980 & 23 & 26,56 & 19,11 & 0,72 & \\
1980 & 24 & 28,93 & 10,66 & 0,37 & 0,73 \\
\hline
\end{tabular}

Tabela 6 k. Dados de ETr e ETm durante o ciclo da cana planta, variedade CO775, período 1979-1980, em Pradópolis.

\begin{tabular}{|c|c|c|c|c|c|}
\hline ANO & $\mathrm{DEC}$ & $\begin{array}{c}E T m \\
\mathrm{~mm}\end{array}$ & $\begin{array}{l}E T r \\
\mathbf{m m}\end{array}$ & $E T r / E T m$ & $\begin{array}{c}E T r / E T m \\
\text { médio }\end{array}$ \\
\hline 1979 & 7 & 6,50 & 6,50 & 1,00 & \\
\hline 1979 & 8 & 9,61 & 9,61 & 1,00 & \\
\hline 1979 & 9 & 15,70 & 15,19 & 0,97 & \\
\hline 1979 & 10 & 13,57 & 13,57 & 1,00 & \\
\hline 1979 & 11 & 15,96 & 13,79 & 0,86 & \\
\hline 1979 & 12 & 13,44 & 13,44 & 1,00 & \\
\hline 1979 & 13 & 19,89 & 19,89 & 1,00 & \\
\hline 1979 & 14 & 20,12 & 16,56 & 0,82 & \\
\hline 1979 & 15 & 16,43 & 16,43 & 1,00 & \\
\hline 1979 & 16 & 12,86 & 10,61 & 0,83 & \\
\hline 1979 & 17 & 17,02 & 10,97 & 0,64 & \\
\hline 1979 & 18 & 16,87 & 8,20 & 0.49 & \\
\hline 1979 & 19 & 21,84 & 9,44 & 0,43 & \\
\hline 1979 & 20 & 10,69 & 10,69 & 1,00 & \\
\hline 1979 & 21 & 22,15 & 22,15 & 1,00 & \\
\hline 1979 & 22 & 26,49 & 12,11 & 0,46 & \\
\hline 1979 & 23 & 28,79 & 26,43 & 0,92 & \\
\hline 1979 & 24 & 31,58 & 16,95 & 0,54 & 0,87 \\
\hline 1979 & 25 & 25,25 & 11,54 & 0,46 & \\
\hline 1979 & 26 & 26,52 & 26,52 & 1,00 & \\
\hline 1979 & 27 & 42,91 & 39,00 & 0,91 & \\
\hline 1979 & 28 & 44,05 & 39,27 & 0,89 & \\
\hline 1979 & 29 & 45,25 & 45,25 & 1,00 & \\
\hline 1979 & 30 & 44,00 & 30,18 & 0,69 & \\
\hline 1979 & 31 & 54,98 & 54,98 & 1,00 & \\
\hline 1979 & 32 & 50,46 & 49,17 & 0,97 & \\
\hline 1979 & 33 & 47,26 & 47,26 & 1,00 & \\
\hline
\end{tabular}

Tabela 6 1. Dados de ETr e ETm durante o ciclo da cana soca, variedade RE-725828, período 1985-1986, em Pradópolis.

\begin{tabular}{|c|c|c|c|c|c|}
\hline ANO & $\mathrm{DEC}$ & $\begin{array}{c}E T m \\
\mathrm{~mm}\end{array}$ & $\begin{array}{l}\text { ETr } \\
\mathrm{mm}\end{array}$ & ETr/ETm & $\begin{array}{c}E T r / E T m \\
\text { médio }\end{array}$ \\
\hline 1985 & 19 & 4,71 & 0,02 & 0,00 & \\
\hline 1985 & 20 & 3,79 & 0,01 & 0,00 & \\
\hline 1985 & 21 & 4,75 & 1,47 & 0,31 & \\
\hline 1985 & 22 & 14,15 & 5,54 & 0,39 & \\
\hline 1985 & 23 & 13,12 & 3,65 & 0,28 & \\
\hline 1985 & 24 & 16,50 & 4,42 & 0,27 & \\
\hline 1985 & 25 & 17,11 & 4,34 & 0,25 & \\
\hline 1985 & 26 & 31,22 & 4,94 & 0,16 & \\
\hline 1985 & 27 & 27,95 & 4,26 & 0,15 & \\
\hline 1985 & 28 & 32,63 & 6,57 & 0,20 & \\
\hline 1985 & 29 & 43,83 & 3,56 & 0,08 & \\
\hline 1985 & 30 & 50,27 & 48,29 & 0,96 & 0,38 \\
\hline 1985 & 31 & 39,50 & 39,50 & 1,00 & \\
\hline 1985 & 32 & 60,26 & 34,05 & 0,57 & \\
\hline 1985 & 33 & 41,83 & 41,83 & 1,00 & \\
\hline 1985 & 34 & 46,82 & 46,82 & 1,00 & \\
\hline 1985 & 35 & 59,85 & 48,70 & 0,81 & \\
\hline 1985 & 36 & 56,28 & 56,28 & 1,00 & \\
\hline 1986 & 1 & 53,45 & 46,64 & 0,87 & \\
\hline 1986 & 2 & 57,03 & 57,03 & 1,00 & \\
\hline 1986 & 3 & 62,66 & 57,39 & 0,92 & \\
\hline 1986 & 4 & 54,20 & 47,28 & 0,87 & \\
\hline 1986 & 5 & 52,52 & 52,52 & 1,00 & \\
\hline 1986 & 6 & 42,11 & 41,61 & 0,99 & 0,93 \\
\hline 1986 & 7 & 46,23 & 46,23 & 1,00 & \\
\hline 1986 & 8 & 52,48 & 52,48 & 1,00 & \\
\hline 1986 & 9 & 46,90 & 46,90 & 1,00 & \\
\hline
\end{tabular}


Continuação da Tabela $6 \mathbf{k}$.

\begin{tabular}{|c|c|c|c|c|c|}
\hline ANO & $\overline{\mathrm{DEC}}$ & $\begin{array}{c}E T m \\
\mathrm{~mm}\end{array}$ & $\begin{array}{l}E T r \\
\mathrm{~mm}\end{array}$ & ETr/ETm & $\begin{array}{c}E T r / E T m \\
\text { médio }\end{array}$ \\
\hline 1979 & 34 & 56,70 & 56,70 & 1,00 & \\
\hline 1979 & 35 & 47,85 & 47,85 & 1,00 & \\
\hline 1979 & 36 & 56,78 & 56,78 & 1,00 & \\
\hline 1980 & 1 & 45,47 & 42,02 & 0,92 & \\
\hline 1980 & 2 & 48,43 & 48,43 & 1,00 & \\
\hline 1980 & 3 & 55,36 & 55,36 & 1,00 & \\
\hline 1980 & 4 & 53,94 & 53,94 & 1,00 & \\
\hline 1980 & 5 & 43,85 & 43,85 & 1,00 & \\
\hline 1980 & 6 & 34,27 & 34,27 & 1,00 & 0,88 \\
\hline 1980 & 7 & 50,10 & 39,41 & 0,79 & \\
\hline 1980 & 8 & 47,54 & 47,54 & 1,00 & \\
\hline 1980 & 9 & 50,22 & 35,95 & 0,72 & \\
\hline 1980 & 10 & 34,69 & 34,69 & 1,00 & \\
\hline 1980 & 11 & 35,88 & 31,33 & 0,87 & \\
\hline 1980 & 12 & 29,47 & 14,83 & 0,50 & \\
\hline 1980 & 13 & 30,09 & 11,24 & 0,37 & \\
\hline 1980 & 14 & 27,75 & 9,27 & 0,33 & \\
\hline 1980 & 15 & 20,79 & 4,65 & 0,22 & \\
\hline 1980 & 16 & 15,03 & 2,81 & 0,19 & \\
\hline 1980 & 17 & 18,95 & 7,25 & 0,38 & \\
\hline 1980 & 18 & 17,63 & 17,63 & 1,00 & \\
\hline 1980 & 19 & 22,02 & 16,29 & 0,74 & \\
\hline 1980 & 20 & 10,42 & 6,54 & 0,63 & \\
\hline 1980 & 21 & 21,07 & 11,32 & 0,54 & \\
\hline 1980 & 22 & 24,81 & 10,60 & 0,43 & \\
\hline 1980 & 23 & 26,56 & 19,11 & 0,72 & \\
\hline 1980 & 24 & 28,93 & 10,66 & 0,37 & \\
\hline 1980 & 25 & 26,04 & 5,93 & 0,23 & \\
\hline 1980 & 26 & 27,95 & 27,95 & 1,00 & \\
\hline 1980 & 27 & 27,69 & 27,69 & 1,00 & 0,70 \\
\hline
\end{tabular}

Continuação da Tabela $6 \mathrm{l}$.

\begin{tabular}{cccccc}
\hline ANO & DEC & $\begin{array}{c}E T m \\
\text { mm }\end{array}$ & $\begin{array}{c}\text { ETr } \\
\text { mm }\end{array}$ & $\begin{array}{c}\text { ETr/ETm } \\
\text { ETr/ETm } \\
\text { médio }\end{array}$ \\
\hline 1986 & 10 & 47,78 & 37,99 & 0,80 & \\
1986 & 11 & 38,57 & 30,99 & 0,80 & \\
1986 & 12 & 34,37 & 15,13 & 0,44 & \\
1986 & 13 & 27,69 & 27,69 & 1,00 & \\
1986 & 14 & 32,51 & 32,51 & 1,00 & \\
1986 & 15 & 31,03 & 19,80 & 0,64 & \\
1986 & 16 & 15,57 & 7,34 & 0,47 & \\
1986 & 17 & 24,38 & 9,42 & 0,39 & \\
1986 & 18 & 20,91 & 6,44 & 0,31 & \\
1986 & 19 & 17,79 & 4,51 & 0,25 & \\
1986 & 20 & 19,12 & 4,04 & 0,21 & \\
1986 & 21 & 21,51 & 21,51 & 1,00 & 0,69 \\
\hline
\end{tabular}




\section{REFERÊNCIAS BIBLIOGRAFICAS}

ALFONSI, R. R. Época de semeadura para a cultura do milho (Zea mays L.) baseada na probabilidade do atendimento hídrico em fases fenológicas críticas para o Estado de São Paulo. Piracicaba, 1996. 137p. Tese (Doutorado) - Escola Superior de Agricultura "Luiz de Queiroz", Universidade de São Paulo.

BARBIERI, V. Medidas e estimativas de consumo hídrico em cana-de-açúcar (Saccharum spp). Piracicaba, 1981. 82p. Dissertação (Mestrado) - Escola Superior de Agricultura "Luiz de Queiroz", Universidade de São Paulo.

BARBIERI, V.; TUON, R. L. Metodologia para estimativa da produção potencial de algumas culturas. Piracicaba: ESALQ, Departamento de Fisica e Meteorologia, 1992. $17 \mathrm{p}$.

BARBIERI, V.; TUON, R. L.; ANGELOCCI, L. R. Programa para microcomputador do balanço hídrico (Thornthwaite e Mather - 1955) para dados mensais e decendiais, normais e seqüências. In: CONGRESSO BRASILEIRO DE AGROMETEOROLOGIA, 7, 1991. Resumos. Viçosa, MG., Viçosa: Sociedade Brasileira de Agrometeorologia/Universidade Federal de Viçosa, 1991. p297-299.

BARBIERI, V.; TERUEL, D. A.; SILVA, J. G.; SANTOS, R. M. N. dos. Balanço hídrico de Thornthwaite e Mather modificado para estimativa de deficiência nas culturas. In: CONGRESSO BRASILEIRO DE AGROMETEOROLOGIA, 10., Piracicaba, 1997. Anais. Piracicaba: Sociedade Brasileira de Agrometeorologia; ESALQ, 1997. p.587-589. 
BARNI, N. A.; BERLATO, M. A.; BERGAMASCHI, H.; RIBOLDI, J. Modelo agrometeorológico de predição do rendimento do girassol. Pesquisa Agropecuária Gaúcha, v. 2, n.1, p. 7-31, 1995.

CABRAL, O.; ROCHA, H.; DIAS, M. A.; BRUNINI, O.; CARVALHO, R. Balanço de água no solo em plantação de cana-de-açúcar. In: CONGRESSO BRASILEIRO DE AGROMETEOROLOGIA, 10, Piracicaba, 1997. Anais. Piracicaba: Sociedade Brasileira de Agrometeorologia, ESALQ, 1997. p.593-295.

CAMARGO, M. B. P. Determination of the water balance components and drought sensivity indices for a sorghum crop. Lincoln, 1992. 131p. Thesis (Phd) University of Nebraska.

CAMARGO, M. B. P. de; JÚNIOR, M. J. P.; ORTOLANI, A. A.; ROSA, S. M. Desenvolvimento e teste de modelos agrometeorológicos de estimativa de produtividade de laranjais no estado de São Paulo. In: CONGRESSO BRASILEIRO DE AGROMETEOROLOGIA, 9, Campina Grande, 1995. Resumos. Campina Grande: Sociedade Brasileira de Agrometeorologia; Universidade Federal da Paraiba, 1995. p. 412-414.

CAMARGO, P. N. Fisiologia de la caña de azúcar. Serie Divulgación Técnica, v. 1, n. 6, p.1-60, 1976.

CAMARGO, A. P.; SENTELHAS, P. C. Avaliação do desempenho de diferentes métodos de estimativa da evapotranspiração potencial no Estado de São Paulo, Brasil. Revista Brasileira de Agrometeorologia, v.5 (1), p.89-97, 1997.

COELHO, D. T.; DALE, R. F. An enegy-crop growth variable and temperature function for predicting corn growth and development. Planting to silking. Agronomy Journal, v.72, p.503-510, 1980. 
COSTA, L. C. Modelagem e simulação em agrometeorologia. In: CONGRESSO BRASILEIRO DE AGROMETEOROLOGIA, 10, Piracicaba, 1997. Suplemento dos anais. Piracicaba: Sociedade Brasileira de Agrometeorologia; ESALQ, 1997. p.3-6.

DOORENBOS, J.; KASSAM, A. H. Efectos del agua sobre el rendimiento de los cultivos. Roma: FAO, 1979.212p. (FAO. Riego y Drenaje, 33).

DOORENBOS, J.; PRUITT, W. O. Necessidades hídricas das culturas. Campina Grande: Universidade Federal da Paraíba, 1997. 204 p. (FAO. Irrigação e Drenagem, 24).

IRVINE, J. E. Relations of photosynthetic rates and leaf and canopy characters to sugar cane yield. Crop Science, v.15, p.671-676, 1980.

JENSEN, M. E. Water consumption by agricultural plants. In: KOZLOWSKI, T. T. (Ed.) Water deficits and plant growth. New York: Academic Press, 1968. v.2, p.1-22.

MACHADO, E. C. Fisiologia de produção de cana-de-açúcar. Crescimento. In: PARANHOS, S. B. Cana-de-açúcar: cultivo e utilização. Campinas: Fundação Cargill, 1987. V.1, cap. 1, p.56-87.

MATZENAUER, R.; BERGAMASCHI, H.; BERLATO, M. A.; RIBOLDI, J. Modelos agrometeorológicos para estimativa do rendimento de milho, em função da disponibilidade hídrica no estado do Rio Grande do Sul. Pesquisa Agropecuária Gaúcha, v.1, n.2, p.141-274, 1995.

MENDONÇA, P. de V. Sobre o novo método de balanço hidrológico do solo de Thornthwaite-Mather. In: CONGRESSO LUSO-ESPANHOL PARA O PROGRESSO DAS CIÊNCIAS, 24, Madrid, 1958. Anais. Madrid: Instituto Superior de Agronomia. 1958. p.271-282. 
MEYER, S. J.; HUBBARD, K G.; WILHITE, D. A. A crop specific drought index for corn. I. Model development and validation. Agronomy Journal, v.86, p.388-395, 1992.

OMETTO, J. C. Freqüência de irrigação em cana-de-açúcar. Piracicaba: FEALQ, 1988. $77 \mathrm{p}$.

ORTOLANI, A. A.; SENTELHAS, P. C.; CAMARGO, M. B. P.; PEZZOPANE, J. E. M.; GONÇALVES, P. S. Modelos agrometeorológicos para estimativa da produção anual e sazonal de látex em seringueira. Revista Brasileira de Agrometeorologia, v.4, n.1, p.147-150, 1996.

PEREIRA, A. R.; ARRUDA, H. V. Ajuste prático de curvas na pesquisa biológica. Campinas: Fundação Cargill, 1987. 50p.

PEREIRA, A. R.; VILLA NOVA, N. A.; SEDIYAMA, G. C. Evapo(transpi)ração. Piracicaba: FEALQ, 1997. 183p.

REICHARDT, C. Dinâmica da matéria e da energia em ecossistemas. 2 ed. Piracicaba: ESALQ, Depto. Física e Meteorologia, 1996. 513 p.

ROSENFELD, U. Período crítico de deficiência hídrica para a cana planta em cultura da cana-de-açúcar (Saccharum spp.). Piracicaba, 1989. 89p. Dissertação (Mestrado) Escola Superior de Agricultura "Luiz de Queiroz", Universidade de São Paulo.

ROSENFELD, U.; LEME, F.J.A. Produtividade da cana-de-açúcar irrigada por aspersão. Estudo de épocas de irrigação. In: CONGRESSO NACIONAL DA STAB, 3. São Paulo, 1984. Anais. São Paulo: STAB, 1984. p.18-24.

SCARDUA, R. Clima e a irrigação na produção agro-industrial da cana-de-açúcar. Piracicaba, 1985. 122p. Tese (Livre Docência) - Escola Superior de Agricultura “Luiz de Queiroz", Universidade de São Paulo. 
SCARDUA, R.; ROSENFELD, U. Irrigação da cana. Sistema radicular. In: PARANHOS, S. B. Cana-de-açúcar: cultivo e utilização. Campinas: Fundação Cargill, 1987. v.1, cap. 3, 373-431.

SOARES, A. S. Modelo para avaliação do efeito do déficit e do excesso hídrico sobre o rendimento do milho na localidade de Urussanga, Santa Catarina. Piracicaba, 1996. 88p. Dissertação (Mestrado) - Escola Superior de Agricultura "Luiz de Queiroz", Universidade de São Paulo.

STEEL, R. G. D.; TORRIE, J. H. Bioestadistica: principios y procedimientos. México: Mc Graw-Hill, 1985. cap.10, p 231-262 : Regresion lineal.

TERUEL, D. A. Modelagem do índice de área foliar da cana-de-açúcar em diferentes regimes hídricos. Piracicaba, 1996. 93p. Dissertação (Mestrado) - Escola Superior de Agricultura “Luiz de Queiroz”, Universidade de São Paulo.

THOMPSON, L. M. Wather and technology in the prediction of corn in the corn Belt. Agronomy Journal, v.61, p.453-456, 1969.

THORNTHWAITE, C. W. An approach toward a rational classification of climate. Geogr. Rev., 38:55 - 94, 1948.

THORNTHWAITE, C. W.l; MATHER, J. R. The water balance. Climatology, v.8, n.1, p.104, 1955.

TUBELIS, A. A chuva e a produção agrícola. São Paulo: Nobel, 1988.85 p.

WILLMOTT, J. C. On the validation of models. Physical Geography, v.2, p.184-194, 1981.

ZACHARIAS, S.; HEATWOLE, C. D.; COAKLEY, C. W. Robust quantitative techniques for validating pesticide transport models. Transactions of the ASAE, v.39, n.1, p.47-54, 1996. 